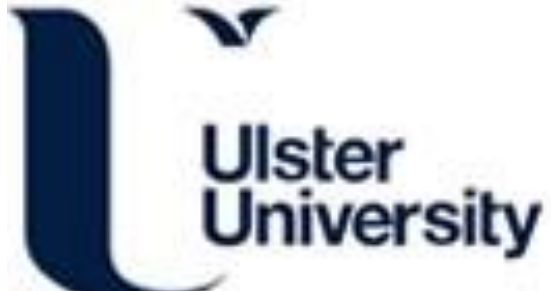

\section{Modelling an integrated impact of fire, explosion and combustion products during transitional events caused by an accidental release of LNG}

Baalisampang, T., Abbassi, R., Garaniya, V., Khan, F., \& Dadashzadeh, M. (2019). Modelling an integrated impact of fire, explosion and combustion products during transitional events caused by an accidental release of LNG. Process Safety and Environmental Protection, 128, 259-272. https://doi.org/10.1016/j.psep.2019.06.005

Link to publication record in Ulster University Research Portal

\section{Published in:}

Process Safety and Environmental Protection

Publication Status:

Published (in print/issue): 01/08/2019

DOI:

10.1016/j.psep.2019.06.005

\section{Document Version}

Author Accepted version

\section{General rights}

Copyright for the publications made accessible via Ulster University's Research Portal is retained by the author(s) and / or other copyright owners and it is a condition of accessing these publications that users recognise and abide by the legal requirements associated with these rights.

\section{Take down policy}

The Research Portal is Ulster University's institutional repository that provides access to Ulster's research outputs. Every effort has been made to ensure that content in the Research Portal does not infringe any person's rights, or applicable UK laws. If you discover content in the Research Portal that you believe breaches copyright or violates any law, please contact pure-support@ulster.ac.uk. 


\section{Manuscript Details}

\section{Manuscript number}

Title
PSEP_2019_94_R3

Modelling an integrated impact of fire, explosion and combustion products during transitional events caused by an accidental release of LNG

Full Length Article

\section{Article type}

Abstract

In a complex processing facility, there is likelihood of occurrence of cascading scenarios, i.e. hydrocarbon release, fire, explosion and dispersion of combustion products. The consequence of such scenarios, when combined, can be more severe than their individual impact. Hence, actual impact can be only represented by integration of above mentioned events. A novel methodology is proposed to model an evolving accident scenario during an incidental release of LNG in a complex processing facility. The methodology is applied to a case study considering transitional scenarios namely spill, pool formation and evaporation of LNG, dispersion of natural gas, and the consequent fire, explosion and dispersion of combustion products using Computational Fluid Dynamics (CFD). Probit functions are employed to analyze individual impacts and a ranking method is used to combine various impacts to identify risk during the transitional events. The results confirmed that in a large and complex facility, an LNG fire can transit to a vapor cloud explosion if the necessary conditions are met, i.e. the flammable range, ignition source with enough energy and congestion/confinement level. Therefore, the integrated consequences are more severe than those associated with the individual ones, and need to be properly assessed. This study would provide an insight for an effective analysis of potential consequences of an LNG spill in any LNG processing facility and it can be useful for the safety measured design of process facilities.

\section{Keywords}

Taxonomy

Manuscript region of origin

Corresponding Author

Corresponding Author's

Institution

Order of Authors

Suggested reviewers
LNG spill, accident transition, integrated consequence, CFD

Explosion, Fire, Hazard

Asia Pacific

Rouzbeh Abbassi

Macquarie University

Til Baalisampang, Rouzbeh Abbassi, Vikram Garaniya, Faisal Khan, Mohammad Dadashzadeh

Changhang XU, Ming Yang, Mohammadmahdi Ghiji, Ehsan Arzaghi, Filippo De Carlo

\section{Submission Files Included in this PDF}

\section{File Name [File Type]}

Cover Letter.docx [Cover Letter]

Comments and Responses.docx [Response to Reviewers]

Revised manuscript.docx [Revised Manuscript with Changes Marked]

Revised manuscript without track changes.docx [Manuscript File]

To view all the submission files, including those not included in the PDF, click on the manuscript title on your EVISE Homepage, then click 'Download zip file'.

\section{Research Data Related to this Submission}

There are no linked research data sets for this submission. The following reason is given:

The required data are available within the manuscript. 
Dear Editor,

Kindly find attached, our revised manuscript entitled "Modelling an integrated impact of fire, explosion and combustion products during transitional events caused by an accidental release of LNG" for the possible publication in the "Journal of Process Safety and Environmental Protection". This is original work of authors and unpublished. I am corresponding author and all authors are agreed to submit this MS to this journal. There is no conflict of interest.

Best regards,

Dr Rouzbeh Abbassi

Senior Lecturer,

School of Engineering,

Macquarie University Sydney, NSW, Australia 


\section{Responses to Editor's and Reviewer's Comments}

\section{Editor}

Comment 1. Your paper should become acceptable for publication pending suitable minor revision and modification of the article in light of the appended reviewer comments.

Response 1. Thank you very much for your time and consideration. The comments provided by the reviewer have been considered and the manuscript has been revised accordingly.

\section{Reviewer 1:}

Comment 1: The reviewer must apologize for not being able to ask a question in such a manner that the authors understand the point the reviewer is trying to make. Apologies for that. What the reviewer wants to point out that the pressure increase developed during the dispersion is 1 mbar. Do the authors believe that a difference of 1 mbar in initial pressure will have a substantial effect on the final pressure? Using simple equations like the ideal gas law will help you assess the effect on the final pressure, knowing the adiabatic flame temperature.

Response 1: Thank you very much for your time and providing a precise review of this manuscript. In this study, authors do not believe that 1 mbar initial pressure will have a substantial effect on the final pressure. Nevertheless, the main purpose of illustrating the maximum pressure developed in the layout during the leak and the dispersion is to assess the potential location of a Vapour Cloud Explosion (VCE). To clarify this for the future reviewers, the following sentences have been added in the updated manuscript.

The variation of air pressure in the layout in the presence of the dispersed vapour can be a useful information for assessing the potential location of a VCE. During gas dispersion, gas concentration in the air can create different initial pressure, which is one of the parameters on which the strength of explosion depends (Kundu et al., 2016). In this study, the maximum pressure developed during the dispersion of LNG vapour is 0.001 barg (illustrated in Error! Reference source not found.). The 1 mbar initial pressure may not have a substantial effect on the strength of a VCE.

Comment 2: The authors did not answer the question of the reviewer in the original version of the manuscript. Original comment: Suppose there is a change in wind direction, it is raining, there is snow, the leak is small than assumed by the authors, the companies use water mist systems for dispersion, time, the company has installed sniffers (generally the case), et cetera, 
how does this affect the outcome of your analysis? Are the authors aware that there are quite some parameters at stake?

Response 2: Thank you. Authors acknowledge that a change in weather conditions such as wind direction, snow, rains and source terms may affect the outcome of an analysis. Because responses to gas leak and its dispersion are strongly dependent on the operating parameters and one set of parameters may not represent all scenarios. Thus, a combination of strategies needs to be applied by considering prevalent operating conditions. For illustration purpose, the authors have presented only a specific case in this study. Once operating conditions such as wind speed, wind direction, snow, rain or other parameter changes, the response need to be evaluated accordingly considering different scenarios. Through this study, the authors wish to convey that use of systematic approach help to envisage a range of scenarios and thus required responses can be obtained accordingly. For clarification, the authors have added following sentences in 'Conclusion' section of the revised version of the manuscript.

A change in weather conditions and source terms may affect the outcome of an analysis related to gas leak and dispersion. Responses to gas leak and its dispersion are strongly dependent on these parameters and one set of parameters may not represent all cases. For illustration purpose, this study has presented only a specific case. Once operating conditions such as wind speed, wind direction, snow, rain or other parameter changes, the response need to be evaluated accordingly. The current study serves to highlight the importance of transitional events modelling and expands the scope of the integrated consequence modelling approach. Despite having complex correlations among various parameters involved in LNG spill and subsequent events, the integrated risk profiles can be effective for designing safety systems to mitigate potential effects and risk associated with thermal radiation, overpressure and combustion products during fire and/or explosion events. Consideration of effects among thermal radiation, overpressure and combustion products in the transitional event modelling, makes the study unique and realistic in safety analysis of an LNG processing facility.

Comment 3: Minor grammatical changes and typos

Response 3: They have been considered and the manuscript has been revised accordingly. 


\section{Modelling an integrated impact of fire, explosion and combustion products during transitional events caused by an accidental release of LNG}

Til Baalisampanga, Rouzbeh Abbassi ${ }^{\mathrm{b}, *}$, Vikram Garaniya ${ }^{\mathrm{a}}$, Faisal Khan ${ }^{\mathrm{c}}$, Mohammad Dadashzadeh $^{\mathrm{d}}$

a National Centre for Maritime Engineering and Hydrodynamics, Australian Maritime College, University of Tasmania, Launceston, Tasmania, Australia, 7248.

bSchool of Engineering, Faculty of Science and Engineering, Macquarie University, Sydney, NSW, Australia, 2109.

${ }^{\mathrm{c}}$ Centre for Risk, Integrity and Safety Engineering, Faculty of Engineering \& Applied Science, Memorial University of Newfoundland, St. John's, NL, Canada.

dHydrogen Safety Engineering and Research Centre (HySAFER), Ulster University, Newtownabbey, Northern Ireland, UK.

* Corresponding Author: rouzbeh.abbassi@mq.edu.au

\section{Abstract}

In a complex processing facility, there is likelihood of occurrence of cascading scenarios, i.e. hydrocarbon release, fire, explosion and dispersion of combustion products. The consequence of such scenarios, when combined, can be more severe than their individual impact. Hence, actual impact can be only represented by integration of above mentioned events. A novel methodology is proposed to model an evolving accident scenario during an incidental release of LNG in a complex processing facility. The methodology is applied to a case study considering transitional scenarios namely spill, pool formation and evaporation of LNG, dispersion of natural gas, and the consequent fire, explosion and dispersion of combustion products using Computational Fluid Dynamics (CFD). Probit functions are employed to analyze individual impacts and a ranking method is used to combine various impacts to identify risk during the transitional events. The results confirmed that in a large and complex facility, an LNG fire can transit to a vapor cloud explosion if the necessary conditions are met, i.e. the flammable range, ignition source with enough energy and congestion/confinement level. Therefore, the integrated consequences are more severe than those associated with the individual ones, and need to be properly assessed. This study would provide an insight for an effective analysis of potential consequences of an LNG spill in any LNG processing facility and it can be useful for the safety measured design of process facilities.

Keywords: LNG spill, accident transition, integrated consequence, CFD 


\section{Introduction}

LNG is considered as a safe and environmentally-friendly fuel. Safe storage, processing, transportation and usage are mandatory requirements for any fuel and LNG continues to reveal a long track record of safety in all these areas (Yeo et al., 2016). However, in a complex processing facility such as a floating liquefied natural gas (FLNG) (Baksh et al., 2016a, b), an incidental release of LNG may not simply lead to an event with only its individual impact. There is likelihood of escalating a minor event into more damaging events. For instance, an accidental release of LNG in a production facility has the potential to pose several hazards such as fire, explosion, brittle fracture, asphyxiation and freeze burn/frostbite. A leakage of LNG may be a single minor event itself. However, due to instantaneous vaporisation, it is likely to cause several events such as a fireball, flash fire, Vapour Cloud Explosion (VCE), and pool fire when the vapour is ignited. Escalation of the mentioned events to a storage facility, may lead to Boiling Liquid Expanding Vapour Explosion (BLEVE). The entire sequence of events and their interactions during an LNG spill event in an FLNG processing facility is illustrated in Fig. 1.

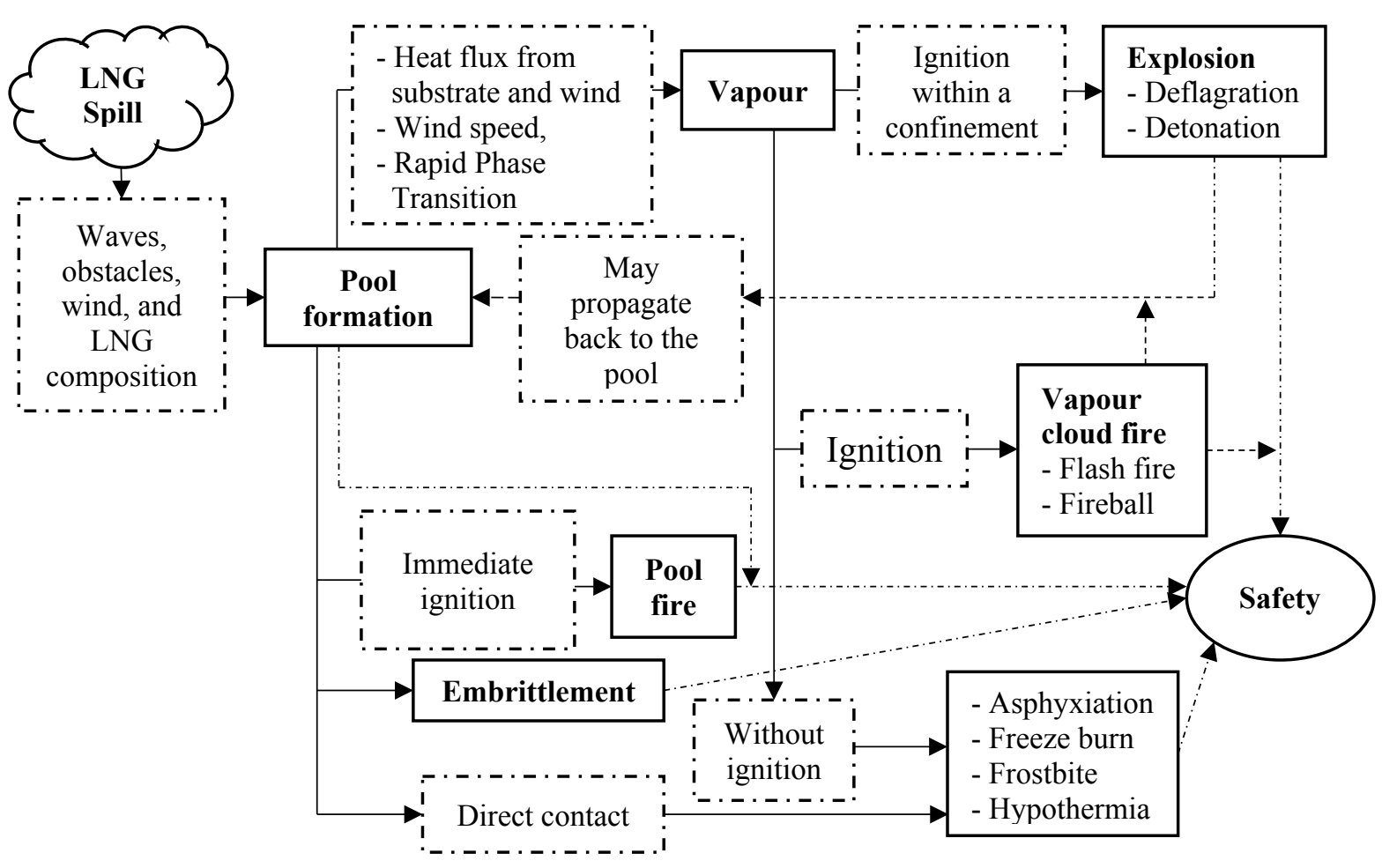

Fig. 1. LNG spill events (adapted from Ikealumba and Wu (2014) with some modifications).

Due to the potential of having several events during an unintended LNG spill, the US Government Accountability Office (GAO) commissioned a study and recommended to improve the state of knowledge surrounding the potential for cascading damage to LNG vessels 
in the case of an incidental release of LNG (US Government Accountability Office (GAO), 2007). The study of cascading damage issues has proven difficult primarily because these events require the analysis of the interaction of a series of complex physical phenomena such as LNG flow, heat transfer, fracture and damage. Petti et al. (2013) summarized the outcomes of the studies on cascading damage (Figueroa et al., 2011; Petti and Kalan, 2011; Petti et al., 2011) which explored the cryogenic and fire thermal damage to an LNG ship during a large LNG cargo tank breach.

In these studies (Figueroa et al., 2011; Petti and Kalan, 2011; Petti et al., 2011), impacts (pressure wave, shrapnel or projectile) from the explosion are not considered in the cascading damage analysis. Examples of evolving accident scenarios are reported in (Ouddai et al., 2012; Petrie and Großbritannien, 1988). The Piper Alpha tragedy in 1988 caused 165 deaths due to an explosion after the release of flammable material. In the accident, leakage of gas occurred, and the presence of an ignition source caused multiple events such as a fireball and jet fire, followed by VCEs. The sequence of events led to the total loss of the platform (Pate -Cornell, 1993). In 2004, an LNG accident occurred in the Skikda LNG plant in Algeria resulting in 27 casualties, 56 injuries and $\$ 900$ million loss. During this multiple explosions occurred due to excessive pressure in an adjacent boiler (Ouddai et al., 2012). The BP's Texas City refinery explosion in 2005 caused 15 deaths and 180 injuries due to hydrocarbon release and subsequent fire and explosion (Manca and Brambilla, 2012). The release resulted in a VCE followed by a pool fire (Broadribb, 2006). In 2010, the Macondo accident in the Gulf of Mexico occurred with a series of events such as blowout, dispersion of released hydrocarbons, explosion and fire (Deepwater Horizon Study Group (DHSG), 2011). The flame propagating from the explosion reached the flammable vapour dispersed over the platform and led to the fire at the source of release at the drilling floor. Major accidents that occurred in process facilities are well explained in (Abdolhamidzadeh et al., 2011; Al-shanini et al., 2014; Khan and Abbasi, 1999). These accidents are mainly associated with fires, explosions and toxic product release. Most past studies regarding fire and explosion accidents were limited to individual fires or explosions or combustion products modelling and did not address evolving accident scenarios (Dadashzadeh et al., 2013a; Dadashzadeh et al., 2014; Gavelli et al., 2011; Kim and Salvesen, 2002). For instance, Dadashzadeh et al. (2013a) modelled the dispersion of flammable gas integrated with explosion consequences of the BP Deepwater Horizon explosion using a Flame Acceleration Simulator (FLACS). Smoke and heat radiation released from the fire also affect human health and offshore structures; however, this impact was not addressed in the consequence analysis. Dadashzadeh et al. (2014) proposed a methodology for toxicity risk 
assessment during an LNG fire and revealed that high risks are found at the process facility due to higher concentrations of combustion products and longer exposure time. However, the direct consequence of fire was not considered. Baalisampang et al. (2017a) and Baalisampang et al. (2017b) modelled the impact of a fire in a typical FLNG processing facility. Other potential events, their interactions, and consequences were not included by Baalisampang et al. (2017a). Kim and Salvesen (2002) conducted a study on LNG vapour release, which was addressed as a possible VCE. However, a potential fire scenario was not considered. Another study by Koo et al. (2009) focused on pool fire modelling only and no consideration was given to a VCE or other possible interactions such as a jet fire. But in most cases, fire, explosion and combustion product release occur one after another or simultaneously resulting in integrated consequences (Baalisampang et al., 2018a; Baalisampang et al., 2018b). Reviews of past accidents (Al-shanini et al., 2014; Dadashzadeh et al., 2013a; Manca and Brambilla, 2012) and models (Al-shanini et al., 2014; Baksh et al., 2015; Kim and Salvesen, 2002; Koo et al., 2009) demonstrate a need to evaluate the entire accident sequence to mitigate the impact, to develop appropriate response methods and to prevent accidents by designing safety measures in the system. Combination of various accidental events is important as one event may lead to another and increases the overall consequences. To model entire impacts of a potential accident in a complex processing facility, it is essential to consider transitional event scenarios because in such modelling, entire causes and effects of a series of events are considered. In comparison to onshore processing facilities, offshore facilities are deemed more vulnerable to transitional events due to limited topside space and harsh environmental conditions (Baalisampang et al., 2016). Some offshore accidents involving transitional events are given in Table 1.

Table 1

Offshore fire and explosion accidents associated with multiple events

\begin{tabular}{|c|c|c|c|}
\hline $\begin{array}{l}\text { Accident name, year } \\
\text { and geographical } \\
\text { region }\end{array}$ & Event sequence & Consequences & References \\
\hline $\begin{array}{l}\text { Piper Alpha, 1988, } \\
\text { Europe North Sea }\end{array}$ & $\underset{\text { Release } \longrightarrow \text { Explosion }}{\longrightarrow}$ & $\begin{array}{l}165 \text { fatalities, total } \\
\text { loss }\end{array}$ & $\begin{array}{l}\text { (Pate - } \\
\text { Cornell, } \\
1993)\end{array}$ \\
\hline $\begin{array}{l}\text { High Island Pipeline, } \\
\text { 1989, US GOM }\end{array}$ & $\begin{array}{l}\text { Collision } \longrightarrow \text { Release } \longrightarrow \\
\text { Explosion } \longrightarrow \text { Fire }\end{array}$ & $\begin{array}{l}11 \text { fatalities, } 4 \text { injuries } \\
\text { and significant } \\
\text { damage }\end{array}$ & $\begin{array}{l}\text { (OPG, } \\
2010 b)\end{array}$ \\
\hline $\begin{array}{l}\text { Enchova Central, 1984, } \\
\text { America South East }\end{array}$ & $\begin{array}{l}\text { Blowout } \longrightarrow \text { Fire } \longrightarrow \\
\text { Explosion }\end{array}$ & $\begin{array}{l}42 \text { Fatalities, } 19 \\
\text { injuries and } \\
\text { significant damages }\end{array}$ & $\begin{array}{l}(\mathrm{OPG}, \\
2010 \mathrm{~b})\end{array}$ \\
\hline
\end{tabular}




\begin{tabular}{|c|c|c|c|}
\hline $\begin{array}{l}\text { Lake Maracaibo, 1993, } \\
\text { America South East }\end{array}$ & Explosion $\longrightarrow$ Fire & $\begin{array}{l}11 \text { fatalities, } \\
\text { significant damage }\end{array}$ & $\begin{array}{l}\text { (OPG, } \\
2010 b)\end{array}$ \\
\hline $\begin{array}{l}\text { Ubit, 1995, } \\
\text { Africa West }\end{array}$ & Explosion $\longrightarrow$ Fire & $\begin{array}{l}10 \text { fatalities, } 23 \\
\text { injuries and severe } \\
\text { damage }\end{array}$ & $\begin{array}{l}(\mathrm{OPG} \\
2010 \mathrm{~b})\end{array}$ \\
\hline $\begin{array}{l}\text { Petrobras P-36, 2001, } \\
\text { America South East }\end{array}$ & $\begin{array}{l}\text { Explosion } \longrightarrow \text { Fire } \longrightarrow \\
\text { Capsizing }\end{array}$ & 11 fatalities, total loss & $\begin{array}{l}\text { (OPG, } \\
2010 b)\end{array}$ \\
\hline $\begin{array}{l}\text { Bombay High North, } \\
\text { 2005, Asia South }\end{array}$ & $\begin{array}{l}\text { Collision } \longrightarrow \text { Release } \longrightarrow \\
\text { Fire }\end{array}$ & $\begin{array}{l}12 \text { fatalities, severe } \\
\text { damage to the jacket }\end{array}$ & $\begin{array}{l}\text { (OPG, } \\
2010 b)\end{array}$ \\
\hline $\begin{array}{l}\text { Deepwater Horizon, } \\
2010, \text { GOM }\end{array}$ & $\begin{array}{l}\text { Blowout } \longrightarrow \text { Release } \longrightarrow \\
\text { Fire } \longrightarrow \text { Explosion }\end{array}$ & $\begin{array}{l}11 \text { people died, } 17 \\
\text { injuries and total loss }\end{array}$ & $\begin{array}{l}\text { (Deepwater } \\
\text { Horizon } \\
\text { Study Group } \\
\text { (DHSG), } \\
2011 \text { ) }\end{array}$ \\
\hline $\begin{array}{l}\text { Black Elk, 2012, } \\
\text { GOM }\end{array}$ & $\begin{array}{l}\text { Release } \longrightarrow \text { Fire } \longrightarrow \\
\text { Explosion }\end{array}$ & $\begin{array}{l}3 \text { people died, } \\
\text { pollutant spill }\end{array}$ & $\begin{array}{l}\text { (BSEE, } \\
2013)\end{array}$ \\
\hline $\begin{array}{l}\text { SOKAR platform, } \\
2014, \\
\text { Caspian Sea }\end{array}$ & Explosion $\longrightarrow$ Fire & $\begin{array}{l}12 \text { people fell into the } \\
\text { sea }\end{array}$ & $\begin{array}{l}\text { (Fattakhova } \\
\text { and } \\
\text { Barakhnina, } \\
\text { 2015) }\end{array}$ \\
\hline $\begin{array}{l}\text { Abkatun Alfa platform, } \\
\text { 2015, GOM }\end{array}$ & Explosion $\longrightarrow$ Fire & $\begin{array}{l}7 \text { people died, } 45 \\
\text { injuries }\end{array}$ & $\begin{array}{l}\text { (Offshore } \\
\text { Post- } \\
\text { Everything } \\
\text { offshore } \\
\text { energy, } \\
2015)\end{array}$ \\
\hline
\end{tabular}

In fire and explosion accidents, a combined impact assessment is assumed to provide a more accurate consequence than individual one. In fire and explosion accidents, a damage potential (radius) can be increased if the impact of combustion products is considered (Dadashzadeh et al., 2014). During fire and explosion accidents, depending upon the types of burning materials and their combustion products, people are exposed to adverse health effects. For an integrated impact study, Khan and Amyotte (2004) proposed a methodology that incorporated fire, explosion and toxic release damage indices to evaluate the inherent safety of a facility based on inherent safety guidelines. Dadashzadeh et al. (2013b) proposed a new methodology for modelling an integrated consequence of fire and explosion using the Fire Dynamics Simulator (FDS) and FLACS and concluded that the risk of combined consequences is higher than each individual risk. But potential risk from combustion products during fire and/or explosion was not considered in the study. Niazi et al. (2018) proposed an integrated consequence modelling approach for fire and combustion products using risk based and grid- 
based approaches and claimed that the risk posed by thermal radiation is confined only to the lower deck. But the risk of exposure to combustion products was presentfound in the a larger areaportion than that of the radiation, due to-under the influence of wind. Unlike previous studies (Dadashzadeh et al., 2013b; Khan and Amyotte, 2004; Niazi et al., 2018), the current study proposes a risk-based approach to model an integrated impact of fire, explosion and combustion products during an accidental release of LNG in a typical FLNG processing facility.

\section{Methodology}

This study proposes a methodology that models an integrated impact of evolving accident scenarios such as release, pool fire, explosion events and dispersion of combustion products as illustrated in Fig. 2. Currently, several Quantitative Risk Assessment (QRA) softwares tools such as IMESAFR (Tatom et al., 2011), Riskcurves (GexCon, 2018b), EFFECTS (GexCon, 2018a), Riskan (Lewis, 2005), HAMS-GPS (HAMSAGARS) and Phast and Safeti (DNV-GL, 2018) are available for accident modelling. They are simpler and faster than most CFD tools. A majority of QRA software tools lacks the capability of considering complex effects of geometry and equipment in the simulation and cannot model evolving accident scenarios. But thise studyeurrent appreach considers the effect of complex geometry and/or equipment and models cascading events and their impacts using the following five steps.

In step 1, LNG release scenario, pool formation, vaporisation and dispersion of LNG vapour are modelled using FLACS. These phenomena are simulated with careful consideration of plausible scenarios. 


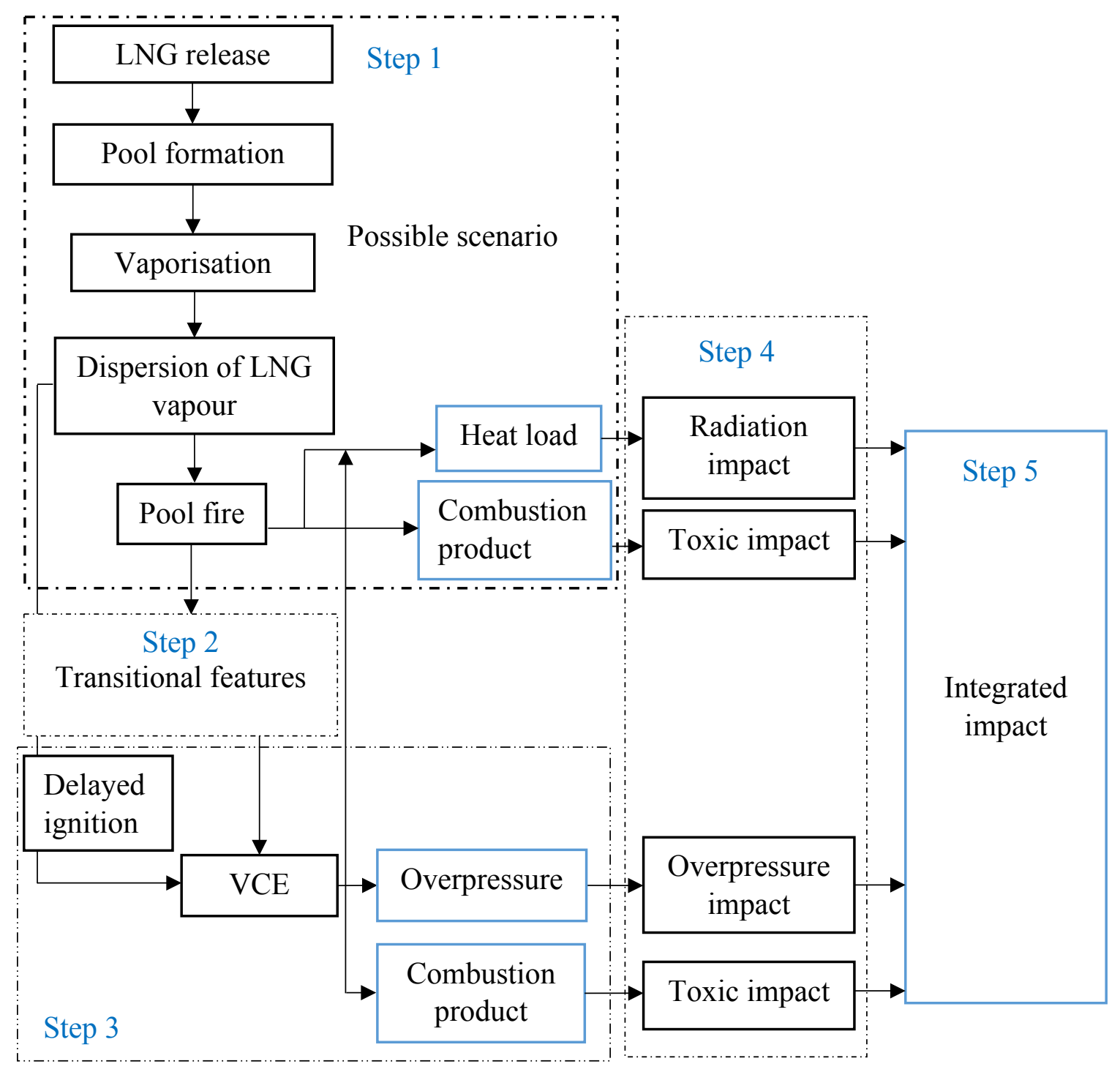

Fig. 2. Proposed methodology for modelling an integrated impact of transitional events to human during an LNG spill.

In step 2, the potential transitional phenomena are considered by attending to a series of events such as dispersion of LNG vapour, pool fire and VCE. In this transitional event, the phenomenological changes to spilled LNG and vaporisation due to a culmination of atmospheric effects and thermal radiation are considered for assessing the occurrence of potential cascadingtransitional events. The thermal load obtained from the pool fire is used as the source of ignition for the VCE. For transitional events to occur, some minimum conditions need to be fulfilled. For instance, a dispersion event can transit to pool fire only if the flammability condition is met. Similarly, an VCE occurs when pertinent conditions such as confinement, turbulence, ignition source, and flammable gas cloud are present_(Atkinson et al., 2017; Center for Chemical Process Safety, 1996). These pertinent conditions are considered as stimuli for the transitions (events) (Alzbutas, 2015). Turbulence is required for the flame front 
to accelerate to the speeds required for a VCE which is typically formed by the interaction between the flame front and obstacles (Center for Chemical Process Safety, 1996). General conditions required to cause a particular event are considered as stimuli for the transitions (events) (Alzbutas, 2015). During a release, with the vaporisation and dispersion of LNG in air, only a vapour concentration in the range of 5-15 vol.\% will sustain the propagation of a flame upon ignition. The concentration of the vapour above the upper explosion limit may act as feed gas to the fire. The remaining vapour concentration may act as feed gas to the fire. However, if the dispersed vapours-concentration accumulateoutside this range builds everpressure in nearby semi-confined or confined areas, the fire may transform to an $\mathrm{VCE}$ upon ignition. This may increase the severity of consequence in total. If the flammable gas release is not ignited immediately, a vapor plume will form which will drift and disperse by the ambient winds and/or natural ventilation. If the vapour is ignited, but does not explode, it will result in a flash fire, in which the gas cloud within the flammable range burns very rapidly. If the vapour is not isolated during this time, the flash fire may burn to yield a jet fire at the source of the release, under the condition that the concentration range is appropriate, and the leak is present.

In step 3, the heat released from the pool fire is modelled as the potential ignition source to ignite the flammable gas accumulated at a position away from the pool fire location such that the fire did not consume the rich vapour cloud from this location. It was assumed that this location did not get direct fire flame and the presence of high thermal radiation from the fire resulted in an autoignition of the vapour or influenced other ignition sources to ignite. During a release of a flammable gas, if the ignition is delayed by 5-10 min, a VCE may be the outcome (Assael and Kakosimos, 2010; Soman and Sundararaj, 2012). For ignition to take place, the vapour cloud must be within the flammable range, while at the same time a source able to supply the required energy must be available (Assael and Kakosimos, 2010). To model a pool fire transiting to a VCE, thermal radiation and other parameters such as temperature and pressure development are extracted from the previous step. There are various models available for gas explosion modelling, like empirical, phenomenological and CFD (Lea and Ledin, 2002). According to Tam and Lee (1998), CFD codes are inherently more flexible than both empirical and phenomenological models and are applicable to all fields. Some commonly used CFD models for explosion simulations are EXSIM, FLACS and AutoReaGas (Lea and Ledin, 2002). FLACS developed by the Global Explosion Consultants (GexCon AS) has been used widely for the modelling of gas dispersion and explosion in onshore or offshore facilities (Hansen et al., 2005). In this study, FLACS is used to model the fire and explosion scenarios. 
In step 4, the consequences of fire, explosion and/or combustion product release are analysed individually using probit functions. The heat load obtained from the fire is used to assess the fire impact to assets and people. The probability of human impacts from the heat radiation is calculated by Eq. (2), considering the probit model given in Eq. (1).

Probit function $(P r)=c_{1}+c_{2} \ln D$,

The probability of injury or death $(P)=F_{k} \frac{1}{2}\left[1+\operatorname{erf}\left(\frac{\operatorname{Pr}-5}{\sqrt{2}}\right)\right]$,

where $D$ is the thermal dose $\left(\frac{k W}{m^{2}}\right)^{\frac{4}{3}} s, c_{1}$ and $c_{2}$ are probit coefficients, $F_{k}$ is a clothes correction factor, and erf is the error function. The thermal dose is obtained from the post processing file using inbuilt utilities in FLACS.

Sudden large changes in pressure due to an explosion can lead to dramatic and possibly fatal damage to vital human organs such as lungs and ears. The impact of explosion is assessed based on the calculation of the probability (P) of injury or death employing Eqs. (3)-(8).

Probit function $(P r)=c_{1}+c_{2} \ln S$,

The probability of injury or death $(\mathrm{P})=\frac{1}{2}\left[1+\operatorname{erf}\left(\frac{\operatorname{Pr}-5}{\sqrt{2}}\right)\right]$,

where variable $S$ is defined according to the type of the effect calculated by $S=\left(\frac{4.2}{\bar{P}}+\frac{1.3}{\bar{i}}\right)$, where $\bar{i}$ is the scaled impulse $\left(P a^{\frac{1}{2}} \cdot s . \mathrm{kg}^{-\frac{1}{3}}\right), \bar{P}$ is scaled pressure (-) and $c_{1}$ and $c_{2}$ are probit coefficients (Assael and Kakosimos, 2010). Explosion effects on humans are usually categorised as:

1. Direct or primary effects

The overpressure from the explosion can cause injury to sensitive human organs, or death.

2. Indirect effects

The indirect effects are sub-divided into two categories

a. Secondary effects refer to injuries or death caused by fragments or debris thrown by explosion's blast,

b. Tertiary effects that refer to injuries or death caused by whole-body displacement and collision with stationary objects or structures, because of the explosion's blast waves. 
The probabilities of impact to lung, eardrum rupture, head impact and whole-body displacement impact are calculated using Eq. (4). However, the $\operatorname{Pr}$ are different. In this study, the following probit functions are used for each type of impact (Assael and Kakosimos, 2010). For lung damage, $\operatorname{Pr}=5-5.74 \ln S$

For eardrum damage, $\operatorname{Pr}=-12.6+1.524 \ln P_{S}$

For head impact, $\operatorname{Pr}=5-8.49 \ln S$

For whole-body displacement, $\operatorname{Pr}=5-2.44 \ln S$

where $P_{s}$ is overpressure (Pa). According to Clancey (1972) cited in Crowl and Louvar (2011) $1-99 \%$ fatalities can occur when exposed to over 2 bar.

Toxicity of combustion products accounts for a major cause of death and injury from unwanted fires (Hartzell, 1992). The main combustion products are divided into two types: asphyxiant gases, which prevent oxygen uptake by cells, leading to loss of consciousness and death; irritant gases which cause immediate incapacitation affecting eyes and upper respiratory tract long-term damage in the lung (Hull and Stec, 2010). Because of these harmful effects, they can seriously jeopardise evacuation. During an LNG fire or VCE, carbon monoxide (CO) and nitrogen dioxide $\left(\mathrm{NO}_{2}\right)$ are the main toxic combustion products (Dadashzadeh et al., 2014).

In the step 5, the integrated impact of fire, explosion and combustion product release is estimated. For integration of fire and VCE effects a grid-based approach is used such that consequence severity can be mapped as an index. To estimate risk of each event, a risk-based approach was further adopted using a severity index and probability of each effect. The severity index for each type of effect $\left(\mathrm{S}_{i}\right)$ is estimated using expert judgment. The effects are ranked based on their severity of damages (Table 2) and experts' judgment on a scale of 1-10.

Table 2

Severity scores for human effects caused by fire and explosion (Dadashzadeh et al., 2013b)

\begin{tabular}{|l|l|l|l|l|l|l|l|}
\hline & \multicolumn{2}{|l|}{ Fire } & \multicolumn{2}{l|}{ Explosion } \\
\hline Effects & $\begin{array}{l}\text { First } \\
\text { degree } \\
\text { burn }\end{array}$ & $\begin{array}{l}\text { Second } \\
\text { degree } \\
\text { burn }\end{array}$ & Death & $\begin{array}{l}\text { Lung } \\
\text { damage }\end{array}$ & $\begin{array}{l}\text { Eardrum } \\
\text { rupture } \\
\text { (injury) }\end{array}$ & $\begin{array}{l}\text { Head } \\
\text { impact } \\
\text { (death) }\end{array}$ & $\begin{array}{l}\text { Whole body } \\
\text { displacement } \\
\text { (death) }\end{array}$ \\
\hline Score (S) & 2 & 5 & 10 & 10 & 5 & 10 & 10 \\
\hline
\end{tabular}

The severity index for each effect at any location of the plant is calculated as follows:

$\operatorname{Risk}_{i}=\mathrm{S}_{i} \times \mathrm{P}_{i}$

Where, $\operatorname{Risk}_{i}$ denotes the severity index for each effect and $i$ denotes the effects (first degree injury, second degree injury and death for fire; lung damage, eardrum rupture, head impact and 
whole-body displacement for explosion). At each grid point, the maximum severity index among the various effects of each accident is considered using Eqs. (10) and (11) for a fire and explosion respectively.

$\operatorname{Risk}_{f}=$ maximum [Risk ${ }_{\text {First degree burn }}$, Risk $_{\text {Second degree burn }}$, Risk $\left._{\text {Death }}\right]$

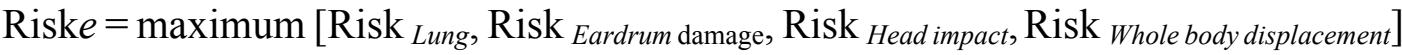

The total risk of fire and VCE (Risk $f e$ ) at any location is estimated using Eq. (12),

$\operatorname{Risk}_{f e}=\operatorname{Risk}_{f}+\operatorname{Risk}_{e}$

Using the Risk $\mathrm{fe}_{f e}$ at any location of the layout, risk contour can be obtained considering cumulative effects of a fire and VCE.

The toxicity risk assessment is carried out according to the methodology proposed by Dadashzadeh et al. (2014). A hazard index (HI) was estimated at each grid point of the layout using Eq. (13) (National Research Council, 1998).

$H I=\frac{\text { Estimated concentration }\left(\mathrm{mg} / \mathrm{m}^{3}\right)}{\text { Reference toxic value }\left(\mathrm{mg} / \mathrm{m}^{3}\right)}$

For toxic risk estimation of each contaminant of the combustion product, Eq. (13) can be written as in Eq. (14).

Risk $_{\text {combustion product }}=\frac{\text { Exposure concentration }}{T L V-S T E L}$

Where TLV-STEL is the Threshold limit value - Short Term Exposure Limit $\left(\mathrm{mg} / \mathrm{m}^{3}\right)$. By adding the hazard quotients (hazard indices) for the individual emission toxicants, the hazard quotient of all toxicants is obtained as shown in Eq. (15). A risk of a health effect is assumed to exist at those exposure locations where the hazard index exceeds 1 .

Risk $_{\text {Total combustion product }}=$ Risk $_{\mathrm{CO}}+$ Risk $_{\mathrm{NO}_{2}}$

Finally, the integrated risk at any location of the facility is estimated by investigating the Risk $\mathrm{fe}_{f}$

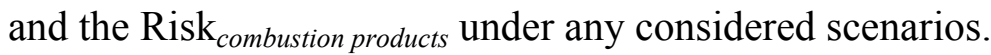

\section{Application of the integrated methodology: a case study}

The proposed methodology is applied to a typical layout consisting of several process equipment as shown in Fig. 3. Leak, vaporisation and dispersion are strongly dependent on the operating parameters and may need to consider prevalent operating conditions. In this case study, prevalent operating conditions are considered based on FLACS user's manual (GexCon AS, 2013). In this scenario, $10 \mathrm{~kg} / \mathrm{s}$ of LNG is released at an LNG processing plant. According to Woodward (2010) the appropriate wind speed for flammable cloud dispersion is usually 
close to 2 to $4 \mathrm{~m} / \mathrm{s}$ and thus, the wind speed is taken as $3 \mathrm{~m} / \mathrm{s}$ with an ambient temperature of $20^{\circ} \mathrm{C}$. A pool of LNG is formed at the release location and vaporization occurs due to the ambient conditions. The vaporized LNG is then dispersed by the wind and a fuel vapour cloud is formed in the process area. At $125 \mathrm{~s}$, an ignition occurs in the process area which leads to a pool fire. After $55 \mathrm{~s}$ the fire transits to a VCE in the congested and confined portion of the facility. This time is chosen based on the presence of the maximum thermal radiation in the layout. The heat load released due to the fire enhances the LNG vaporization over the LNG pool and causes a VCE. A transitional scenario is developed considering the inherent characteristics of the LNG spill and various potential events (such as pool formation, spreading, vaporization, and vapour dispersion) are modelled.

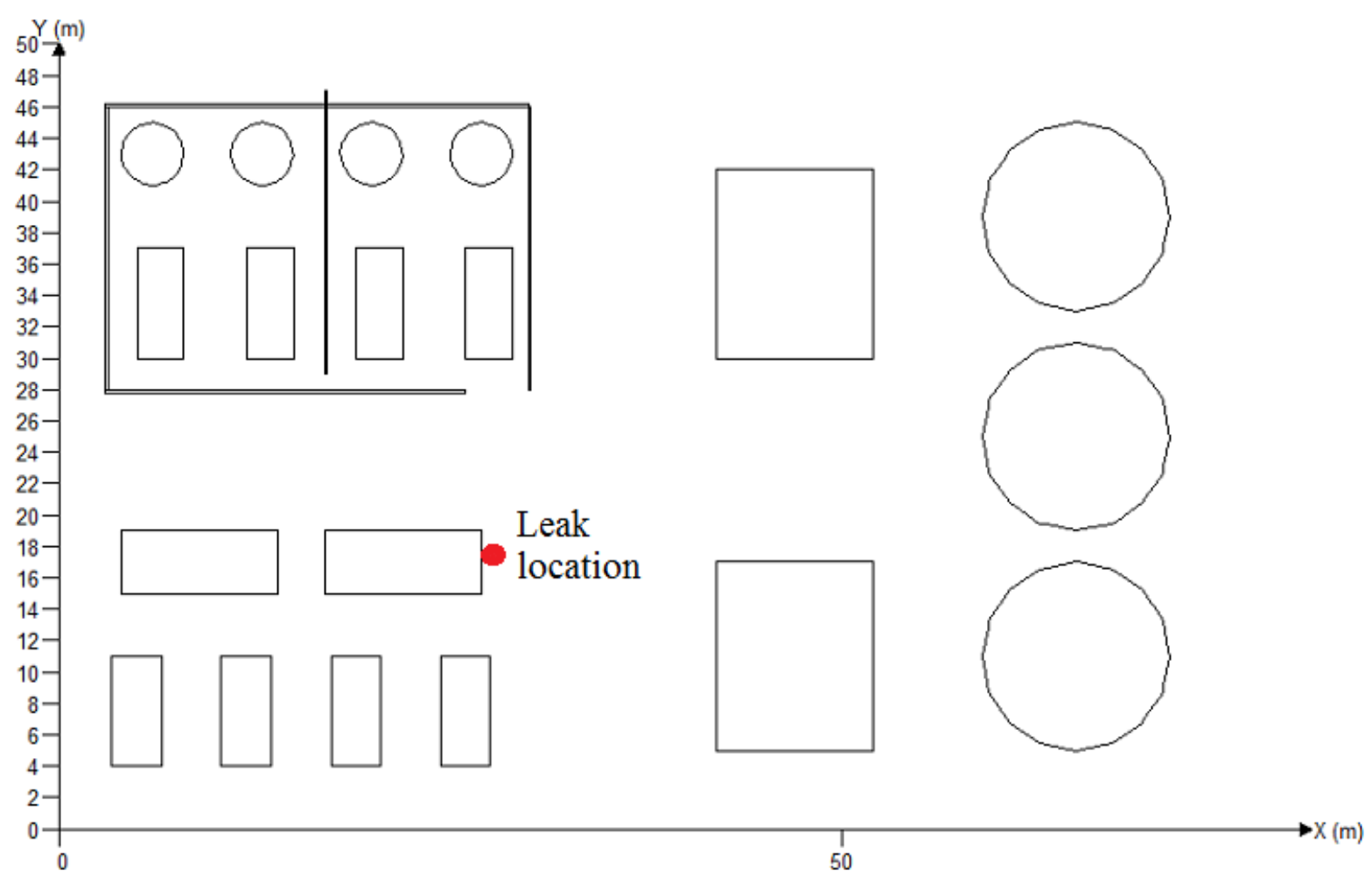

Fig. 3. A layout chosen for the transitional events modelling

\subsection{Release, pool formation, vaporisation and dispersion modelling}

In this scenario, an instantaneous release of LNG is considered which led to a pool formation and formed a flammable vapour plume upon vaporisation. A pool fire is considered with a delayed ignition. The entire layout $85 \mathrm{~m} \times 55 \mathrm{~m} \times 20 \mathrm{~m}$ is considered for simulation with a grid resolution of $0.4 \mathrm{~m}$ for the $\mathrm{x}$ and $\mathrm{y}$ directions and $0.3 \mathrm{~m}$ in the $\mathrm{z}$ direction. A sensitivity analysis was performed using volumetric concentration to select the grid size for a solution independent of the mesh size. Around the leak location, the grid resolution was 
adjusted to $0.2 \mathrm{~m}$ while at the locations far from the pool area, grids were stretched according to grid refinement guideline given in GexCon AS (2013). The LNG was assumed to be composed of $85 \%$ methane, $10 \%$ ethane and $5 \%$ propane. According to Pitblado et al. (2005) the maximum credible puncture hole is $250 \mathrm{~mm}$. Thus, a point leak is considered from a 0.05 $\mathrm{m}^{2}$ hole for $120 \mathrm{~s}$ forming a pool. A dynamic pool model (PM3) is chosen which means that the pool spreads with non-uniform pool temperature due to the influence of heat and mass transfer in each control volume (GexCon AS, 2013). A constant evaporation rate of 0.14 $\mathrm{kg} /\left(\mathrm{m}^{2} \mathrm{~s}\right)$ is considered based on the OPG (2010a). The considered leak parameters are given in

Table 3.

Table 3

Leak parameters considered in the release scenario

\begin{tabular}{|l|l|}
\hline Leak type & Jet \\
\hline Leak position & $(26.5,20,1.2) \mathrm{m}$ \\
\hline Leak direction & $+\mathrm{X}$ \\
\hline Start time & $5 \mathrm{~s}$ \\
\hline Duration & $120 \mathrm{~s}$ \\
\hline Outlet & \\
a. Area & $0.05 \mathrm{~m}^{2}$ \\
b. Mass flow rate & $10 \mathrm{~kg} / \mathrm{s}$ \\
c. Relative turbulence intensity & $0.02(\mathrm{Low})$ \\
d. Turbulence length scale & $0.025 \mathrm{~m}$ \\
e. Temperature & $-160^{\circ} \mathrm{C}$ \\
\hline
\end{tabular}

The initial and boundary conditions assigned for the simulation are provided in Table $\mathbf{4}$ and Table 5 respectively. The Euler boundary condition is a zero pressure condition and demands significant distance in all directions (GexCon AS, 2013).

\section{Table 4}

Initial conditions used

\begin{tabular}{|l|l|}
\hline Parameters & Values \\
\hline Characteristic velocity & $0.1 \mathrm{~m} / \mathrm{s}$ \\
\hline Relative turbulence intensity & 0.1 \\
\hline Turbulence length scale & $0.01 \mathrm{~m}$ \\
\hline Temperature & $20^{\circ} \mathrm{C}$ \\
\hline
\end{tabular}




\begin{tabular}{|l|l|}
\hline Ambient pressure & $100 \mathrm{kPa}$ \\
\hline Ground roughness & $0.001 \mathrm{~m}$ \\
\hline Reference height & $2 \mathrm{~m}$ \\
\hline Pasquill stability class & $\mathrm{F}$ \\
\hline
\end{tabular}

\section{Table 5}

Boundary conditions

\begin{tabular}{|l|l|}
\hline Name & Type \\
\hline XLO & Wind \\
\hline XHI & Euler \\
\hline YLO & Wind \\
\hline YHI & Euler \\
\hline ZLO & Euler \\
\hline ZHI & Euler \\
\hline
\end{tabular}

All parameters required for post processing are given in Table 6.

Table 6

A list of simulated parameters

\begin{tabular}{|l|l|}
\hline Output parameters & Unit \\
\hline Pressure (P) & $\mathrm{barg}$ \\
\hline Maximum pressure (PMAX) & $\mathrm{barg}$ \\
\hline Velocity vector (VVEC) & $\mathrm{m} / \mathrm{s}$ \\
\hline Combustion product mass fraction (PROD) & - \\
\hline Temperature (T) & $\mathrm{K}$ \\
\hline Mass fraction of carbon monoxide (CO) & - \\
\hline Radiative heat flux (QRAD) & $\mathrm{kW} / \mathrm{m}^{2}$ \\
\hline Total heat flux (Q) & $\mathrm{kW} / \mathrm{m}^{2}$ \\
\hline Mass fraction of soot (SOOT) & - \\
\hline Heat dose (QDOSE) & $\left(\left(\mathrm{kW} / \mathrm{m}^{2}\right)^{\wedge}(4 / 3) \mathrm{s}\right)$ \\
\hline
\end{tabular}




\begin{tabular}{|l|l|}
\hline Mass fraction of Nitrogen Dioxide $\left(\mathrm{NO}_{2}\right)$ & - \\
\hline Probability of death (PDEATH) & - \\
\hline Toxic probit (PROBIT) & - \\
\hline Toxic concentration (TCONS) & $\mathrm{mg} / \mathrm{m}^{3}$ \\
\hline Toxic dose (TDOSE) & $\mathrm{mg} / \mathrm{m}^{3}$. minute \\
\hline
\end{tabular}

The vaporised fuel concentrations in the layout are monitored during the dispersion as shown in Figs. 4 and 5. The presence of flammable concentrations $(0.05-0.15)$ indicates that the fuel has the potential to be ignited in several areas of the layout. This would likely contribute to the occurrence of transitional events or evolving accident scenarios.

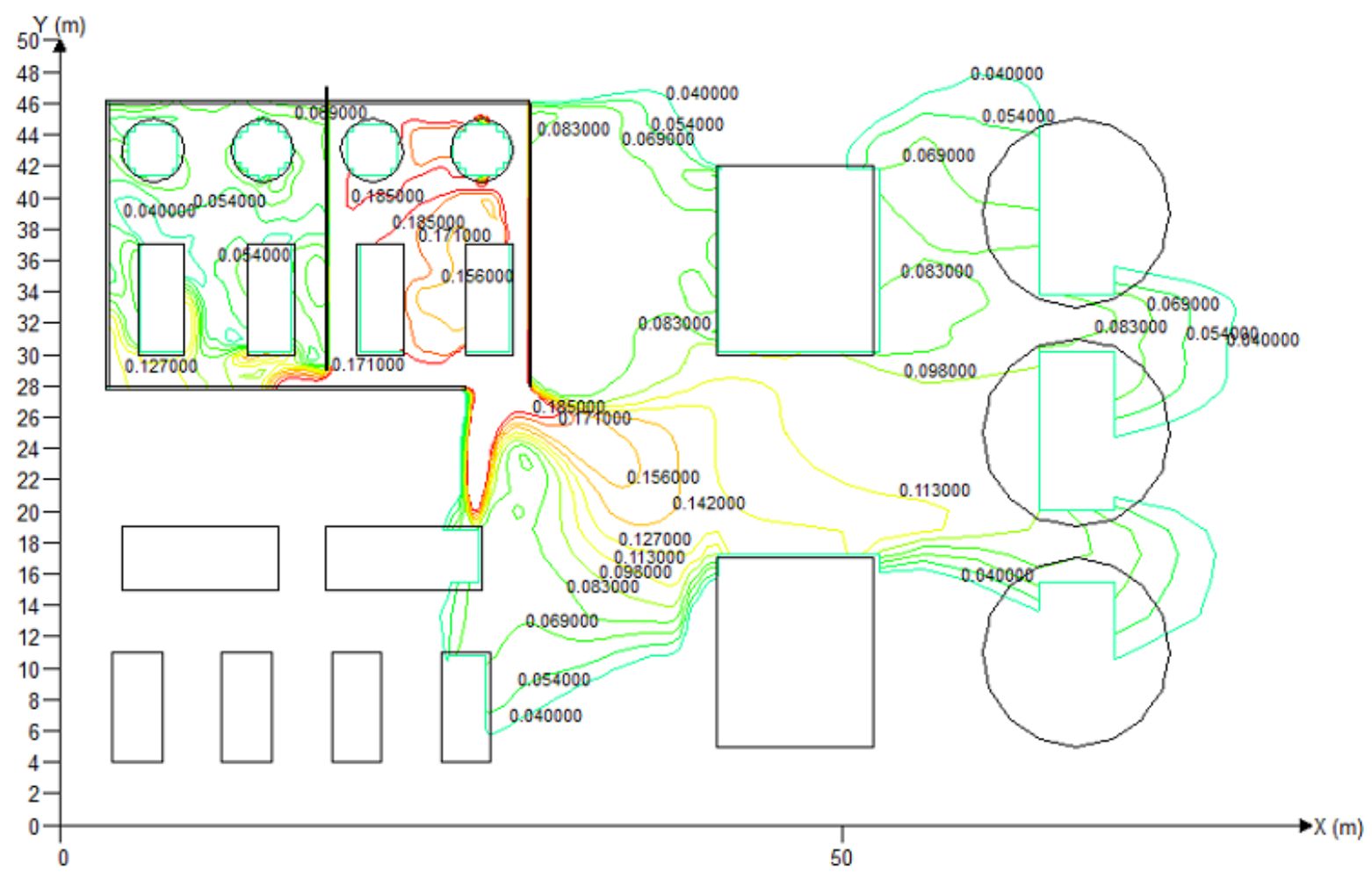

Fig. 4. Dispersion of vaporised $L N G$ over the layout $\left(\mathrm{m}^{3} / \mathrm{m}^{3}\right)$ at time $125 \mathrm{~s}$ 


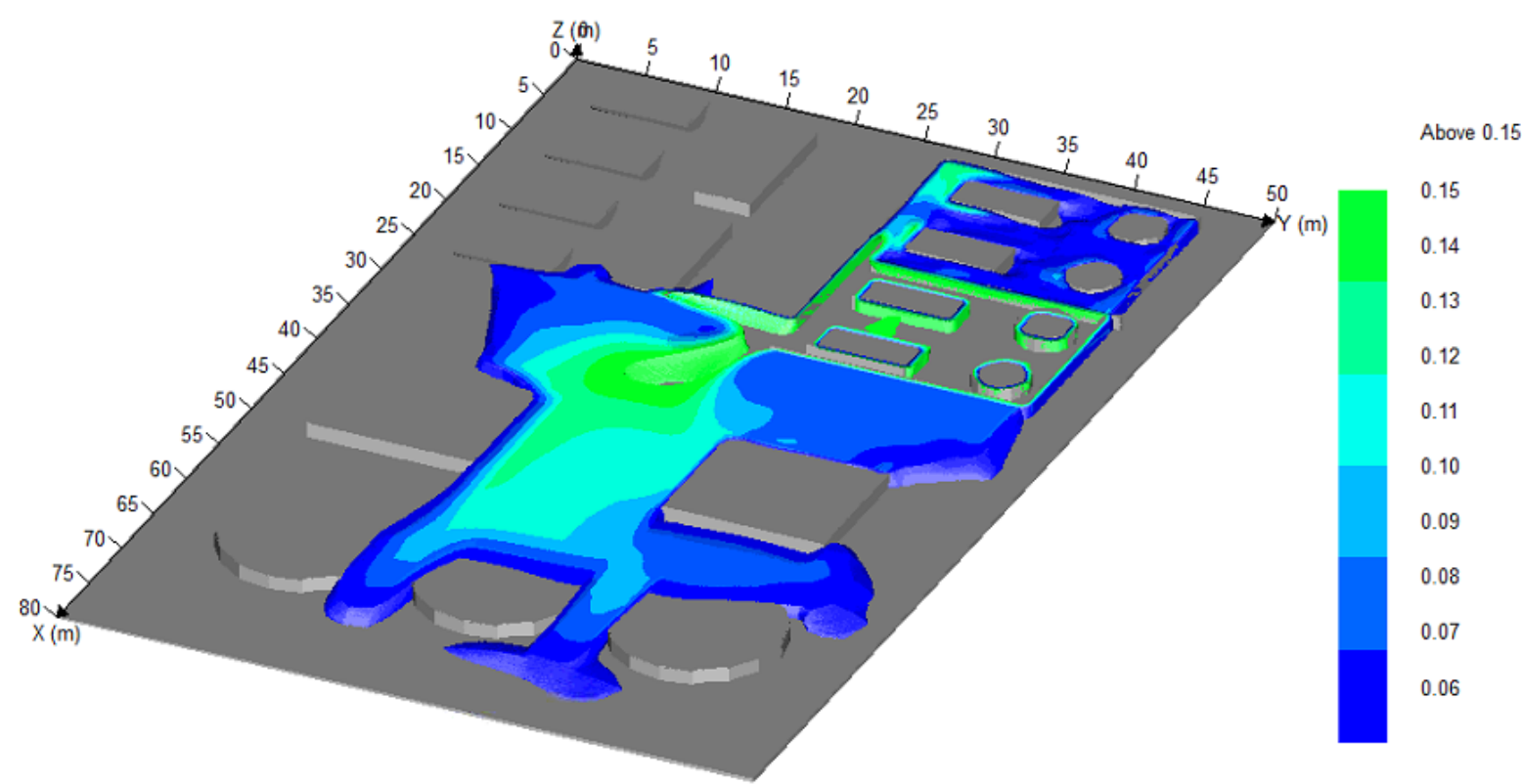

Below 0.05

Fig. 5. 3D dispersion of fuel in the layout $\left(\mathrm{m}^{3} / \mathrm{m}^{3}\right)$ at $125 \mathrm{~s}$ which shows the maximum volume of gas cloud.

\subsection{Assessing the possibility of transitional features}

A VCE is considered as the final event and to identify transitional features, fire modelling is considered. Based on the dispersion characteristics of the LNG vapour, a pool fire is modelled with a delayed ignition $125 \mathrm{~s}$ using the FLACS fire model as demonstrated in Fig. 6. In the fire simulation, the Discrete Transfer Method (DTM) model is used because this is the most accurate radiation model (GexCon AS, 2013). Emissivity of 0.85 is used because it is applicable to most steel surfaces. To provide numerical stability, radiation start ramp is considered to be 1 (GexCon AS, 2013). The Eddy Dissipation Concept (EDC) is chosen as the combustion model. The Formation Oxidation model is chosen as the soot model. For typical hydrocarbons, the soot yield is in the order of $1 \%$ (GexCon AS, 2013). Radiation, smoke and engulfment are the main hazards of a pool fire (Jagger and O'Sullivan, 2004). The possibility of ignition of the accumulated LNG vapour due to the thermal radiation release from the fire needs to be assessed for transitioning to a VCE. 


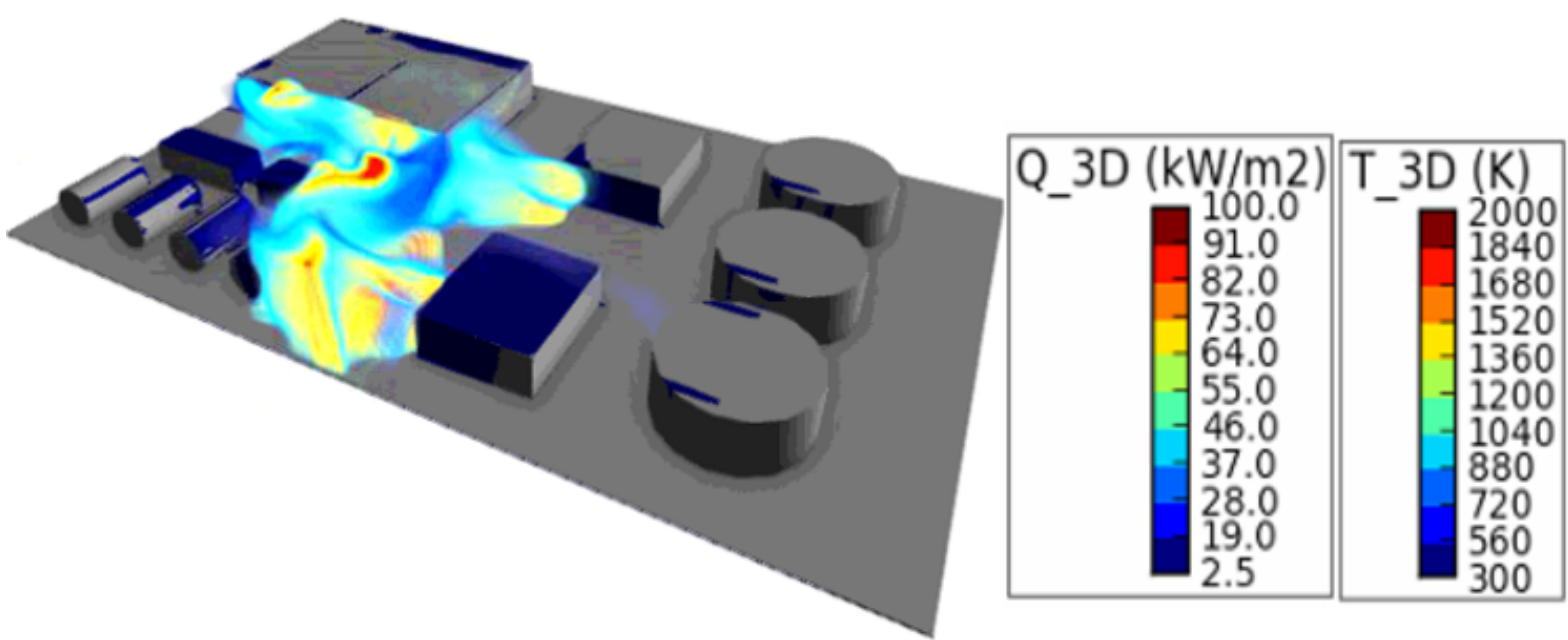

Fig. 6. 3D pool fire model at $125 \mathrm{~s}$

The main purpose of the transitional event modelling is to analyse if the fire or dispersed vapour can cause a VCE or flash fire in the presence of an existing fire. The most likely location of an VCE can be identified based on the presence of a flammable concentration of LNG vapour, confinement/equipment congestion and ignition source. An autoignition can be a source of ignition of the vapour or heated objects due to the thermal radiation from the fire (Planas-Cuchi et al., 1997; Zheng and Chen, 2011). According to the fuel concentration and its developed pressure during LNG vapour dispersion, a transition of the pool fire to a VCE is modelled. The transition from fire to VCE is considered after $55 \mathrm{~s}$ of the start of the fire, that is at $180 \mathrm{~s}$. The small pressure developed during LNG vapour dispersion is demonstrated in Fig. 7.

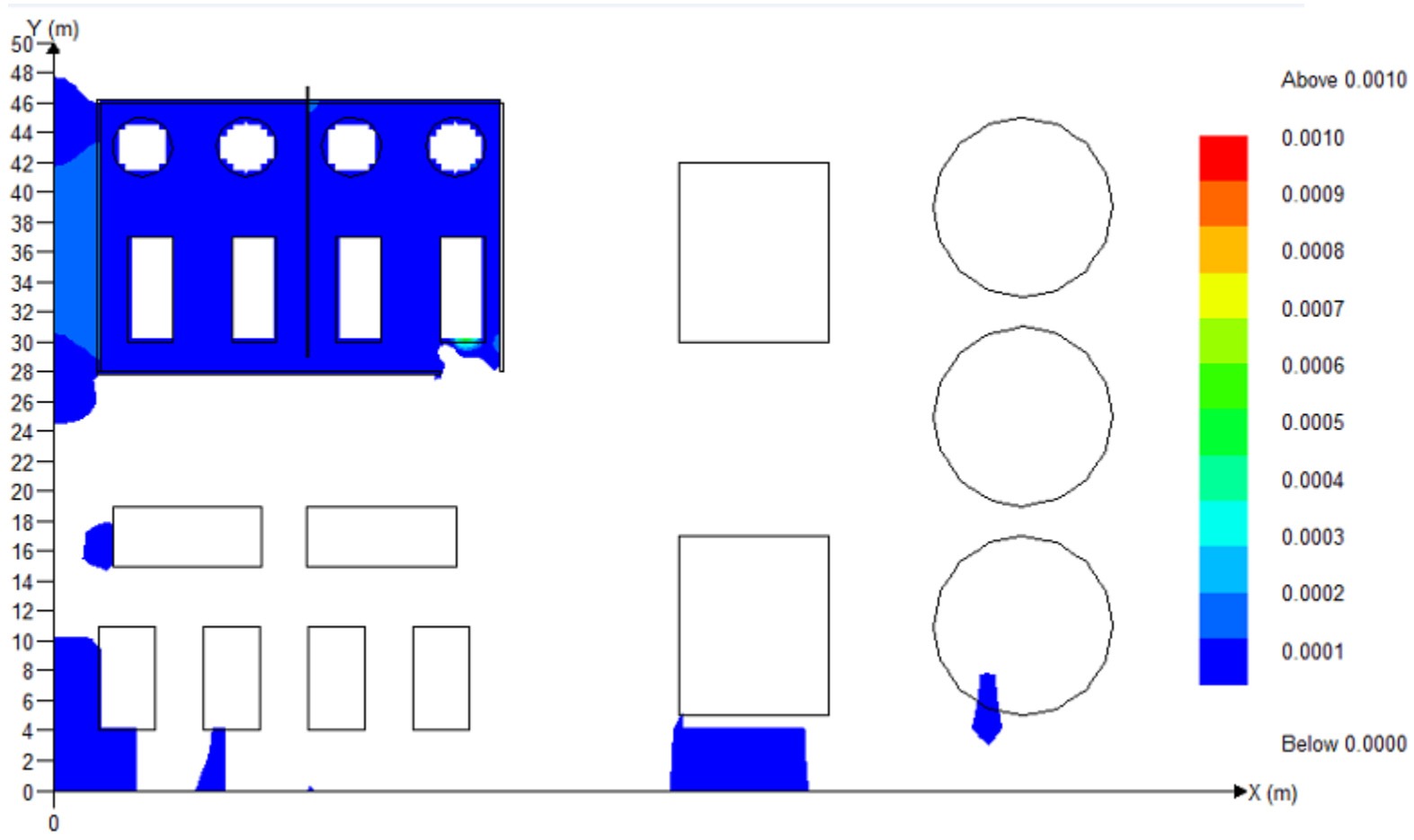

Fig. 7. Pressure developed in in the layout during dispersion of the fuel (barg) 


\subsection{Toxic potency assessment of combustion products}

During LNG (mainly methane) fire, $\mathrm{CO}$, Carbon dioxide, $\mathrm{NO}_{2}$, unburnt methane and water are produced as combustion products depending on complete or incomplete combustion reaction.

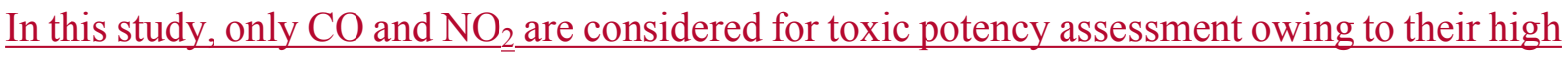
toxicity According to (Dadashzadeh et al., 2014). $\mathrm{CO}$ and $\mathrm{NO}_{2}$-are considered as the main combustion products of LNG fire. Thus, $\mathrm{CO}$ and $\mathrm{NO}_{2}$-are used for toxic potency assessment in this study. The different symptoms and health effects of $\mathrm{CO}$ and $\mathrm{NO}_{2}$ are found in Purser et al. (2015) and the National Research Council (1998)_respectively.As shown in Table 7, the concentration levels of $\mathrm{CO}$ can have different health effects.

\section{Table 7}

Health effects at different concentrations of CO (Purser et al., 2015)

\begin{tabular}{|c|c|c|c|c|}
\hline $\begin{array}{l}\text { COin } \\
\text { air/ppm }\end{array}$ & $\begin{array}{l}\text { COin } \\
\text { airt } \\
\left(\mathrm{mg} / \mathrm{m}^{3}\right)\end{array}$ & $\begin{array}{l}\text { Inspired } \\
\% \%\end{array}$ & $\begin{array}{l}\text { Carboxyhemoglobin } \\
\text { (СОН̈) by ranges } \\
\text { (арргөx.) }\end{array}$ & Toxic effects \\
\hline 4 & 1.15 & 0.0001 & $\theta$ & None. COHb normal range \\
\hline 3 & 3.44 & & & $\begin{array}{l}\text { 1-1.5\%. Note that inhaled } \mathrm{CO} \\
\text { adds to the baseline value }\end{array}$ \\
\hline 9 & 10.31 & & $z$ & $\begin{array}{l}\text { Vasodilation, slight reduction in } \\
\text { time to exhaustion, possibly minor } \\
\text { central nervous system effects }\end{array}$ \\
\hline 10 & 11.46 & $\theta .001$ & & \\
\hline 30 & 34.37 & & 5 & \\
\hline 50 & 57.28 & & & $\begin{array}{l}\text { Reduced performance of complex } \\
\text { tasks }\end{array}$ \\
\hline 70 & 80.19 & & 10 & \\
\hline 99 & 103.1 & & & $\begin{array}{l}\text { Headache, nausea, impaired } \\
\text { judgement, lethargy, dizziness, } \\
\text { shortness of breath (not marked } \\
\text { early on) }\end{array}$ \\
\hline 100 & 114.56 & 0.01 & 20 & \\
\hline
\end{tabular}




\begin{tabular}{|l|l|l|l|l|}
\hline 300 & 343.68 & & & $\begin{array}{l}\text { Severe headache, vomiting, } \\
\text { eonfusion. Collapse. Death may } \\
\text { eccur }\end{array}$ \\
\hline 700 & 801.92 & & 50 & Fits \\
\hline 900 & 1031.04 & & & Coma, weak pulse, slow breathing \\
\hline 1000 & 1145.60 & 0.1 & & Death \\
\hline 3000 & 3436.81 & & 80 & Rapidly fatal \\
\hline 10000 & & 1 & & \\
\hline 100000 & & 10 & & \\
\hline
\end{tabular}

The different health effects of $\mathrm{NO}_{2}$-concentrations are illustrated in Table 8 .

Table 8

Health effects of $\mathrm{NO}_{z}$ at 30 minutes exposure (National Research Council, 1998)

\subsection{Integration of impact analysis}

In this current study, an integrated impact analysis is conducted according to the step 5 of the methodology. The risks severity of combustion products was not directly normalised with those of thermal radiation and overpressure. However, an integrated impact analysis is conducted by investigating the risk contours of fire, VCE and combustion products. Similar to Dadashzadeh et al. (2013b), an integrated risk contour is used for assessing the impact of transitional accident scenarios in the facility.

\section{Results and discussion}

\subsection{Results for transition modelling}

The released LNG dispersed in the air resulted in a flammable vapour concentration over the plant not only adjacent to the leak location but also away from it. The autoignition temperature of LNG (primarily methane) is $1004^{\circ} \mathrm{F}$ (813.15K) (Foss et al., 2003). High temperatures and radiation from the fire reach the congested/confined areas, indicating that during the fire, there is a possibility of transitioning the fire into a VCE. The range of radiation and temperature generated during the fire are given in Figs. 8 and 9 respectively. 


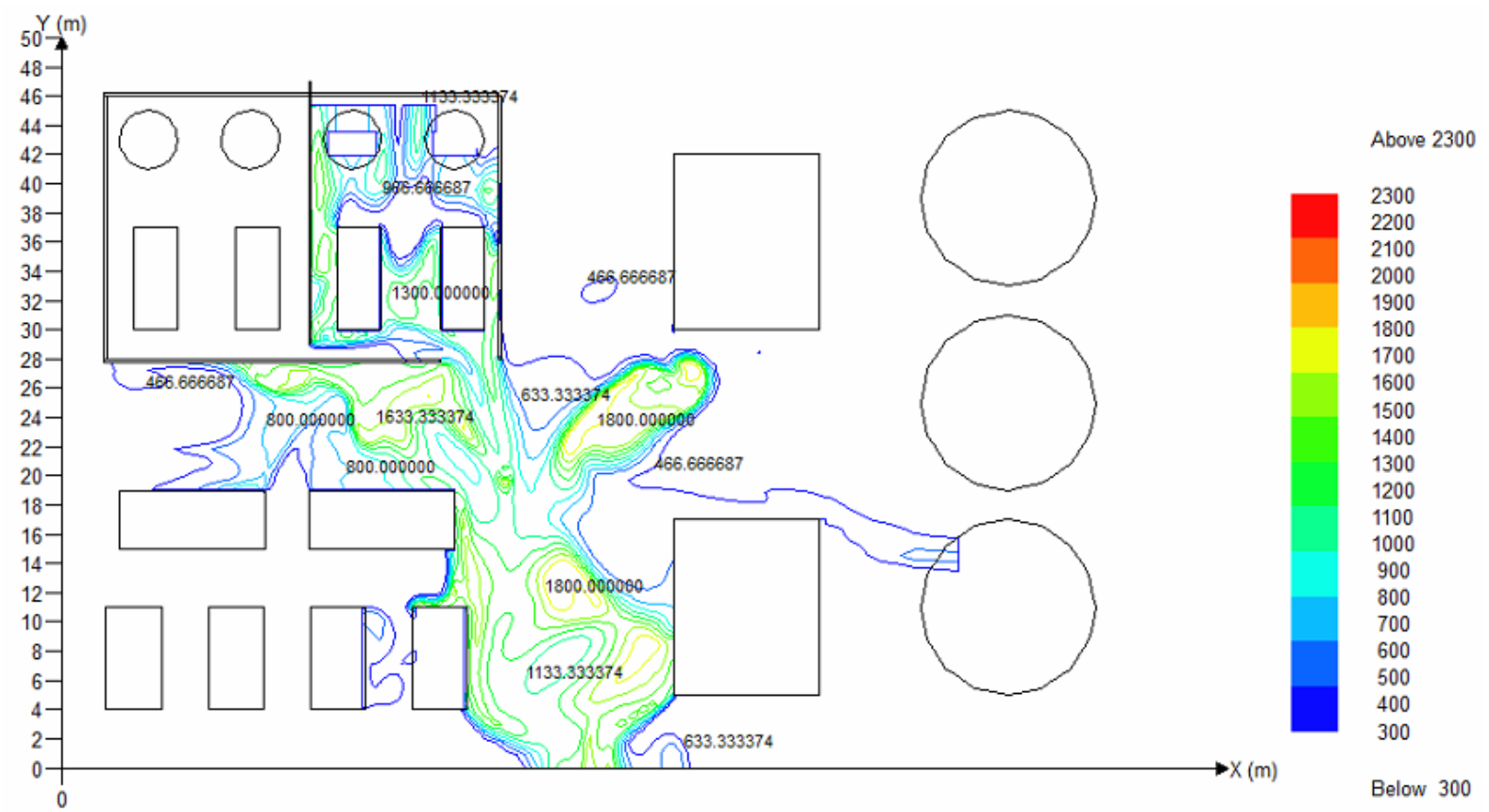

Fig. 8. Temperature distribution over the layout during the pool fire $(\mathrm{K})$ at $180 \mathrm{~s}$

The maximum temperatures and thermal radiation are $2300 \mathrm{~K}$ and $80 \mathrm{~kW} / \mathrm{m}^{2}$ respectively. These high temperature and thermal radiation may easily contribute in causing other fires in adjacent areas. The variation of air pressure in the layout in the presence of the dispersed vapour can be a useful information for assessing the potential location of a VCE. During gases dispersion, concentration in the air can create different initial pressure, which is one of the parameters on which the strength of explosion depends (Kundu et al., 2016). In this study, the maximum pressure developed during the dispersion of LNG vapour is 0.001 barg (illustrated in Fig. 7). The 1 mbar initial pressure may not have a substantial effect on the strength of a VCE. The pressure developed during the dispersion of LNG vapour is 0.001 barg (illustrated in Fig. 7). The maximum pressure developed during the dispersion of the LNG vapour is about 0.001 barg as illustrated in Fig. 7. The output results obtained from the fire modelling and the dispersion modelling show that the transition to a VCE or a flash fire is possible. 


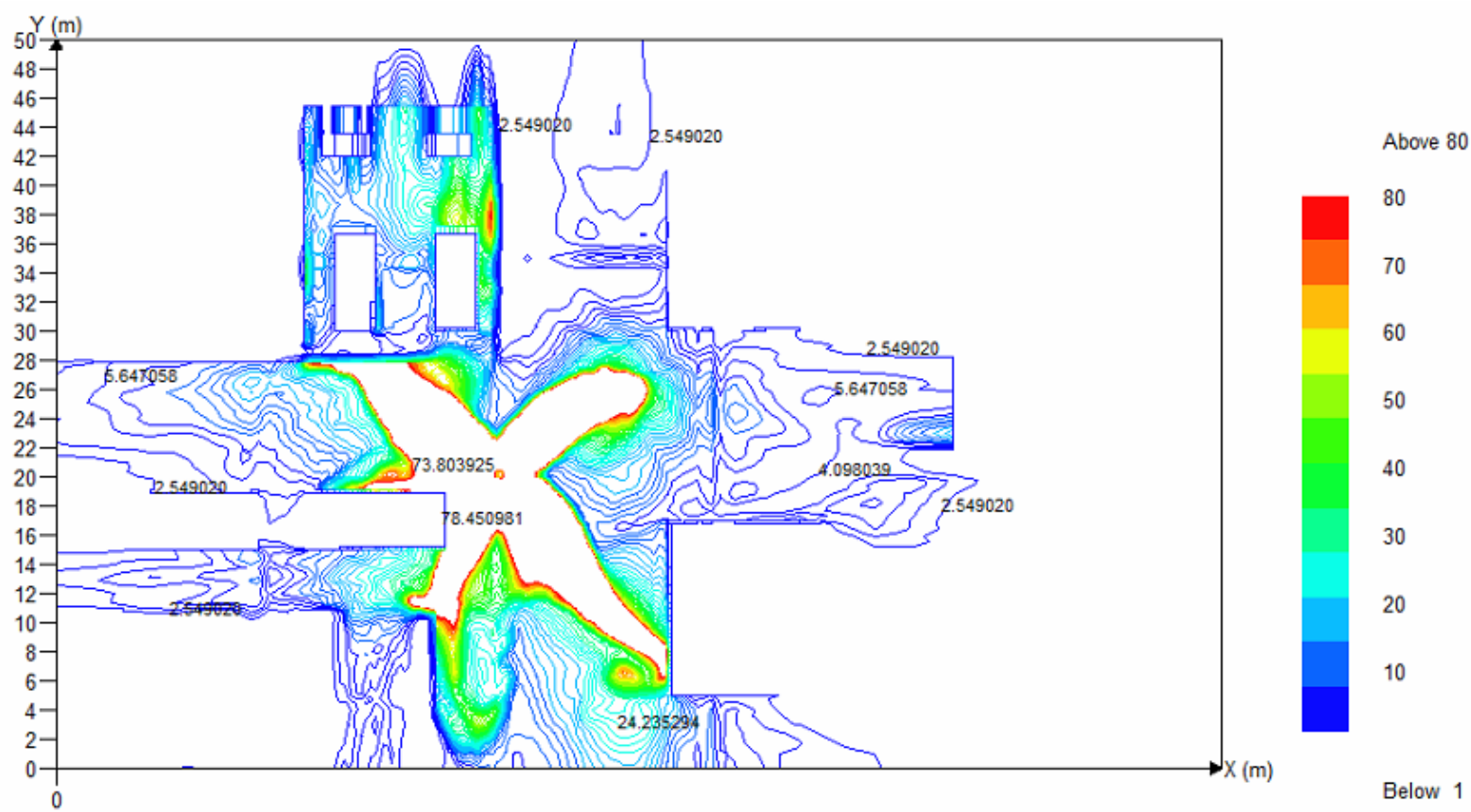

Fig. 9. Radiation from the fire over the layout $\left(\mathrm{kW} / \mathrm{m}^{2}\right)$ at $180 \mathrm{~s}$

\subsection{Thermal radiation impact}

The tenability limit for human beings is approximately $2.5 \mathrm{~kW} / \mathrm{m}^{2}$ (Mannan, 2012). The presence of thermal radiation greater than $2.5 \mathrm{~kW} / \mathrm{m}^{2}$ indicates that the fire can have serious effects to human and adjacent assets. The probability of injuries (first and second-degree burn) and the probability of death at different location of the plant are calculated using the thermal radiation. The maximum damage distance for various effects of fire is given in Table 7.

Table 7

Maximum damage distance for various effects of fire

\begin{tabular}{|l|l|l|}
\hline Effects on humans & Heat flux $\mathbf{( k W / \mathbf { m } ^ { 2 } )}$ & $\begin{array}{l}\text { Maximum damage } \\
\text { distance (m) }\end{array}$ \\
\hline $\begin{array}{l}100 \% \text { lethality in } 1 \mathrm{~min} . \\
1 \% \text { lethality in } 10 \mathrm{~s}\end{array}$ & 37.5 & 26.2 \\
\hline $\begin{array}{l}100 \% \text { lethality in } 1 \mathrm{~min} . \text { Serious } \\
\text { injuries in } 10 \mathrm{~s}\end{array}$ & 25 & 33.5 \\
\hline $\begin{array}{l}1 \% \text { lethality in } 1 \text { min. } \\
\text { First degree burns in } 10 \mathrm{~s}\end{array}$ & 12 & 36.7 \\
\hline $\begin{array}{l}\text { No lethality. } \\
\text { 2nd degree burns probable. }\end{array}$ & 4 & 39.8 \\
\hline
\end{tabular}




\begin{tabular}{|l|l|l|}
\hline Pain after exposure of $20 \mathrm{~s}$. & & \\
\hline $\begin{array}{l}\text { Acceptable limit for prolonged } \\
\text { exposure }\end{array}$ & 1.6 & 43.5 \\
\hline
\end{tabular}

The fire risk index of all grid points was calculated and plotted over the layout as demonstrated in Fig. 10. The risk index $\left(\operatorname{Risk}_{f e}\right)$ varies from 1 to the maximum value of 10 at the flame surface.

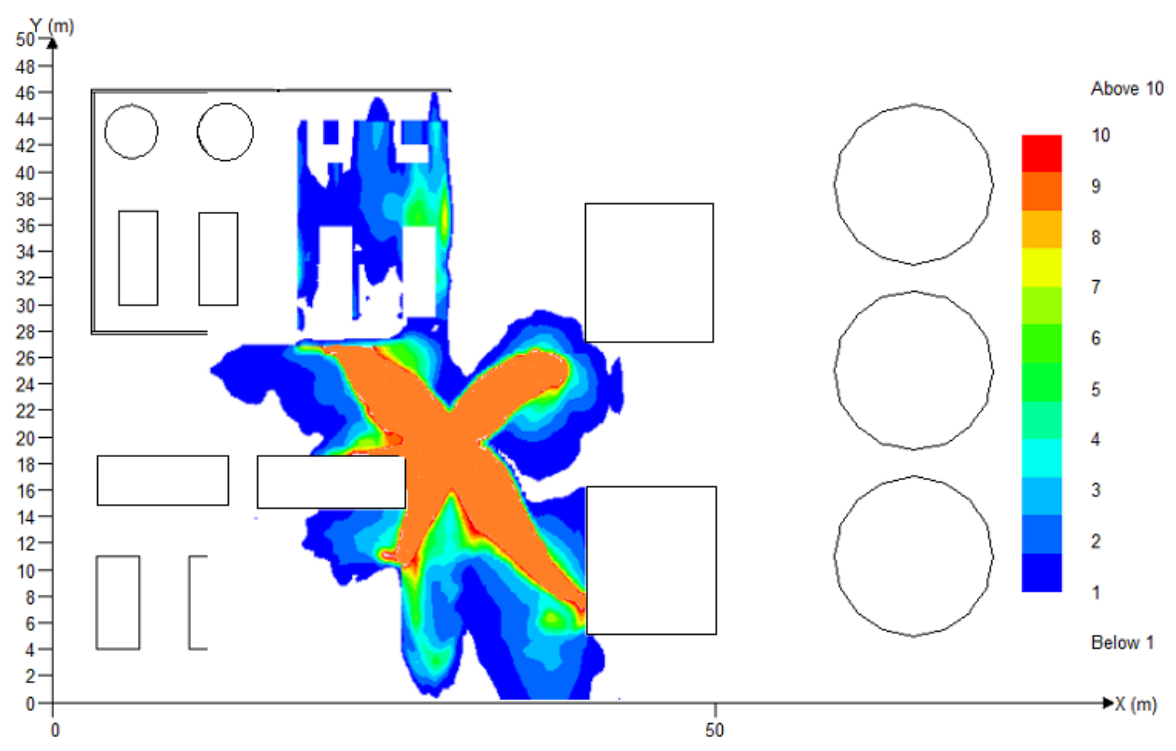

Fig. 10. Fire risk contour in the layout at $180 \mathrm{~s}$

\subsection{VCE impact and risk assessment}

The impact of the VCE and its subsequent risk are assessed based on the overpressure developed during the VCE. The explosion overpressure ranges from 0 to 2 barg over the layout and high pressures are found in the areas with a high congestion/confinement level as shown in Fig. 11. The developed pressures are limited within a portion of the congested layout. However, the developed pressures can result in damages to assets and humans in those areas of the facility. The damage distance from the VCE ignition point is illustrated in Table 8.

Table 8

Damage distance from the VCE ignition point

\begin{tabular}{|l|l|}
\hline Effects & $\begin{array}{l}\text { Distance from the } \\
\text { ignition point }(\mathbf{m})\end{array}$ \\
\hline $100 \%$ fatality & 4.60 \\
\hline $60 \%$ fatality & 6.25 \\
\hline
\end{tabular}




\begin{tabular}{|l|l|}
\hline Fatal distance limit & 7.80 \\
\hline Eardrum damage limit & 10.30 \\
\hline Safe distance & 15 \\
\hline
\end{tabular}

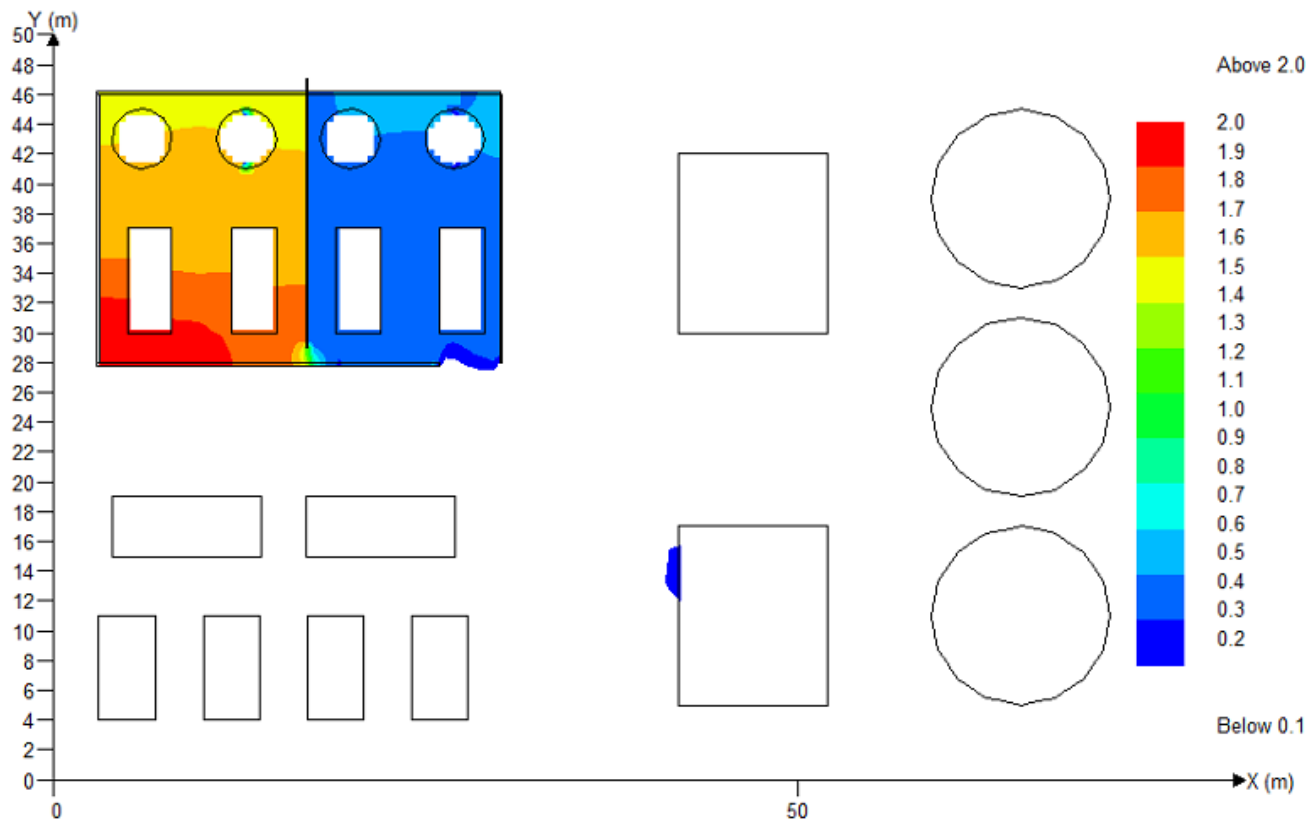

Fig. 11. VCE pressure over the plant (barg) at $180 \mathrm{~s}$

Using the probit model, the probabilities of injuries or death caused by the overpressure were estimated. Subsequently, the VCE risk index $\left(\operatorname{Risk}_{e}\right)$ was calculated and plotted over the facility as shown in Fig. 12. The values of the VCE risk index vary from 1 to 10 . Index 1 corresponds to very low risk and the index 10 shows the maximum risk. A high-risk index is found in the congested/confined areas and vice-versa. 


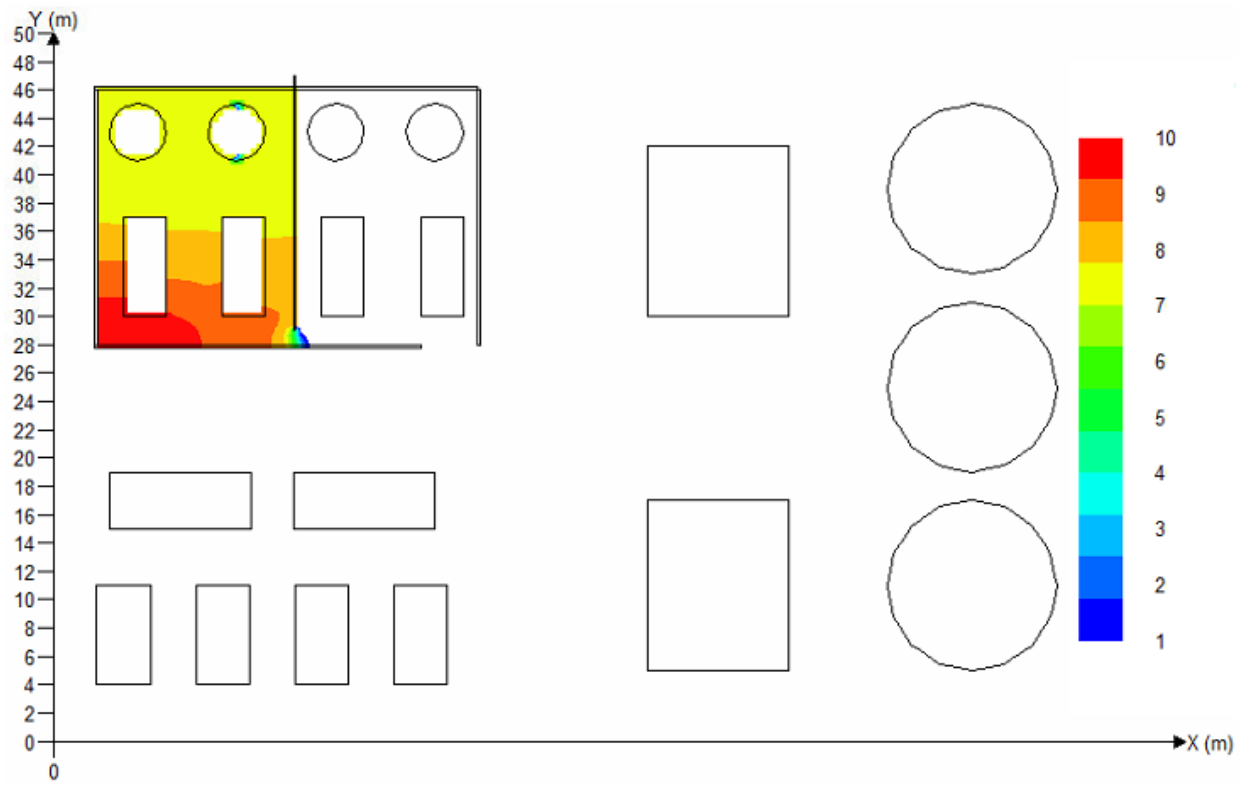

Fig. 12. Explosion risk profile at $180 \mathrm{~s}$

\subsection{Combustion product impact}

The toxic concentration $\left(\mathrm{mg} / \mathrm{m}^{3}\right)$ data obtained from the fire and explosion simulations were used for the toxicity assessment. The concentrations of contaminants are high near the fire and explosion locations and confined areas. The toxic concentration of $\mathrm{NO}_{2}$ is given in Fig. 13. In confined areas, the concentration of $\mathrm{NO}_{2}$ is more than $10^{5} \mathrm{mg} / \mathrm{m}^{3}$. Carbon monoxide is very toxic and a concentration of $1.28 \%$ leads to death within 2-3 minutes (Struttmann et al., 1998). The toxic concentration of $\mathrm{CO}$ is illustrated in Fig. 14. The higher concentrations of $\mathrm{NO}_{2}$ are present in larger areas of the layout than those of $\mathrm{CO}$. The obtained $\mathrm{NO}_{2}$ and $\mathrm{CO}$ values are relatively high because these concentrations were measured when there was ongoing fire. Risk values are high around the fire and VCE locations due to higher concentrations of contaminants. This is because a risk value directly depends on exposure duration and concentration. 


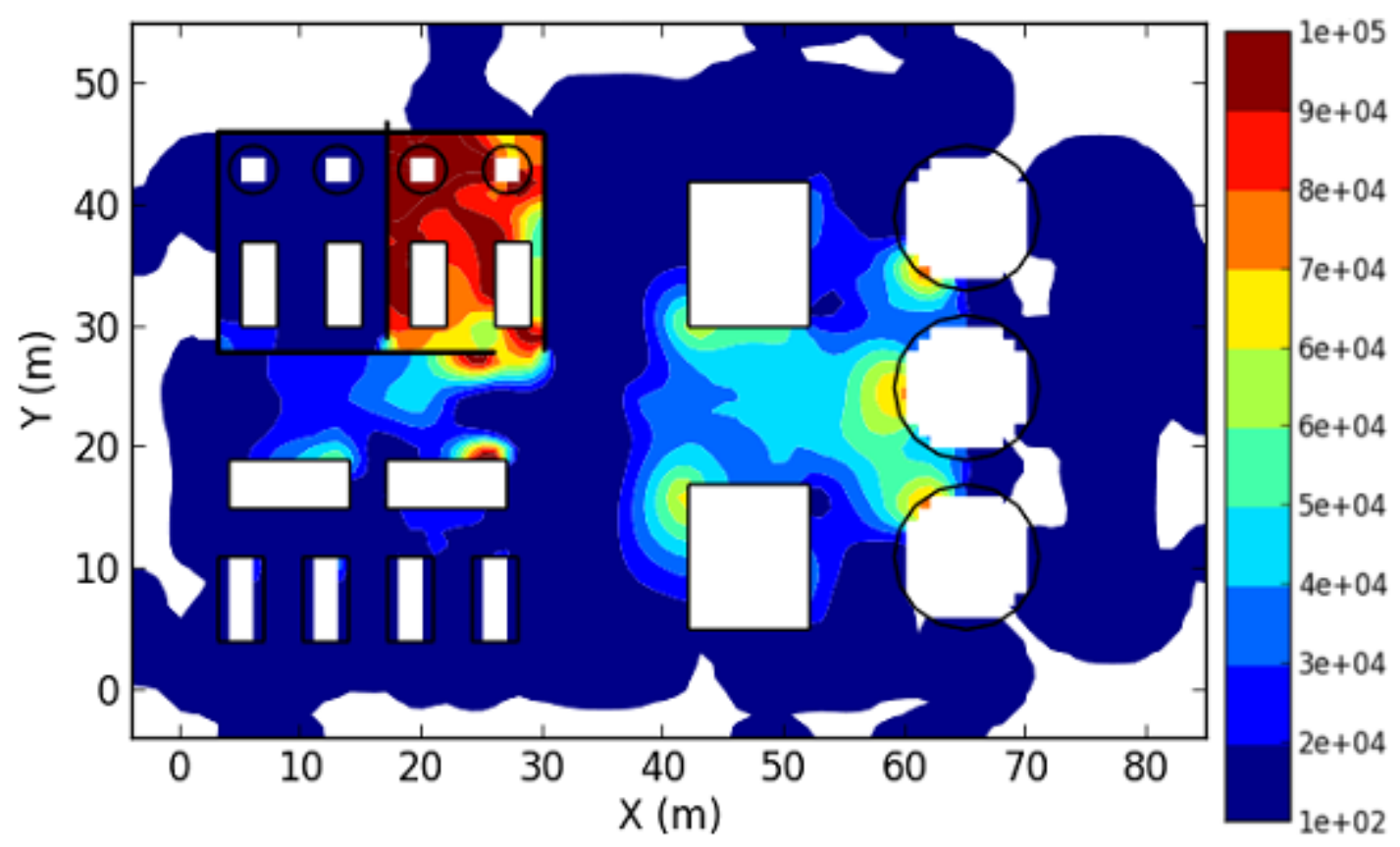

Fig. 13. Concentration of $\mathrm{NO}_{2}$ over the layout $\left(\mathrm{mg} / \mathrm{m}^{3}\right)$ at $180 \mathrm{~s}$

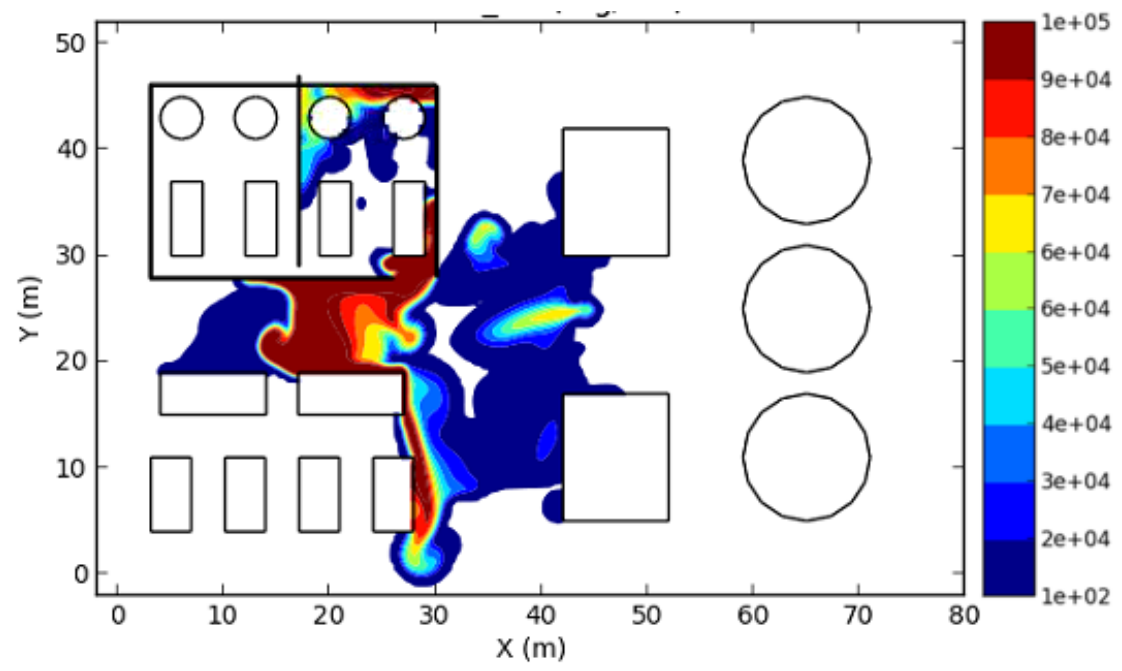

Fig. 14. Toxic concentration of $\mathrm{CO}\left(\mathrm{mg} / \mathrm{m}^{3}\right)$ at $180 \mathrm{~s}$

\subsection{Integrated impact during transition of fire to $\mathrm{VCE}$}

In most fire and/or explosion events, injury or fatality can be caused by combustion products in addition to radiation or overpressure hazards. Fig. 15 demonstrates the integrated risk contours in the layout because of thermal radiation and overpressure during the fire and VCE. For simplicity, the range of risk index is normalised between 1 and 10 in the integrated risk profile. High risk indices are available in the fire location and the VCE area due to the inherent nature of those events. 


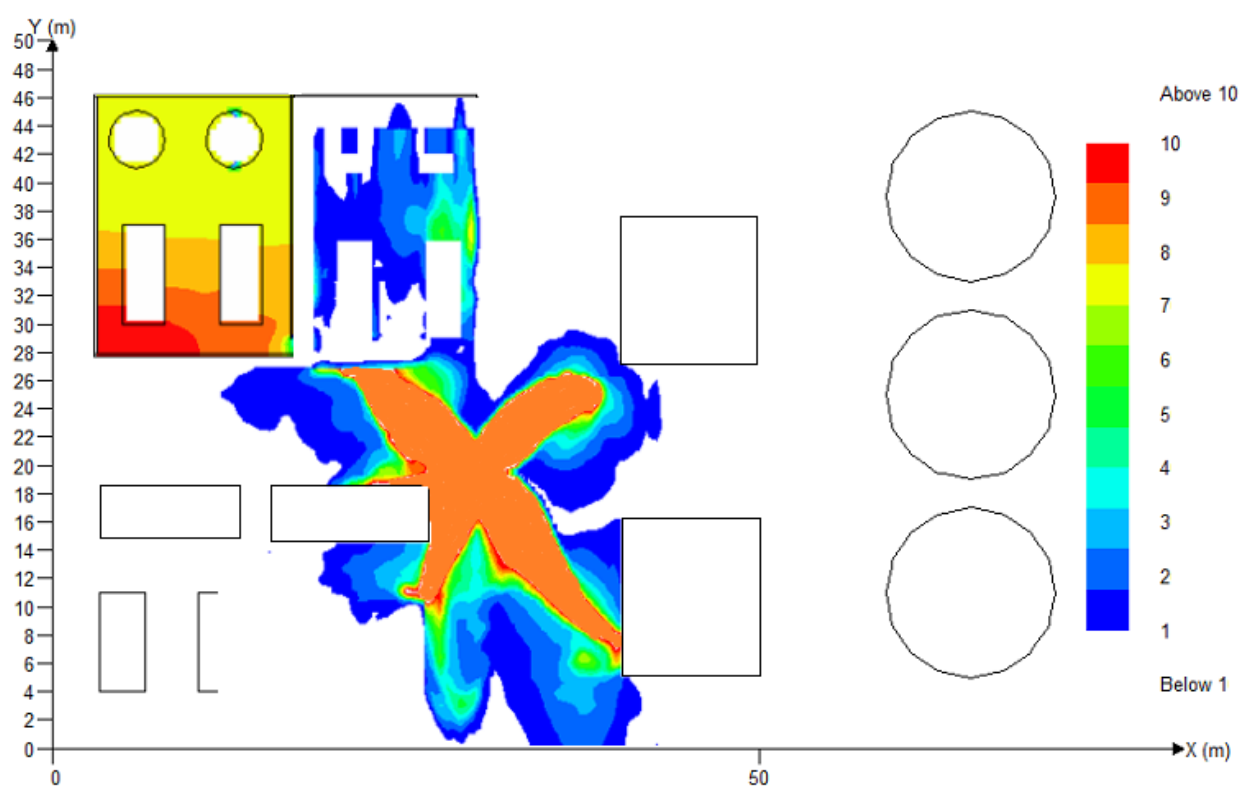

Fig. 15. Integrated risk profile of the fire and the VCE at $180 \mathrm{~s}$

In toxicity risk assessment, an integrated risk of both contaminants is considered as shown in Fig. 16. The total combustion product risk shows that significant portions of the facility exceed the acceptable level of risk which is 1 . The integrated risk profile of contaminants indicates that the high-risk area is larger than that of the integrated impact of fire and VCE as seen in Fig. 15 and Fig. 16. However, due to the short exposure duration, the severity of the combustion products is lower than that of thermal radiation and overpressure. This shows that the impact of transitional events such as fire and VCE along with combustion products is more severe than an individual phenomenon because more portions of the facility exceeded the acceptable level of risk.

The current approach incorporates an additional feature to the previous integrated consequence studies such as Khan and Amyotte (2004) and Dadashzadeh et al. (2013b). Khan and Amyotte (2004) incorporated fire, explosion and toxic release damage indices, but did not directly assess the consequence. The adopted technique in Khan and Amyotte (2004) cannot be useful for visualizing the area directly affected by fire, explosion and combustion products. The severity of consequence would have been different if the impact of the combustion product was considered by Dadashzadeh et al. (2013b). During a fire and/or explosion, the potential risk from combustion products can be too simple to ignore because toxicity has been a major cause of death and injury from fires (Hartzell, 1992).

This paper illustrated only a specific case study. However, any changes in operating conditions such as wind speed, wind direction, snow, rain or other parameters can be 


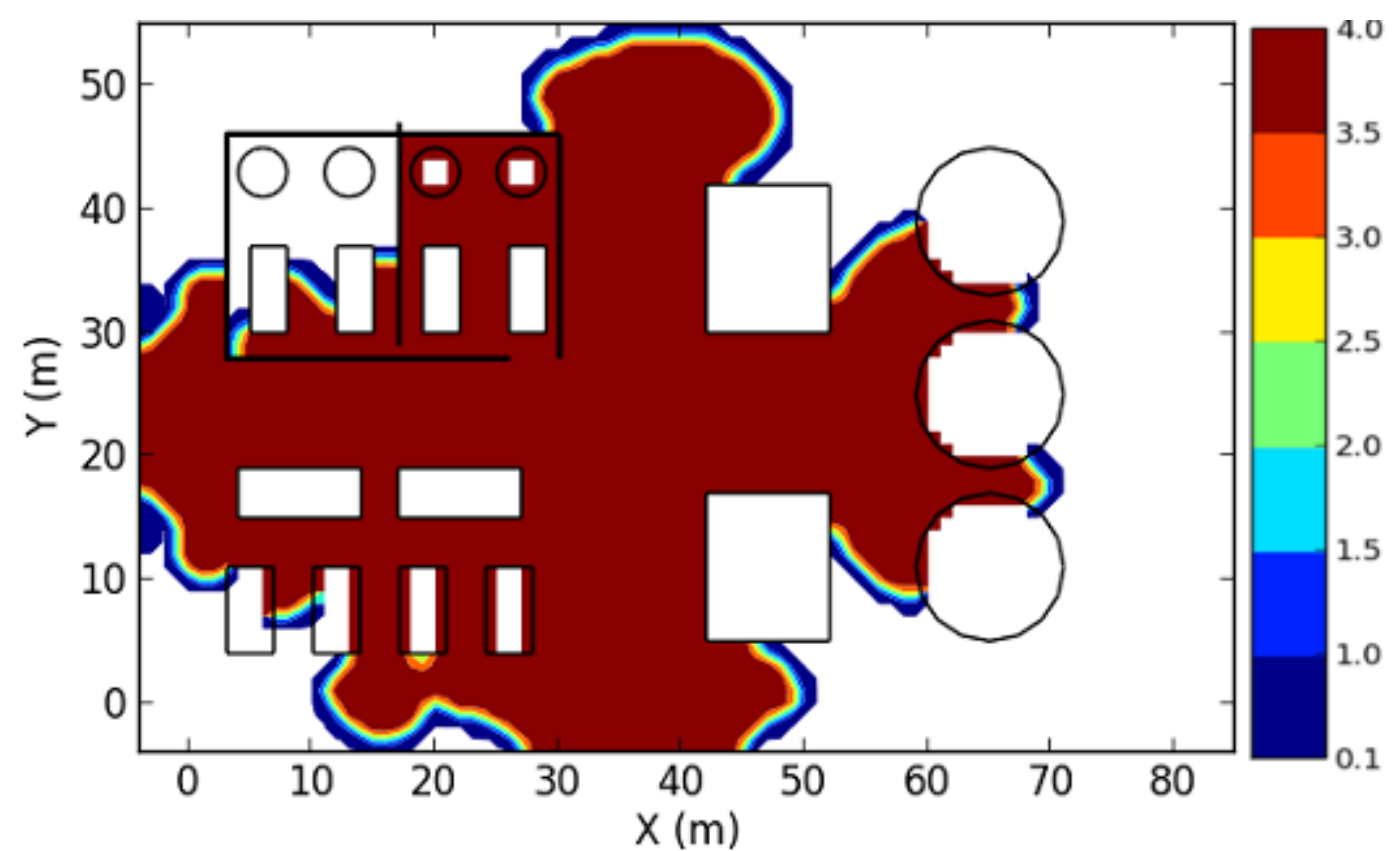

Fig. 16. Integrated risk of combustion products at $180 \mathrm{~s}$

\section{Conclusions}

In Liquified Natural Gas (LNG) processing facilities, there is a possibility of a fire transitioning into a Vapour Cloud Explosion (VCE) or vice-versa during an accidental release of hydrocarbons as demonstrated in various past fire and explosion accidents. Identification of potential location of transitional events is useful for understanding the occurrence of cascading accident scenarios. A framework has been proposed for modelling transitional events (fire, VCE and combustion product release) and their integrated consequences using Computational Fluid Dynamics (CFD). The proposed framework was applied to a case study considering an accidental LNG release, including vaporisation, a pool fire and a VCE. The impact of each individual event was assessed, and an integrated consequence was modelled using a risk-based approach. The severity of risk during each event in the layout was compared. By analysing the LNG spill, vaporisation, dispersion and subsequent fire in the layout, it is foreseeable that a pool fire can transit to a VCE because of the availability of required suitable conditions such as a flammable vapour concentration, ignition source and congestion/confinement. The risk of the overpressure was limited to confined spaces and was insignificant in other areas. The risk of thermal radiation was present in a larger area in comparison to the VCE. The risk of combustion products was present in a larger area than those of radiation and the overpressure, 
but its severity was lower due to the short exposure duration. It was found that the integrated risk of transitional events was higher than that of the individual risk.

A cChanges in weather conditions and source terms may affect the outcome of an analysis related to gas leak and dispersion. Responses to gas leak and its dispersion are strongly dependent on these parameters and one set of parameters may not represent all cases. For illustration purpose, this study has presented only a specific case. Once operating conditions such as wind speed, wind direction, snow, rain or other parameter changes, the response need to be evaluated accordingly. The current study serves to highlight the importance of transitional events modelling and expands the scope of the integrated consequence modelling approach. Despite having complex correlations among various parameters involved in LNG spill and subsequent events, the integrated risk profiles can be effective for designing safety systems to mitigate potential effects and risks of thermal radiation, overpressure and combustion products during fire and/or explosion events. Consideration of effects among thermal radiation, overpressure and combustion products in the transitional event modelling, makes the study unique and realistic in safety analysis of an LNG processing facility. The propesed methodology would be useful for the safety measure design of processing facilities and an effective emergency preparedness plan.

\section{Acknowledgement}

The first author, Til Baalisampang would like to acknowledge the financial support received from the Australian Maritime College (AMC) of the University of Tasmania. The author thankfully acknowledges the technical support received from the Centre for Risk, Integrity and Safety Engineering (c-RISE), Faculty of Engineering \& Applied Science, Memorial University of Newfoundland, St. John's, NL, Canada.

\section{References}

1. Abdolhamidzadeh, B., Abbasi, T., Rashtchian, D., Abbasi, S.A., 2011. Domino effect in process-industry accidents - An inventory of past events and identification of some patterns. Journal of Loss Prevention in the Process Industries 24, 575-593.

2. Al-shanini, A., Ahmad, A., Khan, F., 2014. Accident modelling and analysis in process industries. Journal of Loss Prevention in the Process Industries 32, 319-334.

3. Alzbutas, R., 2015. Probabilistic dynamics for integrated analysis of accident sequences considering uncertain events. Science and Technology of Nuclear Installations 2015. 
4. Assael, M.J., Kakosimos, K.E., 2010. Fires, explosions, and toxic gas dispersions: Effects calculation and risk analysis. CRC Press.

5. Atkinson, G., Cowpe, E., Halliday, J., Painter, D., 2017. A review of very large vapour cloud explosions: Cloud formation and explosion severity. Journal of Loss Prevention in the Process Industries 48, 367-375.

6. Baalisampang, T., Abbassi, R., Garaniya, V., Khan, F., Dadashzadeh, M., 2017a. Fire impact assessment in FLNG processing facilities using Computational Fluid Dynamics (CFD). Fire Safety Journal 92, 42-52.

7. Baalisampang, T., Abbassi, R., Garaniya, V., Khan, F., Dadashzadeh, M., $2017 b$. Modelling the impacts of fire in a typical FLNG processing facility, Paper Presented at the International Conference on Safety and Fire Engineering-SAFE'17.

8. Baalisampang, T., Abbassi, R., Garaniya, V., Khan, F., Dadashzadeh, M., 2018a. Review and analysis of fire and explosion accidents in maritime transportation. Ocean Engineering 158, 350-366.

9. Baalisampang, T., Abbassi, R., Khan, F., 2018b. Overview of Marine and Offshore Safety. Methods in Chemical Process Safety.

10. Baalisampang, T., Khan, F., Garaniya, V., Chai, S., Abbasi, R., 2016. An Inherently Safer Layout Design for the Liquefaction Process of an FLNG Plant. International Journal of Maritime Engineering 158, Part A2, 91-102.

11. Baksh, A.A., Abbassi, R., Garaniya, V., Khan, F., 2016a. An Application of BN to Envisage Potential Accidents in FLNG Facility, The Twelfth ISOPE Pacific/Asia Offshore Mechanics Symposium. International Society of Offshore and Polar Engineers, Gold Coast, Queensland, Australia, pp. 1-8.

12. Baksh, A.A., Abbassi, R., Garaniya, V., Khan, F., 2016b. A network based approach to envisage potential accidents in offshore process facilities. Process Safety Progress, 114.

13. Baksh, A.A., Khan, F., Gadag, V., Ferdous, R., 2015. Network based approach for predictive accident modelling. Safety science 80, 274-287.

14. Broadribb, M., 2006. Lessons from Texas City - A case history. Loss Prevention Bulletin Institution of Chemical Engineers 192, 3.

15. BSEE, 2013. Investigation of November 16, 2012, Explosion, Fire and Fatalities at West Delta Block 32 Platform E.

16. Center for Chemical Process Safety, 1996. Guidelines for evaluating process plant buildings for external explosions and fires. John Wiley \& Sons, Incorporated. 
17. Clancey, V., 1972. Diagnostic features of explosion damage, 6th Int. Meeting of Forensic Sciences, Edinburgh, 1972.

18. Crowl, D.A., Louvar, J.F., 2011. Chemical process safety: fundamentals with applications. Prentice Hall.

19. Dadashzadeh, M., Abbassi, R., Khan, F., Hawboldt, K., 2013a. Explosion modeling and analysis of BP Deepwater Horizon accident. Safety science 57, 150-160.

20. Dadashzadeh, M., Khan, F., Abbassi, R., Hawboldt, K., 2014. Combustion products toxicity risk assessment in an offshore installation. Process Safety and Environmental Protection 92, 616-624.

21. Dadashzadeh, M., Khan, F., Hawboldt, K., Amyotte, P., 2013b. An integrated approach for fire and explosion consequence modelling. Fire Safety Journal 61, 324-337.

22. Deepwater Horizon Study Group (DHSG), 2011. Final report on the Investigation of the Macondo Well Blowout.

23. DNV-GL, 2018. Digital Solutions SAFETI.

24. Fattakhova, E.Z., Barakhnina, V.B., 2015. Accident rate analysis on the offshore oil and gas production installations and plat-forms. International Journal of Applied and Fundamental Research.

25. Figueroa, V.G., Lopez, C., O’Rourke, K.K., 2011. LNG Cascading Damage Study Volume II: Flow Analysis for Spills from MOSS and Membrane LNG Cargo Tanks. Sandia National Laboratories, Albuquerque, NM.

26. Foss, M.M., Delano, F., Gulen, G., Makaryan, R., 2003. LNG safety and security. Center for Energy Economics (CEE).

27. Gavelli, F., Davis, S.G., Hansen, O.R., 2011. Evaluating the potential for overpressures from the ignition of an LNG vapor cloud during offloading. Journal of Loss Prevention in the process industries $24,908-915$.

28. GexCon, 2018a. EFFECTS: Advanced, easy-to-use Consequence Analysis.

29. GexCon, 2018b. Riskcurves: Comprehensive Quantitative Risk Analysis.

30. GexCon AS, 2013. FLACS v10. 0 User's Manual. January.

31. HAMSAGARS, HAMS-GPS QRA HAZOP EHS Software. HAMSAGARS, New Delhi.

32. Hansen, O., Renoult, J., Sherman, M., Tieszen, S., 2005. Validation of FLACShydrogen CFD consequence prediction model against large scale H2 explosion experiments in the FLAME facility, Proceedings of 1st International Conference on Hydrogen Safety, Pisa, Italy. 
33. Hartzell, G.E., 1992. Advances in combustion toxicology. CRC Press.

34. Hull, T.R., Stec, A.A., 2010. Introduction to fire toxicity, Chapter 1.

35. Ikealumba, W.C., Wu, H., 2014. Some recent advances in liquefied natural gas (LNG) production, spill, dispersion, and safety. Energy \& Fuels 28, 3556-3586.

36. Jagger, S., O’Sullivan, S., 2004. Human vulnerability to thermal radiation offshore. Health and Safety Laboratory, Harpur Hill, Buxton, Derbyshire.

37. Khan, F.I., Abbasi, S., 1999. Major accidents in process industries and an analysis of causes and consequences. Journal of Loss Prevention in the process Industries 12, 361378.

38. Khan, F.I., Amyotte, P.R., 2004. Integrated inherent safety index (I2SI): a tool for inherent safety evaluation. Process safety progress 23, 136-148.

39. Kim, W.K., Salvesen, H.-C., 2002. A study for prevention of Unconfined Vapor Cloud Explosion from spilled LNG confined in dike, CCPS Conference Proceedings, Jacksonville Florida.

40. Koo, J., Kim, H., So, W., Kim, K., Yoon, E., 2009. Safety assessment of LNG terminal focused on the consequence analysis of LNG spills, Proceedings of the 1st annual gas processing symposium.

41. Kundu, S., Zanganeh, J., Moghtaderi, B., 2016. A review on understanding explosions from methane-air mixture. Journal of Loss Prevention in the Process Industries 40, 507 523.

42. Lea, C., Ledin, H., 2002. A review of the state-of-the-art in gas explosion modelling. Health and Safety Laboratory.

43. Lewis, S., 2005. An overview of leading software tools for QRA. American Society of Safety Engineers-Middle East, 18-22.

44. Manca, D., Brambilla, S., 2012. Dynamic simulation of the BP Texas City refinery accident. Journal of Loss Prevention in the Process Industries 25, 950-957.

45. Mannan, S., 2012. Lees' Loss prevention in the process industries: Hazard identification, assessment and control. Butterworth-Heinemann.

46. National Research Council, 1998. Assessment of Exposure-Response Functions for Rocket-Emission Toxicants. National Academies Press.

47. Niazi, U.M., Nasif, M.S., Muhammad, M.B., Imran, M., 2018. Integrated Consequence Modelling for Fire Radiation and Combustion Product Toxicity in offshore Petroleum Platform using Risk Based Approach, MATEC Web of Conferences. EDP Sciences, p. 06013. 
48. Offshore Post-Everything offshore energy, 2015. Abkatun Offshore Explosion Findings Released.

49. OPG, 2010a. Consequence modelling, OPG Risk Assessment Data Directory.

50. OPG, 2010b. Major accidents OPG Risk Assessment Data Directory.

51. Ouddai, R., Chabane, H., Boughaba, A., Frah, M., 2012. The Skikda LNG accident: losses, lessons learned and safety climate assessment. International Journal of Global Energy Issues 35, 518-533.

52. Pate -Cornell, M.E.L., 1993. Learning from the Piper Alpha Accident: A postmortem Analysis of Technical and Organizational Factors. Risk Analysis 13, 215-215.

53. Petrie, J.R., Großbritannien, D.o.E., 1988. Piper Alpha Technical Investigation: Interim Report. Department of Energy.

54. Petti, J.P., Kalan, R.J., 2011. LNG cascading damage study. Volume I, fracture testing report. Sandia National Laboratories.

55. Petti, J.P., Lopez, C., Kalan, R., Dempsey, J.F., Villa, D., Hightower, M.M., Wellman, G., 2013. LNG vessel cascading damage structural and thermal analyses. Sandia National Laboratories (SNL-NM), Albuquerque, NM (United States); Sandia National Laboratories.

56. Petti, J.P., Wellman, G.W., Villa, D., Lopez, C., Figueroa, V.G., Heinstein, M., 2011. LNG Cascading Damage Study Volume III: Vessel Structural and Thermal Analysis Report. Sandia National Laboratories, Albuquerque, NM.

57. Pitblado, R., Baik, J., Hughes, G., Ferro, C., Shaw, S., 2005. Consequences of liquefied natural gas marine incidents. Process safety progress 24, 108-114.

58. Planas-Cuchi, E., Montiel, H., Casal, J., 1997. A survey of the origin, type and consequences of fire accidents in process plants and in the transportation of hazardous materials. Process Safety and Environmental Protection 75, 3-8.

59. Purser, D.A., Maynard, R.L., Wakefield, J.C., 2015. Toxicology, survival and health hazards of combustion products. Royal Society of Chemistry.

60. Soman, A., Sundararaj, G., 2012. Consequence Assessment of Vapour Cloud Explosion Involving Hydrogen Release. International journal of emerging technology and advanced engineering 2, 291-296.

61. Struttmann, T., Scheerer, A., Prince, T.S., Goldstein, L.A., 1998. Unintentional carbon monoxide poisoning from an unlikely source. The Journal of the American Board of Family Practice 11, 481-484. 
62. Tam, V., Lee, R., 1998. Gas explosion modelling of FPSO. Journal of loss prevention in the process industries 11,67-73.

63. Tatom, J., Swisdak, M., IME, L.S., 2011. IMESAFR Version 2.0: A Next Generation Tool for Managing Risk Associated with Commercial Explosives Operations. SAFEX International.

64. US Government Accountability Office (GAO), 2007. Report to Congressional Requesters, public safety consequences of a terrorist attack on a tanker carrying liquefied natural gas need clarification. US Government Accountability Office (GAO) Washington, DC 20548.

65. Woodward, J.L., 2010. Estimating the flammable mass of a vapor cloud. John Wiley \& Sons.

66. Yeo, C., Bhandari, J., Abbassi, R., Garaniya, V., Chai, S., Shomali, B., 2016. Dynamic risk analysis of offloading process in floating liquefied natural gas (FLNG) platform using Bayesian Network. Journal of Loss Prevention in the Process Industries 41, 259269.

67. Zheng, B., Chen, G.h., 2011. Storage tank fire accidents. Process Safety Progress 30, 291-293. 


\section{Modelling an integrated impact of fire, explosion and combustion products during transitional events caused by an accidental release of LNG}

Til Baalisampanga, Rouzbeh Abbassi ${ }^{\mathrm{b}, *}$, Vikram Garaniya ${ }^{\mathrm{a}}$, Faisal Khan ${ }^{\mathrm{c}}$, Mohammad Dadashzadeh $^{\mathrm{d}}$

a National Centre for Maritime Engineering and Hydrodynamics, Australian Maritime College, University of Tasmania, Launceston, Tasmania, Australia, 7248.

bSchool of Engineering, Faculty of Science and Engineering, Macquarie University, Sydney, NSW, Australia, 2109.

${ }^{\mathrm{c}}$ Centre for Risk, Integrity and Safety Engineering, Faculty of Engineering \& Applied Science, Memorial University of Newfoundland, St. John's, NL, Canada.

dHydrogen Safety Engineering and Research Centre (HySAFER), Ulster University, Newtownabbey, Northern Ireland, UK.

* Corresponding Author: rouzbeh.abbassi@mq.edu.au

\section{Abstract}

In a complex processing facility, there is likelihood of occurrence of cascading scenarios, i.e. hydrocarbon release, fire, explosion and dispersion of combustion products. The consequence of such scenarios, when combined, can be more severe than their individual impact. Hence, actual impact can be only represented by integration of above mentioned events. A novel methodology is proposed to model an evolving accident scenario during an incidental release of LNG in a complex processing facility. The methodology is applied to a case study considering transitional scenarios namely spill, pool formation and evaporation of LNG, dispersion of natural gas, and the consequent fire, explosion and dispersion of combustion products using Computational Fluid Dynamics (CFD). Probit functions are employed to analyze individual impacts and a ranking method is used to combine various impacts to identify risk during the transitional events. The results confirmed that in a large and complex facility, an LNG fire can transit to a vapor cloud explosion if the necessary conditions are met, i.e. the flammable range, ignition source with enough energy and congestion/confinement level. Therefore, the integrated consequences are more severe than those associated with the individual ones, and need to be properly assessed. This study would provide an insight for an effective analysis of potential consequences of an LNG spill in any LNG processing facility and it can be useful for the safety measured design of process facilities.

Keywords: LNG spill, accident transition, integrated consequence, CFD 


\section{Introduction}

LNG is considered as a safe and environmentally-friendly fuel. Safe storage, processing, transportation and usage are mandatory requirements for any fuel and LNG continues to reveal a long track record of safety in all these areas (Yeo et al., 2016). However, in a complex processing facility such as a floating liquefied natural gas (FLNG) (Baksh et al., 2016a, b), an incidental release of LNG may not simply lead to an event with only its individual impact. There is likelihood of escalating a minor event into more damaging events. For instance, an accidental release of LNG in a production facility has the potential to pose several hazards such as fire, explosion, brittle fracture, asphyxiation and freeze burn/frostbite. A leakage of LNG may be a single minor event itself. However, due to instantaneous vaporisation, it is likely to cause several events such as a fireball, flash fire, Vapour Cloud Explosion (VCE), and pool fire when the vapour is ignited. Escalation of the mentioned events to a storage facility, may lead to Boiling Liquid Expanding Vapour Explosion (BLEVE). The entire sequence of events and their interactions during an LNG spill event in an FLNG processing facility is illustrated in Fig. 1.

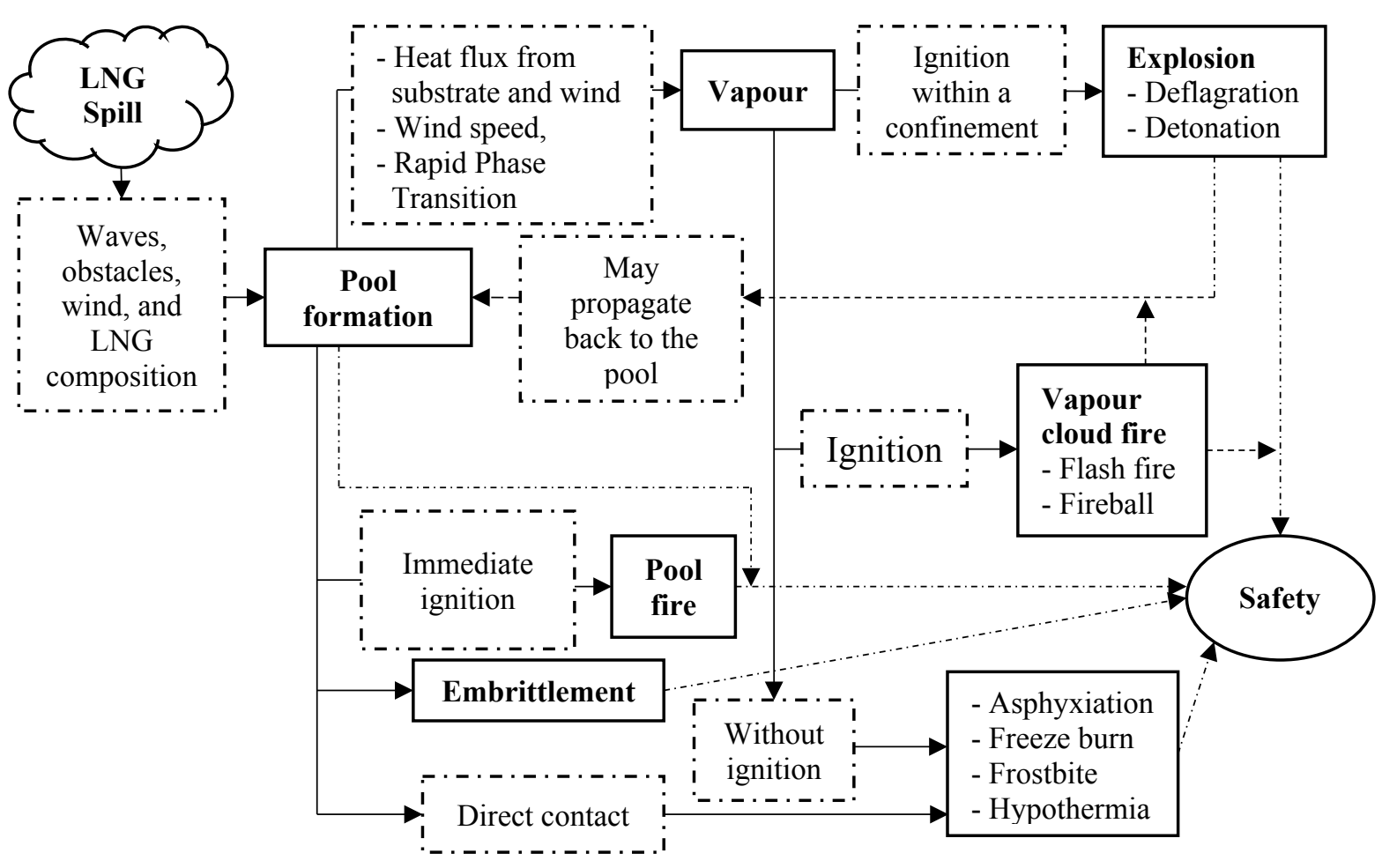

Fig. 1. LNG spill events (adapted from Ikealumba and Wu (2014) with some modifications).

Due to the potential of having several events during an unintended LNG spill, the US Government Accountability Office (GAO) commissioned a study and recommended to improve the state of knowledge surrounding the potential for cascading damage to LNG vessels 
in the case of an incidental release of LNG (US Government Accountability Office (GAO), 2007). The study of cascading damage issues has proven difficult primarily because these events require the analysis of the interaction of a series of complex physical phenomena such as LNG flow, heat transfer, fracture and damage. Petti et al. (2013) summarized the outcomes of the studies on cascading damage (Figueroa et al., 2011; Petti and Kalan, 2011; Petti et al., 2011) which explored the cryogenic and fire thermal damage to an LNG ship during a large LNG cargo tank breach.

In these studies (Figueroa et al., 2011; Petti and Kalan, 2011; Petti et al., 2011), impacts (pressure wave, shrapnel or projectile) from the explosion are not considered in the cascading damage analysis. Examples of evolving accident scenarios are reported in (Ouddai et al., 2012; Petrie and Großbritannien, 1988). The Piper Alpha tragedy in 1988 caused 165 deaths due to an explosion after the release of flammable material. In the accident, leakage of gas occurred, and the presence of an ignition source caused multiple events such as a fireball and jet fire, followed by VCEs. The sequence of events led to the total loss of the platform (Pate -Cornell, 1993). In 2004, an LNG accident occurred in the Skikda LNG plant in Algeria resulting in 27 casualties, 56 injuries and $\$ 900$ million loss. During this multiple explosions occurred due to excessive pressure in an adjacent boiler (Ouddai et al., 2012). The BP's Texas City refinery explosion in 2005 caused 15 deaths and 180 injuries due to hydrocarbon release and subsequent fire and explosion (Manca and Brambilla, 2012). The release resulted in a VCE followed by a pool fire (Broadribb, 2006). In 2010, the Macondo accident in the Gulf of Mexico occurred with a series of events such as blowout, dispersion of released hydrocarbons, explosion and fire (Deepwater Horizon Study Group (DHSG), 2011). The flame propagating from the explosion reached the flammable vapour dispersed over the platform and led to the fire at the source of release at the drilling floor. Major accidents that occurred in process facilities are well explained in (Abdolhamidzadeh et al., 2011; Al-shanini et al., 2014; Khan and Abbasi, 1999). These accidents are mainly associated with fires, explosions and toxic product release. Most past studies regarding fire and explosion accidents were limited to individual fires or explosions or combustion products modelling and did not address evolving accident scenarios (Dadashzadeh et al., 2013a; Dadashzadeh et al., 2014; Gavelli et al., 2011; Kim and Salvesen, 2002). For instance, Dadashzadeh et al. (2013a) modelled the dispersion of flammable gas integrated with explosion consequences of the BP Deepwater Horizon explosion using a Flame Acceleration Simulator (FLACS). Smoke and heat radiation released from the fire also affect human health and offshore structures; however, this impact was not addressed in the consequence analysis. Dadashzadeh et al. (2014) proposed a methodology for toxicity risk 
assessment during an LNG fire and revealed that high risks are found at the process facility due to higher concentrations of combustion products and longer exposure time. However, the direct consequence of fire was not considered. Baalisampang et al. (2017a) and Baalisampang et al. (2017b) modelled the impact of a fire in a typical FLNG processing facility. Other potential events, their interactions, and consequences were not included by Baalisampang et al. (2017a). Kim and Salvesen (2002) conducted a study on LNG vapour release, which was addressed as a possible VCE. However, a potential fire scenario was not considered. Another study by Koo et al. (2009) focused on pool fire modelling only and no consideration was given to a VCE or other possible interactions such as a jet fire. But in most cases, fire, explosion and combustion product release occur one after another or simultaneously resulting in integrated consequences (Baalisampang et al., 2018a; Baalisampang et al., 2018b). Reviews of past accidents (Al-shanini et al., 2014; Dadashzadeh et al., 2013a; Manca and Brambilla, 2012) and models (Al-shanini et al., 2014; Baksh et al., 2015; Kim and Salvesen, 2002; Koo et al., 2009) demonstrate a need to evaluate the entire accident sequence to mitigate the impact, to develop appropriate response methods and to prevent accidents by designing safety measures in the system. Combination of various accidental events is important as one event may lead to another and increases the overall consequences. To model entire impacts of a potential accident in a complex processing facility, it is essential to consider transitional event scenarios because in such modelling, entire causes and effects of a series of events are considered. In comparison to onshore processing facilities, offshore facilities are deemed more vulnerable to transitional events due to limited topside space and harsh environmental conditions (Baalisampang et al., 2016). Some offshore accidents involving transitional events are given in Table 1.

Table 1

Offshore fire and explosion accidents associated with multiple events

\begin{tabular}{|c|c|c|c|}
\hline $\begin{array}{l}\text { Accident name, year } \\
\text { and geographical } \\
\text { region }\end{array}$ & Event sequence & Consequences & References \\
\hline $\begin{array}{l}\text { Piper Alpha, 1988, } \\
\text { Europe North Sea }\end{array}$ & $\underset{\text { Release } \longrightarrow \text { Explosion }}{\longrightarrow}$ & $\begin{array}{l}165 \text { fatalities, total } \\
\text { loss }\end{array}$ & $\begin{array}{l}\text { (Pate - } \\
\text { Cornell, } \\
1993)\end{array}$ \\
\hline $\begin{array}{l}\text { High Island Pipeline, } \\
\text { 1989, US GOM }\end{array}$ & $\begin{array}{l}\text { Collision } \longrightarrow \text { Release } \longrightarrow \\
\text { Explosion } \longrightarrow \text { Fire }\end{array}$ & $\begin{array}{l}11 \text { fatalities, } 4 \text { injuries } \\
\text { and significant } \\
\text { damage }\end{array}$ & $\begin{array}{l}\text { (OPG, } \\
2010 b)\end{array}$ \\
\hline $\begin{array}{l}\text { Enchova Central, 1984, } \\
\text { America South East }\end{array}$ & $\begin{array}{l}\text { Blowout } \longrightarrow \text { Fire } \longrightarrow \\
\text { Explosion }\end{array}$ & $\begin{array}{l}42 \text { Fatalities, } 19 \\
\text { injuries and } \\
\text { significant damages }\end{array}$ & $\begin{array}{l}(\mathrm{OPG}, \\
2010 \mathrm{~b})\end{array}$ \\
\hline
\end{tabular}




\begin{tabular}{|c|c|c|c|}
\hline $\begin{array}{l}\text { Lake Maracaibo, 1993, } \\
\text { America South East }\end{array}$ & Explosion $\longrightarrow$ Fire & $\begin{array}{l}11 \text { fatalities, } \\
\text { significant damage }\end{array}$ & $\begin{array}{l}\text { (OPG, } \\
2010 b)\end{array}$ \\
\hline $\begin{array}{l}\text { Ubit, 1995, } \\
\text { Africa West }\end{array}$ & Explosion $\longrightarrow$ Fire & $\begin{array}{l}10 \text { fatalities, } 23 \\
\text { injuries and severe } \\
\text { damage }\end{array}$ & $\begin{array}{l}(\mathrm{OPG} \\
2010 \mathrm{~b})\end{array}$ \\
\hline $\begin{array}{l}\text { Petrobras P-36, 2001, } \\
\text { America South East }\end{array}$ & $\begin{array}{l}\text { Explosion } \longrightarrow \text { Fire } \longrightarrow \\
\text { Capsizing }\end{array}$ & 11 fatalities, total loss & $\begin{array}{l}\text { (OPG, } \\
2010 b)\end{array}$ \\
\hline $\begin{array}{l}\text { Bombay High North, } \\
\text { 2005, Asia South }\end{array}$ & $\begin{array}{l}\text { Collision } \longrightarrow \text { Release } \longrightarrow \\
\text { Fire }\end{array}$ & $\begin{array}{l}12 \text { fatalities, severe } \\
\text { damage to the jacket }\end{array}$ & $\begin{array}{l}\text { (OPG, } \\
2010 b)\end{array}$ \\
\hline $\begin{array}{l}\text { Deepwater Horizon, } \\
2010, \text { GOM }\end{array}$ & $\begin{array}{l}\text { Blowout } \longrightarrow \text { Release } \longrightarrow \\
\text { Fire } \longrightarrow \text { Explosion }\end{array}$ & $\begin{array}{l}11 \text { people died, } 17 \\
\text { injuries and total loss }\end{array}$ & $\begin{array}{l}\text { (Deepwater } \\
\text { Horizon } \\
\text { Study Group } \\
\text { (DHSG), } \\
2011 \text { ) }\end{array}$ \\
\hline $\begin{array}{l}\text { Black Elk, 2012, } \\
\text { GOM }\end{array}$ & $\begin{array}{l}\text { Release } \longrightarrow \text { Fire } \longrightarrow \\
\text { Explosion }\end{array}$ & $\begin{array}{l}3 \text { people died, } \\
\text { pollutant spill }\end{array}$ & $\begin{array}{l}\text { (BSEE, } \\
2013)\end{array}$ \\
\hline $\begin{array}{l}\text { SOKAR platform, } \\
2014, \\
\text { Caspian Sea }\end{array}$ & Explosion $\longrightarrow$ Fire & $\begin{array}{l}12 \text { people fell into the } \\
\text { sea }\end{array}$ & $\begin{array}{l}\text { (Fattakhova } \\
\text { and } \\
\text { Barakhnina, } \\
\text { 2015) }\end{array}$ \\
\hline $\begin{array}{l}\text { Abkatun Alfa platform, } \\
\text { 2015, GOM }\end{array}$ & Explosion $\longrightarrow$ Fire & $\begin{array}{l}7 \text { people died, } 45 \\
\text { injuries }\end{array}$ & $\begin{array}{l}\text { (Offshore } \\
\text { Post- } \\
\text { Everything } \\
\text { offshore } \\
\text { energy, } \\
2015)\end{array}$ \\
\hline
\end{tabular}

In fire and explosion accidents, a combined impact assessment is assumed to provide a more accurate consequence than individual one. In fire and explosion accidents, a damage potential (radius) can be increased if the impact of combustion products is considered (Dadashzadeh et al., 2014). During fire and explosion accidents, depending upon the types of burning materials and their combustion products, people are exposed to adverse health effects. For an integrated impact study, Khan and Amyotte (2004) proposed a methodology that incorporated fire, explosion and toxic release damage indices to evaluate the inherent safety of a facility based on inherent safety guidelines. Dadashzadeh et al. (2013b) proposed a new methodology for modelling an integrated consequence of fire and explosion using the Fire Dynamics Simulator (FDS) and FLACS and concluded that the risk of combined consequences is higher than each individual risk. But potential risk from combustion products during fire and/or explosion was not considered in the study. Niazi et al. (2018) proposed an integrated consequence modelling approach for fire and combustion products using risk based and grid- 
based approaches and claimed that the risk posed by thermal radiation is confined only to the lower deck. But the risk of exposure to combustion products was present in a larger area than that of the radiation, due to the influence of wind. Unlike previous studies (Dadashzadeh et al., 2013b; Khan and Amyotte, 2004; Niazi et al., 2018), the current study proposes a risk-based approach to model an integrated impact of fire, explosion and combustion products during an accidental release of LNG in a typical FLNG processing facility.

\section{Methodology}

This study proposes a methodology that models an integrated impact of evolving accident scenarios such as release, pool fire, explosion events and dispersion of combustion products as illustrated in Fig. 2. Currently, several Quantitative Risk Assessment (QRA) softwares tools such as IMESAFR (Tatom et al., 2011), Riskcurves (GexCon, 2018b), EFFECTS (GexCon, 2018a), Riskan (Lewis, 2005), HAMS-GPS (HAMSAGARS) and Phast and Safeti (DNV-GL, 2018) are available for accident modelling. They are simpler and faster than most CFD tools. A majority of QRA software tools lacks the capability of considering complex effects of geometry and equipment in the simulation and cannot model evolving accident scenarios. But this study considers the effect of complex geometry and/or equipment and models cascading events and their impacts using the following five steps.

In step 1, LNG release scenario, pool formation, vaporisation and dispersion of LNG vapour are modelled using FLACS. These phenomena are simulated with careful consideration of plausible scenarios. 


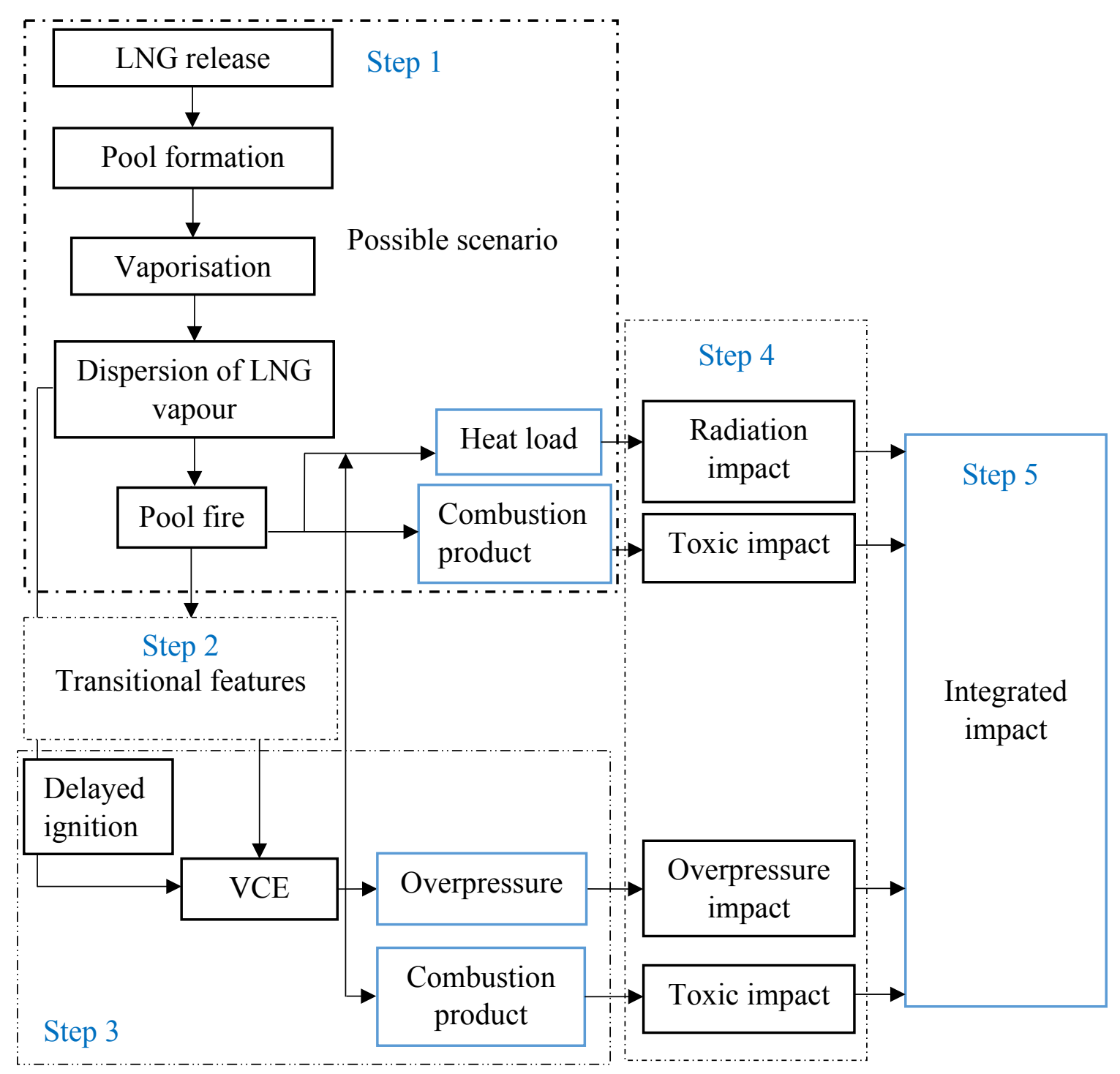

Fig. 2. Proposed methodology for modelling an integrated impact of transitional events to human during an LNG spill.

In step 2, the potential transitional phenomena are considered by attending to a series of events such as dispersion of LNG vapour, pool fire and VCE. The phenomenological changes to spilled LNG and vaporisation due to a culmination of atmospheric effects and thermal radiation are considered for assessing the occurrence of potential cascading events. The thermal load obtained from the pool fire is used as the source of ignition for the VCE. For transitional events to occur, some minimum conditions need to be fulfilled. For instance, a dispersion event can transit to pool fire only if the flammability condition is met. Similarly, a VCE occurs when pertinent conditions such as confinement, turbulence, ignition source, and flammable gas cloud are present (Atkinson et al., 2017; Center for Chemical Process Safety, 1996). These pertinent conditions are considered as stimuli for the transitions (events) (Alzbutas, 2015). During a release, with the vaporisation and dispersion of LNG in air, only a 
vapour concentration in the range of 5-15 vol.\% will sustain the propagation of a flame upon ignition. The concentration of the vapour above the upper explosion limit may act as feed gas to the fire. However, if the dispersed vapours accumulate in nearby semi-confined or confined areas, the fire may transform to a VCE upon ignition. This may increase the severity of consequence in total. If the flammable gas release is not ignited immediately, a vapor plume will form which will drift and disperse by the ambient winds and/or natural ventilation. If the vapour is ignited, but does not explode, it will result in a flash fire, in which the gas cloud within the flammable range burns very rapidly. If the vapour is not isolated during this time, the flash fire may burn to yield a jet fire at the source of the release, under the condition that the concentration range is appropriate, and the leak is present.

In step 3, the heat released from the pool fire is modelled as the potential ignition source to ignite the flammable gas accumulated at a position away from the pool fire location such that the fire did not consume the rich vapour cloud from this location. It was assumed that this location did not get direct fire flame and the presence of high thermal radiation from the fire resulted in an autoignition of the vapour or influenced other ignition sources to ignite. During a release of a flammable gas, if the ignition is delayed by 5-10 min, a VCE may be the outcome (Assael and Kakosimos, 2010; Soman and Sundararaj, 2012). For ignition to take place, the vapour cloud must be within the flammable range, while at the same time a source able to supply the required energy must be available (Assael and Kakosimos, 2010). To model a pool fire transiting to a VCE, thermal radiation and other parameters such as temperature and pressure development are extracted from the previous step. There are various models available for gas explosion modelling, like empirical, phenomenological and CFD (Lea and Ledin, 2002). According to Tam and Lee (1998), CFD codes are inherently more flexible than both empirical and phenomenological models and are applicable to all fields. Some commonly used CFD models for explosion simulations are EXSIM, FLACS and AutoReaGas (Lea and Ledin, 2002). FLACS developed by the Global Explosion Consultants (GexCon AS) has been used widely for the modelling of gas dispersion and explosion in onshore or offshore facilities (Hansen et al., 2005). In this study, FLACS is used to model the fire and explosion scenarios.

In step 4, the consequences of fire, explosion and/or combustion product release are analysed individually using probit functions. The heat load obtained from the fire is used to assess the fire impact to assets and people. The probability of human impacts from the heat radiation is calculated by Eq. (2), considering the probit model given in Eq. (1).

Probit function $(P r)=c_{1}+c_{2} \ln D$, 
The probability of injury or death $(P)=F_{k \frac{1}{2}}\left[1+\operatorname{erf}\left(\frac{\operatorname{Pr}-5}{\sqrt{2}}\right)\right]$,

where $D$ is the thermal dose $\left(\frac{k W}{m^{2}}\right)^{\frac{4}{3}} s, c_{1}$ and $c_{2}$ are probit coefficients, $F_{k}$ is a clothes correction factor, and erf is the error function. The thermal dose is obtained from the post processing file using inbuilt utilities in FLACS.

Sudden large changes in pressure due to an explosion can lead to dramatic and possibly fatal damage to vital human organs such as lungs and ears. The impact of explosion is assessed based on the calculation of the probability (P) of injury or death employing Eqs. (3)-(8).

Probit function $(P r)=c_{1}+c_{2} \ln S$,

The probability of injury or death $(\mathrm{P})=\frac{1}{2}\left[1+\operatorname{erf}\left(\frac{\operatorname{Pr}-5}{\sqrt{2}}\right)\right]$,

where variable $S$ is defined according to the type of the effect calculated by $\mathrm{S}=\left(\frac{4.2}{\bar{P}}+\frac{1.3}{\bar{i}}\right)$, where $\bar{i}$ is the scaled impulse $\left(P a^{\frac{1}{2}} \cdot s . \mathrm{kg}^{-\frac{1}{3}}\right), \bar{P}$ is scaled pressure (-) and $c_{1}$ and $c_{2}$ are probit coefficients (Assael and Kakosimos, 2010). Explosion effects on humans are usually categorised as:

1. Direct or primary effects

The overpressure from the explosion can cause injury to sensitive human organs, or death.

2. Indirect effects

The indirect effects are sub-divided into two categories

a. Secondary effects refer to injuries or death caused by fragments or debris thrown by explosion's blast,

b. Tertiary effects that refer to injuries or death caused by whole-body displacement and collision with stationary objects or structures, because of the explosion's blast waves.

The probabilities of impact to lung, eardrum rupture, head impact and whole-body displacement impact are calculated using Eq. (4). However, the $\operatorname{Pr}$ are different. In this study, the following probit functions are used for each type of impact (Assael and Kakosimos, 2010). For lung damage, $\operatorname{Pr}=5-5.74 \ln S$

For eardrum damage, $\operatorname{Pr}=-12.6+1.524 \ln P_{S}$

For head impact, $\operatorname{Pr}=5-8.49 \ln S$

For whole-body displacement, $\operatorname{Pr}=5-2.44 \ln S$ 
where $P_{s}$ is overpressure (Pa). According to Clancey (1972) cited in Crowl and Louvar (2011) $1-99 \%$ fatalities can occur when exposed to over 2 bar.

Toxicity of combustion products accounts for a major cause of death and injury from unwanted fires (Hartzell, 1992). The main combustion products are divided into two types: asphyxiant gases, which prevent oxygen uptake by cells, leading to loss of consciousness and death; irritant gases which cause immediate incapacitation affecting eyes and upper respiratory tract long-term damage in the lung (Hull and Stec, 2010). Because of these harmful effects, they can seriously jeopardise evacuation. During an LNG fire or VCE, carbon monoxide (CO) and nitrogen dioxide $\left(\mathrm{NO}_{2}\right)$ are the main toxic combustion products (Dadashzadeh et al., 2014).

In the step 5, the integrated impact of fire, explosion and combustion product release is estimated. For integration of fire and VCE effects a grid-based approach is used such that consequence severity can be mapped as an index. To estimate risk of each event, a risk-based approach was further adopted using a severity index and probability of each effect. The severity index for each type of effect $\left(\mathrm{S}_{i}\right)$ is estimated using expert judgment. The effects are ranked based on their severity of damages (Table 2) and experts' judgment on a scale of 1-10.

Table 2

Severity scores for human effects caused by fire and explosion (Dadashzadeh et al., 2013b)

\begin{tabular}{|l|l|l|l|l|l|l|l|}
\hline \multicolumn{3}{|l|}{ Fire } & \multicolumn{2}{l|}{ Explosion } \\
\hline Effects & $\begin{array}{l}\text { First } \\
\text { degree } \\
\text { burn }\end{array}$ & $\begin{array}{l}\text { Second } \\
\text { degree } \\
\text { burn }\end{array}$ & Death & $\begin{array}{l}\text { Lung } \\
\text { damage }\end{array}$ & $\begin{array}{l}\text { Eardrum } \\
\text { rupture } \\
\text { (injury) }\end{array}$ & $\begin{array}{l}\text { Head } \\
\text { impact } \\
\text { (death) }\end{array}$ & $\begin{array}{l}\text { Whole body } \\
\text { displacement } \\
\text { (death) }\end{array}$ \\
\hline Score (S) & 2 & 5 & 10 & 10 & 5 & 10 & 10 \\
\hline
\end{tabular}

The severity index for each effect at any location of the plant is calculated as follows:

$\operatorname{Risk}_{i}=\mathrm{S}_{i} \times \mathrm{P}_{i}$

Where, Risk $_{i}$ denotes the severity index for each effect and $i$ denotes the effects (first degree injury, second degree injury and death for fire; lung damage, eardrum rupture, head impact and whole-body displacement for explosion). At each grid point, the maximum severity index among the various effects of each accident is considered using Eqs. (10) and (11) for a fire and explosion respectively.

$\operatorname{Risk}_{f}=$ maximum [Risk ${ }_{\text {First degree burn }}$, Risk $_{\text {Second degree burn }}$, Risk $_{\text {Death }}$ ]

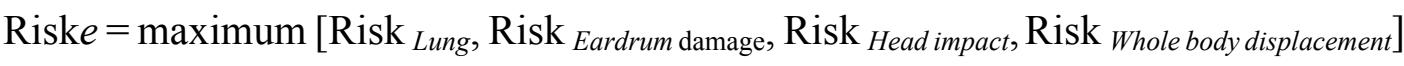

The total risk of fire and VCE (Risk ${ }_{f e}$ ) at any location is estimated using Eq. (12),

$\operatorname{Risk}_{f e}=\operatorname{Risk}_{f}+\operatorname{Risk}_{e}$ 
Using the Risk $f e$ at any location of the layout, risk contour can be obtained considering cumulative effects of a fire and VCE.

The toxicity risk assessment is carried out according to the methodology proposed by Dadashzadeh et al. (2014). A hazard index (HI) was estimated at each grid point of the layout using Eq. (13) (National Research Council, 1998).

$H I=\frac{\text { Estimated concentration }\left(\mathrm{mg} / \mathrm{m}^{3}\right)}{\text { Reference toxic value }\left(\mathrm{mg} / \mathrm{m}^{3}\right)}$

For toxic risk estimation of each contaminant of the combustion product, Eq. (13) can be written as in Eq. (14).

Risk $_{\text {combustion product }}=\frac{\text { Exposure concentration }}{T L V-S T E L}$

Where TLV-STEL is the Threshold limit value - Short Term Exposure Limit $\left(\mathrm{mg} / \mathrm{m}^{3}\right)$. By adding the hazard quotients (hazard indices) for the individual emission toxicants, the hazard quotient of all toxicants is obtained as shown in Eq. (15). A risk of a health effect is assumed to exist at those exposure locations where the hazard index exceeds 1 .

Risk $_{\text {Total combustion product }}=$ Risk $_{C O}+$ Risk $_{\mathrm{NO}_{2}}$

Finally, the integrated risk at any location of the facility is estimated by investigating the Risk $\mathrm{fe}_{f e}$

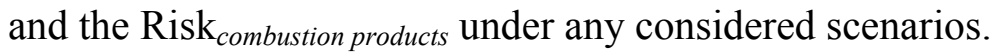

\section{Application of the integrated methodology: a case study}

The proposed methodology is applied to a typical layout consisting of several process equipment as shown in Fig. 3. Leak, vaporisation and dispersion are strongly dependent on the operating parameters and may need to consider prevalent operating conditions. In this case study, prevalent operating conditions are considered based on FLACS user's manual (GexCon AS, 2013). In this scenario, $10 \mathrm{~kg} / \mathrm{s}$ of LNG is released at an LNG processing plant. According to Woodward (2010) the appropriate wind speed for flammable cloud dispersion is usually close to 2 to $4 \mathrm{~m} / \mathrm{s}$ and thus, the wind speed is taken as $3 \mathrm{~m} / \mathrm{s}$ with an ambient temperature of $20^{\circ} \mathrm{C}$. A pool of $\mathrm{LNG}$ is formed at the release location and vaporization occurs due to the ambient conditions. The vaporized LNG is then dispersed by the wind and a fuel vapour cloud is formed in the process area. At $125 \mathrm{~s}$, an ignition occurs in the process area which leads to a pool fire. After $55 \mathrm{~s}$ the fire transits to a VCE in the congested and confined portion of the facility. This time is chosen based on the presence of the maximum thermal radiation in the layout. The heat load released due to the fire enhances the LNG vaporization over the LNG 
pool and causes a VCE. A transitional scenario is developed considering the inherent characteristics of the LNG spill and various potential events (such as pool formation, spreading, vaporization, and vapour dispersion) are modelled.

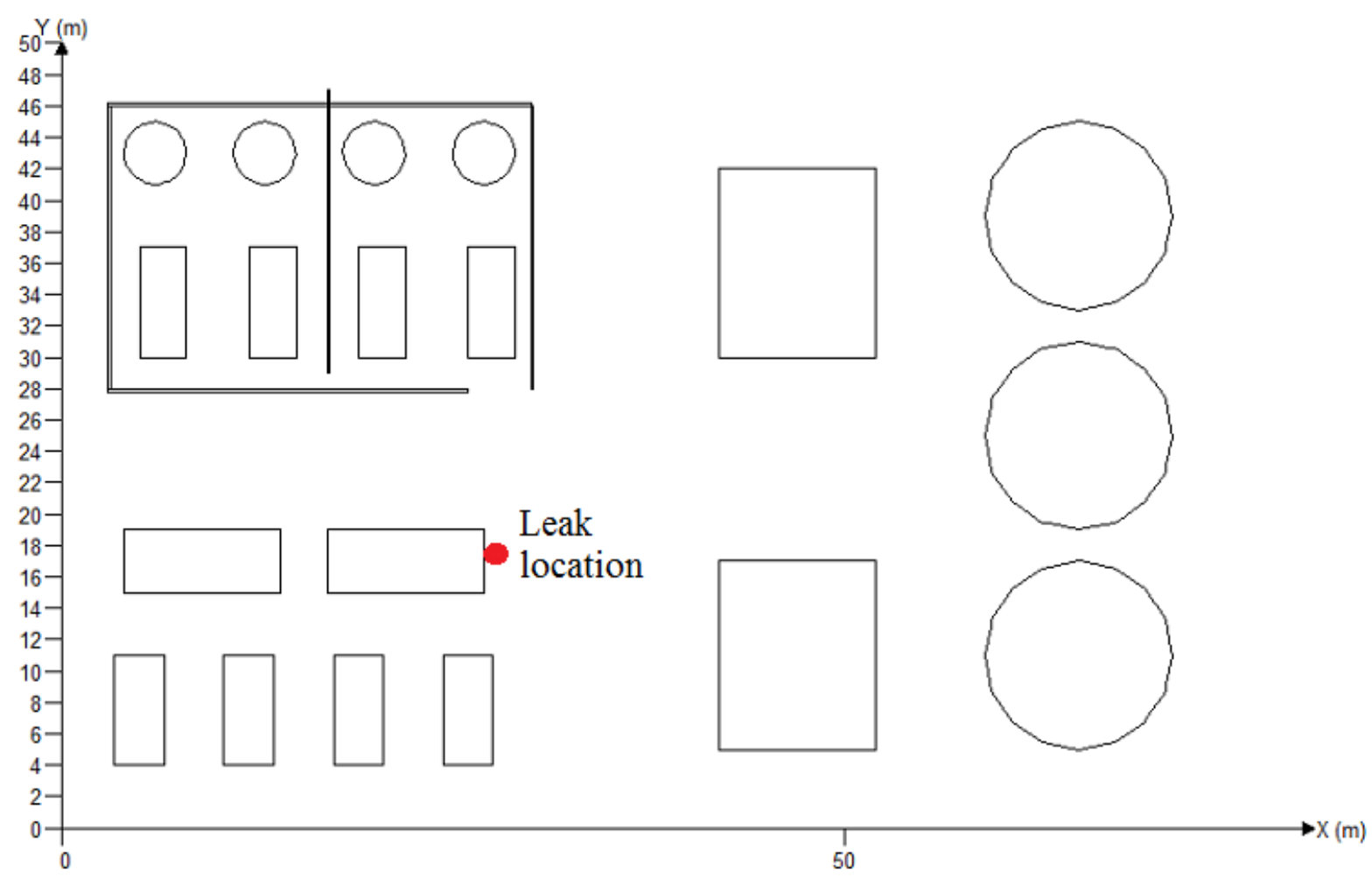

Fig. 3. A layout chosen for the transitional events modelling

\subsection{Release, pool formation, vaporisation and dispersion modelling}

In this scenario, an instantaneous release of LNG is considered which led to a pool formation and formed a flammable vapour plume upon vaporisation. A pool fire is considered with a delayed ignition. The entire layout $85 \mathrm{~m} \times 55 \mathrm{~m} \times 20 \mathrm{~m}$ is considered for simulation with a grid resolution of $0.4 \mathrm{~m}$ for the $\mathrm{x}$ and $\mathrm{y}$ directions and $0.3 \mathrm{~m}$ in the $\mathrm{z}$ direction. A sensitivity analysis was performed using volumetric concentration to select the grid size for a solution independent of the mesh size. Around the leak location, the grid resolution was adjusted to $0.2 \mathrm{~m}$ while at the locations far from the pool area, grids were stretched according to grid refinement guideline given in GexCon AS (2013). The LNG was assumed to be composed of $85 \%$ methane, $10 \%$ ethane and $5 \%$ propane. According to Pitblado et al. (2005) the maximum credible puncture hole is $250 \mathrm{~mm}$. Thus, a point leak is considered from a 0.05 $\mathrm{m}^{2}$ hole for $120 \mathrm{~s}$ forming a pool. A dynamic pool model (PM3) is chosen which means that the pool spreads with non-uniform pool temperature due to the influence of heat and mass transfer in each control volume (GexCon AS, 2013). A constant evaporation rate of 0.14 
$\mathrm{kg} /\left(\mathrm{m}^{2} \mathrm{~s}\right)$ is considered based on the OPG (2010a). The considered leak parameters are given in

Table 3.

Table 3

Leak parameters considered in the release scenario

\begin{tabular}{|l|l|}
\hline Leak type & Jet \\
\hline Leak position & $(26.5,20,1.2) \mathrm{m}$ \\
\hline Leak direction & $+\mathrm{X}$ \\
\hline Start time & $5 \mathrm{~s}$ \\
\hline Duration & $120 \mathrm{~s}$ \\
\hline Outlet & \\
a. Area & $0.05 \mathrm{~m}^{2}$ \\
b. Mass flow rate & $10 \mathrm{~kg} / \mathrm{s}$ \\
c. Relative turbulence intensity & $0.02(\mathrm{Low})$ \\
d. Turbulence length scale & $0.025 \mathrm{~m}$ \\
e. Temperature & $-160^{\circ} \mathrm{C}$ \\
\hline
\end{tabular}

The initial and boundary conditions assigned for the simulation are provided in Table 4 and Table 5 respectively. The Euler boundary condition is a zero pressure condition and demands significant distance in all directions (GexCon AS, 2013).

\section{Table 4}

Initial conditions used

\begin{tabular}{|l|l|}
\hline Parameters & Values \\
\hline Characteristic velocity & $0.1 \mathrm{~m} / \mathrm{s}$ \\
\hline Relative turbulence intensity & 0.1 \\
\hline Turbulence length scale & $0.01 \mathrm{~m}$ \\
\hline Temperature & $20^{\circ} \mathrm{C}$ \\
\hline Ambient pressure & $100 \mathrm{kPa}$ \\
\hline Ground roughness & $0.001 \mathrm{~m}$ \\
\hline Reference height & $2 \mathrm{~m}$ \\
\hline Pasquill stability class & $\mathrm{F}$ \\
\hline
\end{tabular}


Table 5

Boundary conditions

\begin{tabular}{|l|l|}
\hline Name & Type \\
\hline XLO & Wind \\
\hline XHI & Euler \\
\hline YLO & Wind \\
\hline YHI & Euler \\
\hline ZLO & Euler \\
\hline ZHI & Euler \\
\hline
\end{tabular}

All parameters required for post processing are given in Table 6.

Table 6

A list of simulated parameters

\begin{tabular}{|l|l|}
\hline Output parameters & Unit \\
\hline Pressure (P) & barg \\
\hline Maximum pressure (PMAX) & barg \\
\hline Velocity vector (VVEC) & $\mathrm{m} / \mathrm{s}$ \\
\hline Combustion product mass fraction (PROD) & - \\
\hline Temperature (T) & $\mathrm{K}$ \\
\hline Mass fraction of carbon monoxide (CO) & - \\
\hline Radiative heat flux (QRAD) & $\mathrm{kW} / \mathrm{m}^{2}$ \\
\hline Total heat flux (Q) & $\mathrm{kW} / \mathrm{m}^{2}$ \\
\hline Mass fraction of soot (SOOT) & - \\
\hline Heat dose (QDOSE) & $\left(\left(\mathrm{kW} / \mathrm{m}^{2}\right)^{\wedge}(4 / 3) \mathrm{s}\right)$ \\
\hline Mass fraction of Nitrogen Dioxide $\left(\mathrm{NO}_{2}\right)$ & - \\
\hline Probability of death (PDEATH) & - \\
\hline Toxic probit (PROBIT) & - \\
\hline Toxic concentration (TCONS) & $\mathrm{mg} / \mathrm{m}^{3}$ \\
\hline Toxic dose (TDOSE) & $\mathrm{mg} / \mathrm{m}^{3} \cdot \mathrm{minute}^{2}$ \\
\hline
\end{tabular}

The vaporised fuel concentrations in the layout are monitored during the dispersion as shown in Figs. 4 and 5. The presence of flammable concentrations $(0.05-0.15)$ indicates that the fuel 
has the potential to be ignited in several areas of the layout. This would likely contribute to the occurrence of transitional events or evolving accident scenarios.

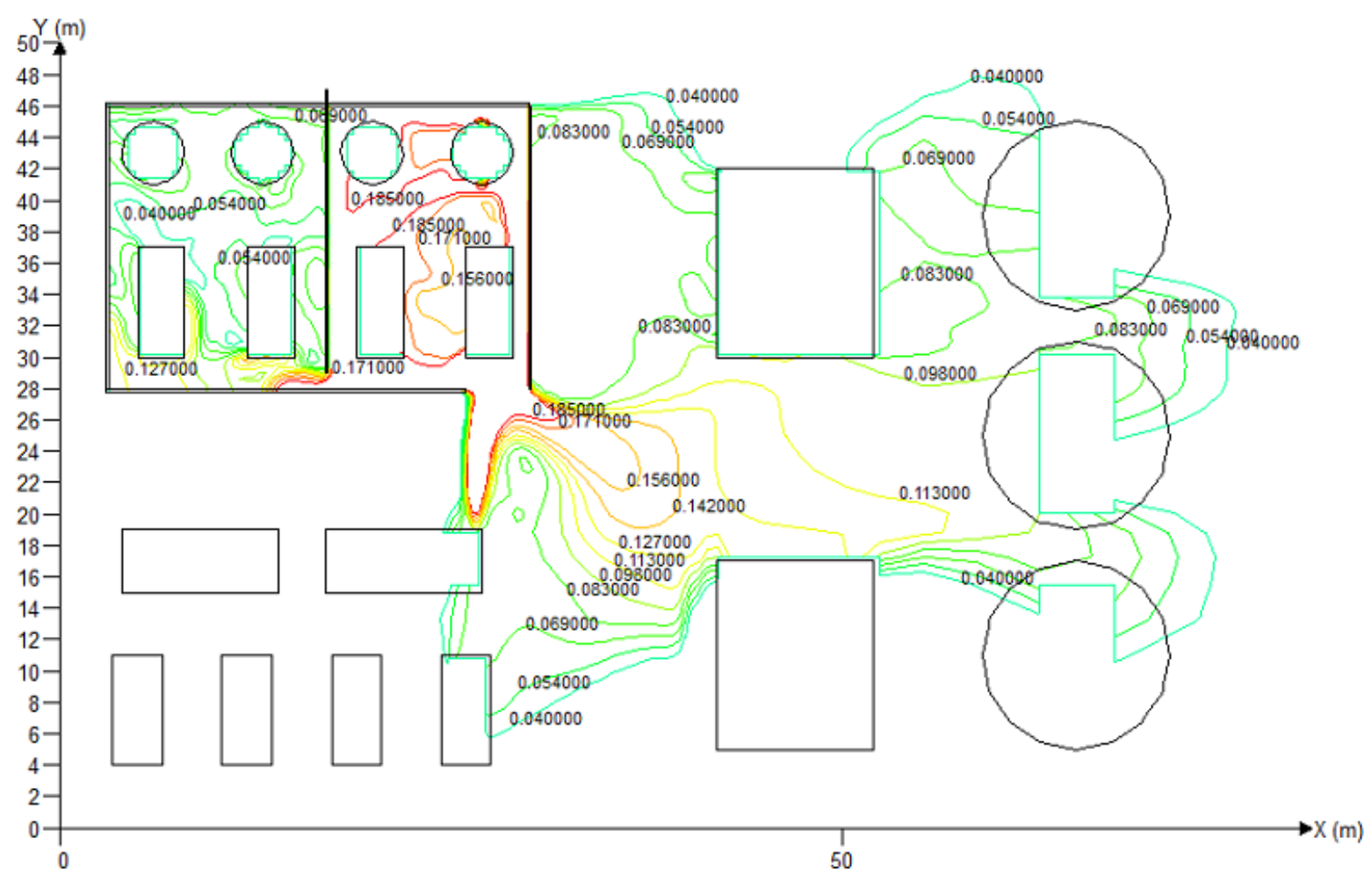

Fig. 4. Dispersion of vaporised LNG over the layout $\left(\mathrm{m}^{3} / \mathrm{m}^{3}\right)$ at time $125 \mathrm{~s}$

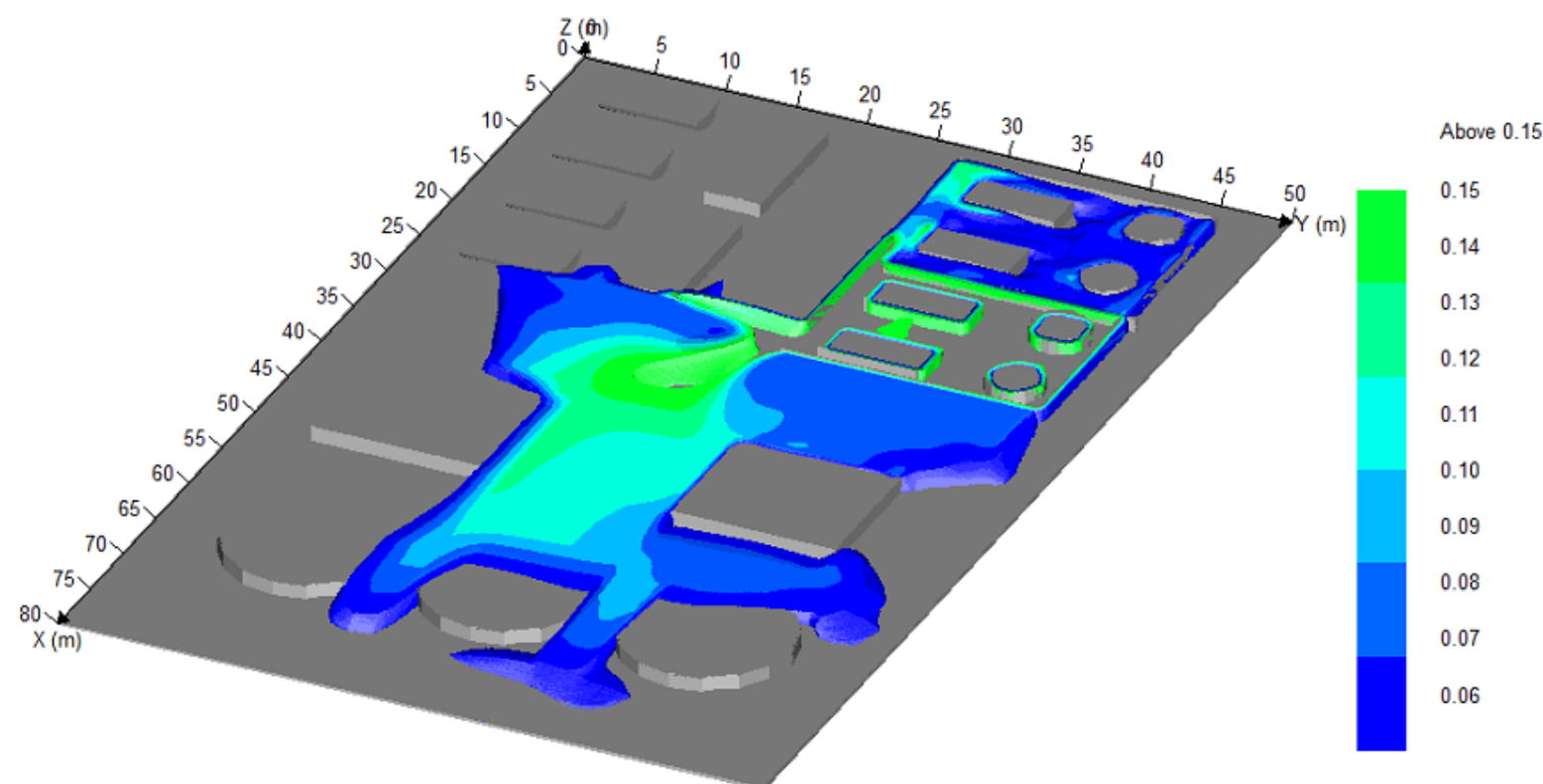

Below 0.05

Fig. 5. 3D dispersion of fuel in the layout $\left(\mathrm{m}^{3} / \mathrm{m}^{3}\right)$ at $125 \mathrm{~s}$ which shows the maximum volume of gas cloud. 


\subsection{Assessing the possibility of transitional features}

A VCE is considered as the final event and to identify transitional features, fire modelling is considered. Based on the dispersion characteristics of the LNG vapour, a pool fire is modelled with a delayed ignition $125 \mathrm{~s}$ using the FLACS fire model as demonstrated in Fig. 6. In the fire simulation, the Discrete Transfer Method (DTM) model is used because this is the most accurate radiation model (GexCon AS, 2013). Emissivity of 0.85 is used because it is applicable to most steel surfaces. To provide numerical stability, radiation start ramp is considered to be 1 (GexCon AS, 2013). The Eddy Dissipation Concept (EDC) is chosen as the combustion model. The Formation Oxidation model is chosen as the soot model. For typical hydrocarbons, the soot yield is in the order of 1\% (GexCon AS, 2013). Radiation, smoke and engulfment are the main hazards of a pool fire (Jagger and O'Sullivan, 2004). The possibility of ignition of the accumulated LNG vapour due to the thermal radiation release from the fire needs to be assessed for transitioning to a VCE.

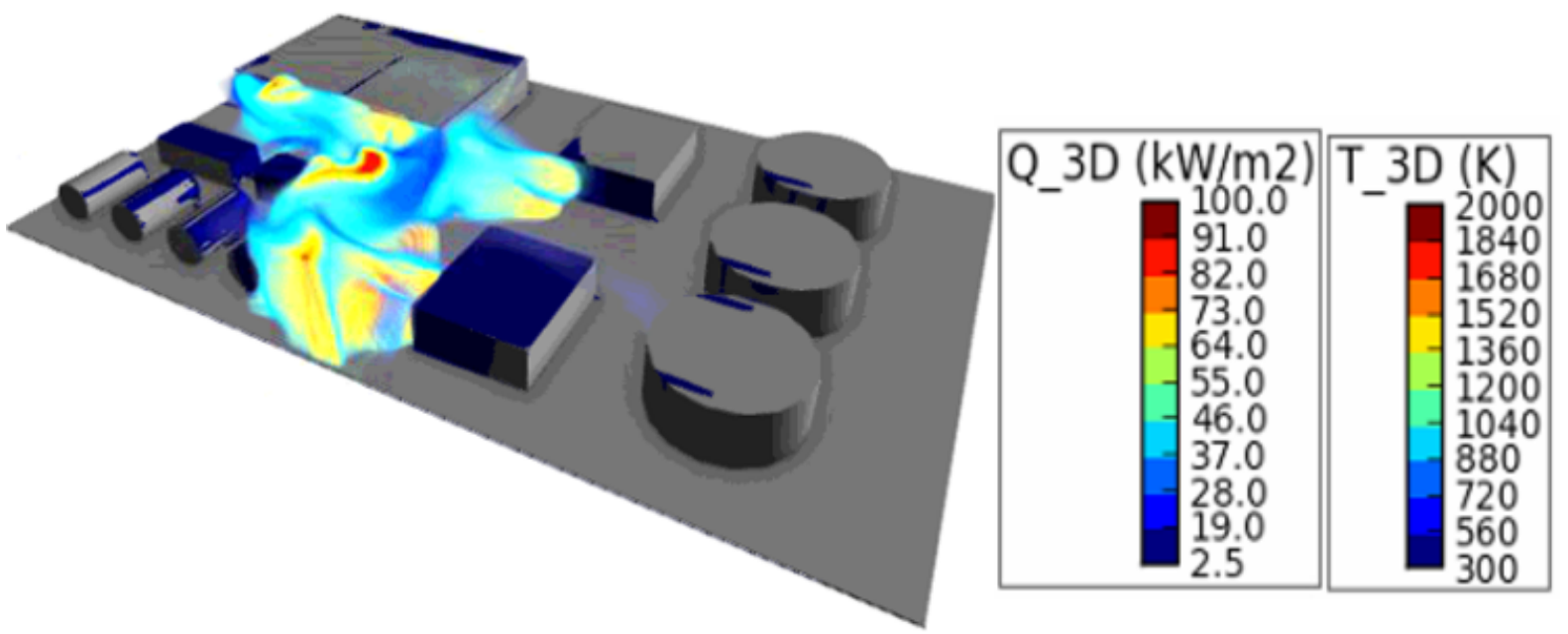

Fig. 6. 3D pool fire model at $125 \mathrm{~s}$

The main purpose of the transitional event modelling is to analyse if the fire or dispersed vapour can cause a VCE or flash fire in the presence of an existing fire. The most likely location of a VCE can be identified based on the presence of a flammable concentration of LNG vapour, confinement/equipment congestion and ignition source. An autoignition can be a source of ignition of the vapour or heated objects due to the thermal radiation from the fire (Planas-Cuchi et al., 1997; Zheng and Chen, 2011). According to the fuel concentration and its developed pressure during LNG vapour dispersion, a transition of the pool fire to a VCE is modelled. The 
transition from fire to VCE is considered after $55 \mathrm{~s}$ of the start of the fire, that is at $180 \mathrm{~s}$. The small pressure developed during LNG vapour dispersion is demonstrated in Fig. 7.

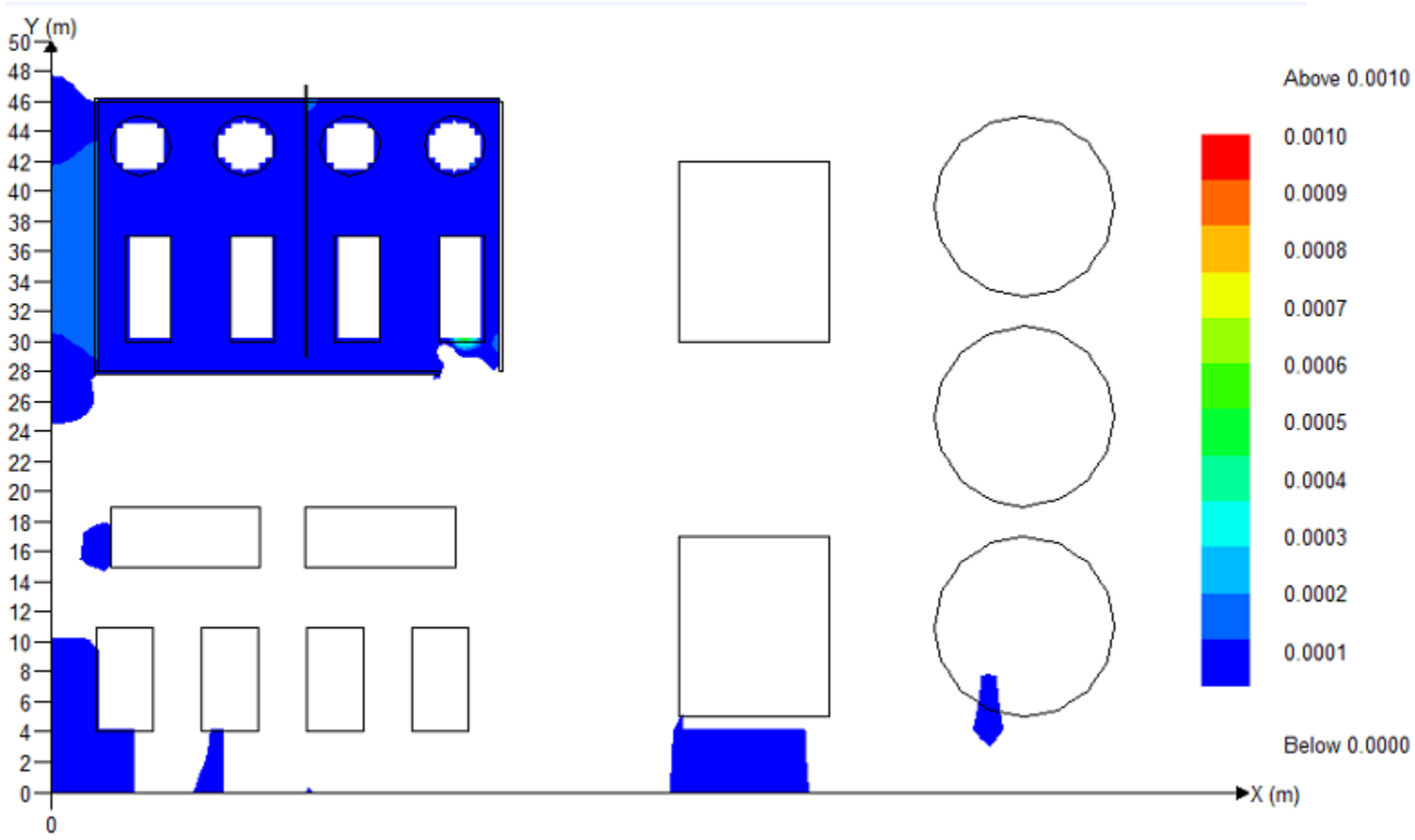

Fig. 7. Pressure developed in in the layout during dispersion of the fuel (barg)

\subsection{Toxic potency assessment of combustion products}

During LNG (mainly methane) fire, $\mathrm{CO}$, Carbon dioxide, $\mathrm{NO}_{2}$, unburnt methane and water are produced as combustion products depending on complete or incomplete combustion reaction. In this study, only $\mathrm{CO}$ and $\mathrm{NO}_{2}$ are considered for toxic potency assessment owing to their high toxicity (Dadashzadeh et al., 2014). The different symptoms and health effects of $\mathrm{CO}$ and $\mathrm{NO}_{2}$ are found in Purser et al. (2015) and the National Research Council (1998) respectively.

\subsection{Integration of impact analysis}

In this current study, an integrated impact analysis is conducted according to the step 5 of the methodology. The risks severity of combustion products was not directly normalised with those of thermal radiation and overpressure. However, an integrated impact analysis is conducted by investigating the risk contours of fire, VCE and combustion products. Similar to Dadashzadeh et al. (2013b), an integrated risk contour is used for assessing the impact of transitional accident scenarios in the facility. 


\section{Results and discussion}

\subsection{Results for transition modelling}

The released LNG dispersed in the air resulted in a flammable vapour concentration over the plant not only adjacent to the leak location but also away from it. The autoignition temperature of LNG (primarily methane) is $1004^{\circ} \mathrm{F}(813.15 \mathrm{~K})$ (Foss et al., 2003). High temperatures and radiation from the fire reach the congested/confined areas, indicating that during the fire, there is a possibility of transitioning the fire into a VCE. The range of radiation and temperature generated during the fire are given in Figs. 8 and 9 respectively.

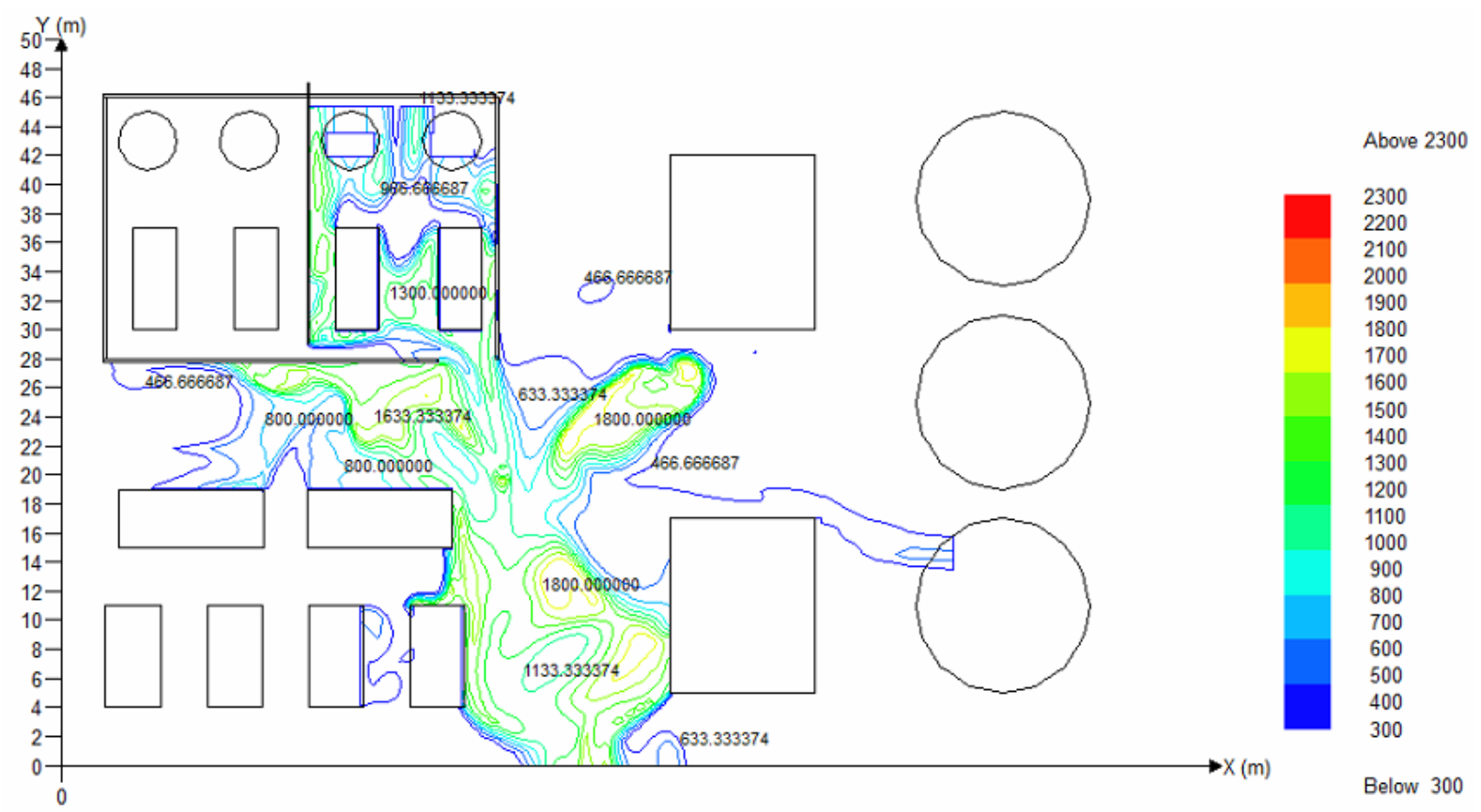

Fig. 8. Temperature distribution over the layout during the pool fire $(\mathrm{K})$ at $180 \mathrm{~s}$

The maximum temperatures and thermal radiation are $2300 \mathrm{~K}$ and $80 \mathrm{~kW} / \mathrm{m}^{2}$ respectively. These high temperature and thermal radiation may easily contribute in causing other fires in adjacent areas. The variation of air pressure in the layout in the presence of the dispersed vapour can be a useful information for assessing the potential location of a VCE. During gases dispersion, concentration in the air can create different initial pressure, which is one of the parameters on which the strength of explosion depends (Kundu et al., 2016). In this study, the maximum pressure developed during the dispersion of LNG vapour is 0.001 barg (illustrated in Fig. 7). The 1 mbar initial pressure may not have a substantial effect on the strength of a VCE. The output results obtained from the fire modelling and the dispersion modelling show that the transition to a VCE or a flash fire is possible. 


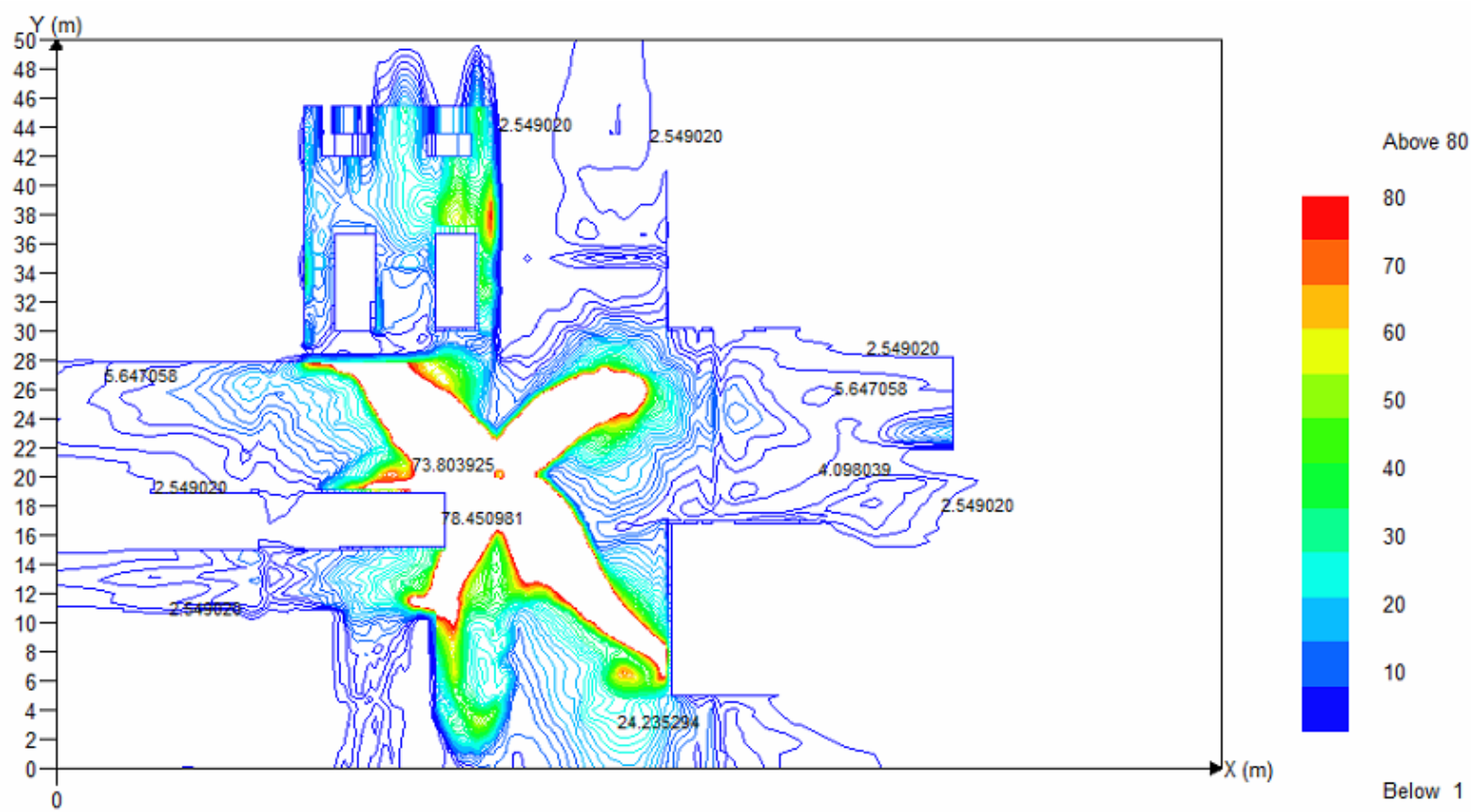

Fig. 9. Radiation from the fire over the layout $\left(\mathrm{kW} / \mathrm{m}^{2}\right)$ at $180 \mathrm{~s}$

\subsection{Thermal radiation impact}

The tenability limit for human beings is approximately $2.5 \mathrm{~kW} / \mathrm{m}^{2}$ (Mannan, 2012). The presence of thermal radiation greater than $2.5 \mathrm{~kW} / \mathrm{m}^{2}$ indicates that the fire can have serious effects to human and adjacent assets. The probability of injuries (first and second-degree burn) and the probability of death at different location of the plant are calculated using the thermal radiation. The maximum damage distance for various effects of fire is given in Table 7.

Table 7

Maximum damage distance for various effects of fire

\begin{tabular}{|l|l|l|}
\hline Effects on humans & Heat flux $\mathbf{( k W / \mathbf { m } ^ { 2 } )}$ & $\begin{array}{l}\text { Maximum damage } \\
\text { distance (m) }\end{array}$ \\
\hline $\begin{array}{l}100 \% \text { lethality in } 1 \mathrm{~min} . \\
1 \% \text { lethality in } 10 \mathrm{~s}\end{array}$ & 37.5 & 26.2 \\
\hline $\begin{array}{l}100 \% \text { lethality in } 1 \mathrm{~min} . \text { Serious } \\
\text { injuries in } 10 \mathrm{~s}\end{array}$ & 25 & 33.5 \\
\hline $\begin{array}{l}1 \% \text { lethality in } 1 \text { min. } \\
\text { First degree burns in } 10 \mathrm{~s}\end{array}$ & 12 & 36.7 \\
\hline $\begin{array}{l}\text { No lethality. } \\
\text { 2nd degree burns probable. }\end{array}$ & 4 & 39.8 \\
\hline
\end{tabular}




\begin{tabular}{|l|l|l|}
\hline Pain after exposure of $20 \mathrm{~s}$. & & \\
\hline $\begin{array}{l}\text { Acceptable limit for prolonged } \\
\text { exposure }\end{array}$ & 1.6 & 43.5 \\
\hline
\end{tabular}

The fire risk index of all grid points was calculated and plotted over the layout as demonstrated in Fig. 10. The risk index $\left(\operatorname{Risk}_{f e}\right)$ varies from 1 to the maximum value of 10 at the flame surface.

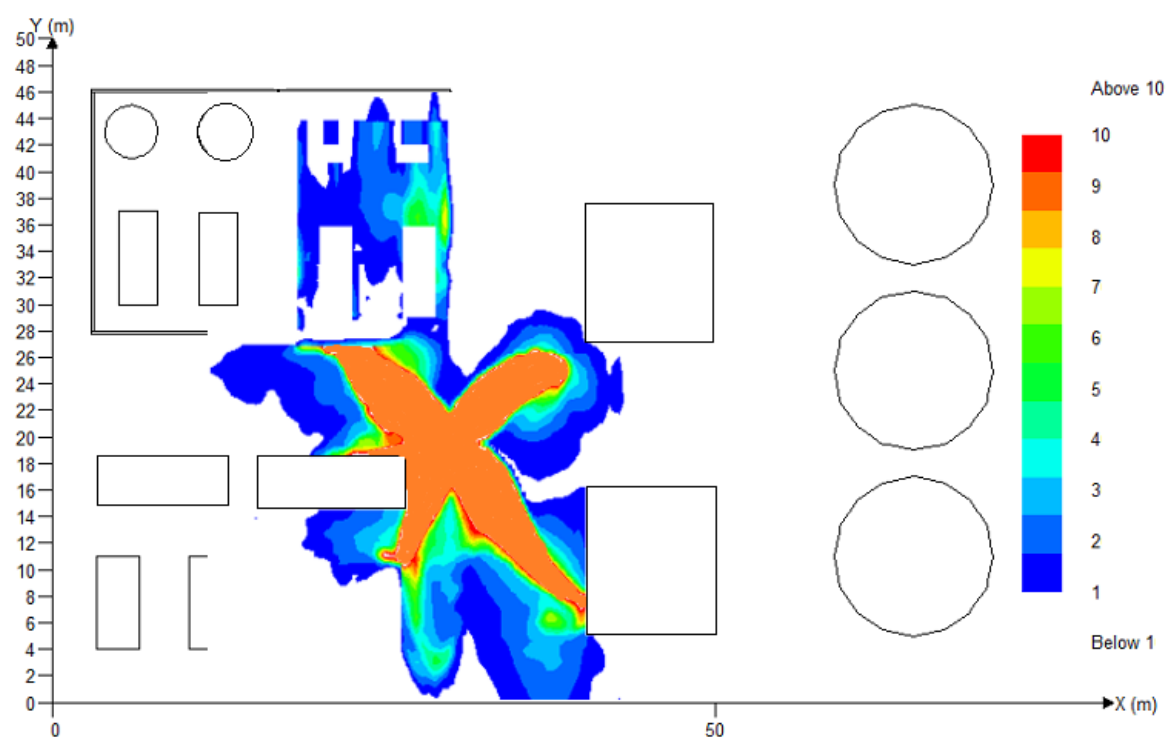

Fig. 10. Fire risk contour in the layout at $180 \mathrm{~s}$

\subsection{VCE impact and risk assessment}

The impact of the VCE and its subsequent risk are assessed based on the overpressure developed during the VCE. The explosion overpressure ranges from 0 to 2 barg over the layout and high pressures are found in the areas with a high congestion/confinement level as shown in Fig. 11. The developed pressures are limited within a portion of the congested layout. However, the developed pressures can result in damages to assets and humans in those areas of the facility. The damage distance from the VCE ignition point is illustrated in Table 8.

Table 8

Damage distance from the VCE ignition point

\begin{tabular}{|l|l|}
\hline Effects & $\begin{array}{l}\text { Distance from the } \\
\text { ignition point }(\mathbf{m})\end{array}$ \\
\hline $100 \%$ fatality & 4.60 \\
\hline $60 \%$ fatality & 6.25 \\
\hline
\end{tabular}




\begin{tabular}{|l|l|}
\hline Fatal distance limit & 7.80 \\
\hline Eardrum damage limit & 10.30 \\
\hline Safe distance & 15 \\
\hline
\end{tabular}

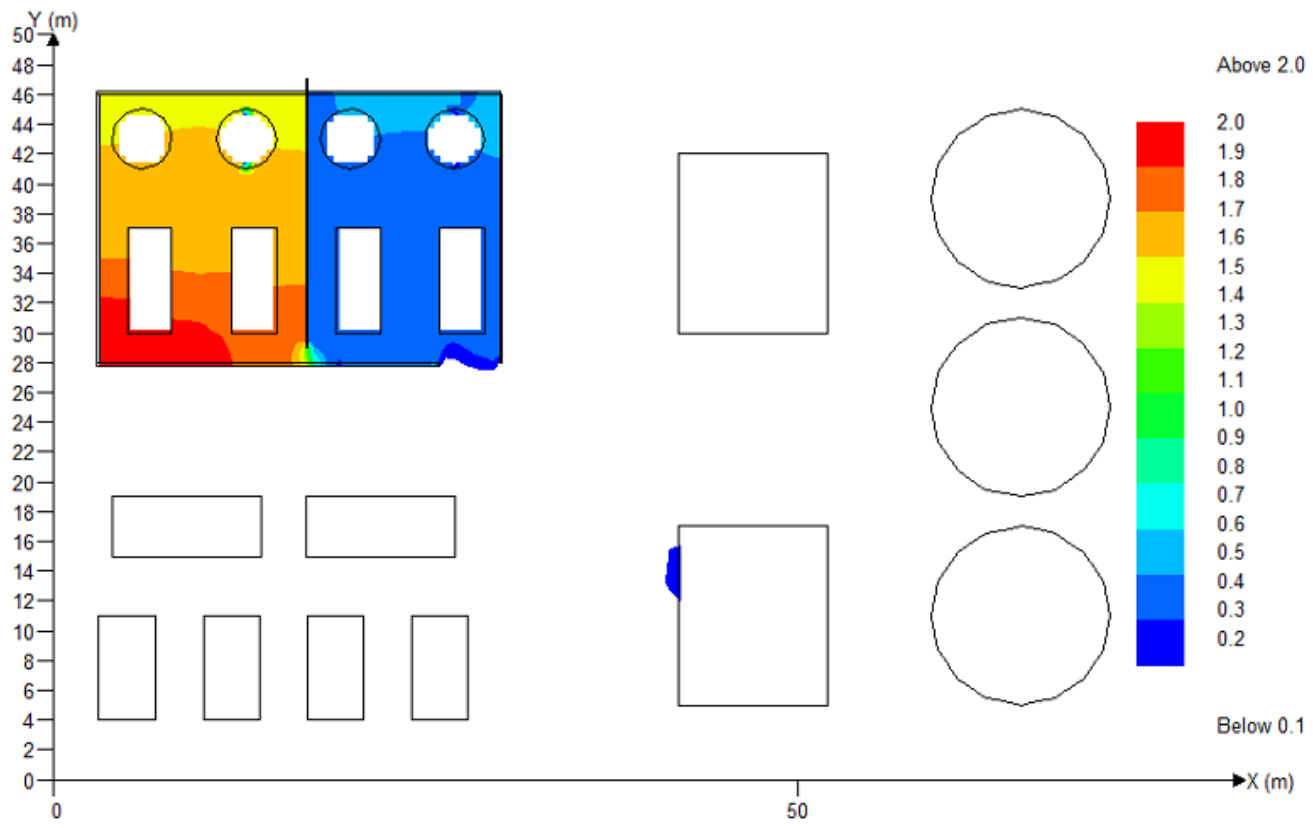

Fig. 11. VCE pressure over the plant (barg) at $180 \mathrm{~s}$

Using the probit model, the probabilities of injuries or death caused by the overpressure were estimated. Subsequently, the VCE risk index $\left(\operatorname{Risk}_{e}\right)$ was calculated and plotted over the facility as shown in Fig. 12. The values of the VCE risk index vary from 1 to 10 . Index 1 corresponds to very low risk and the index 10 shows the maximum risk. A high-risk index is found in the congested/confined areas and vice-versa. 


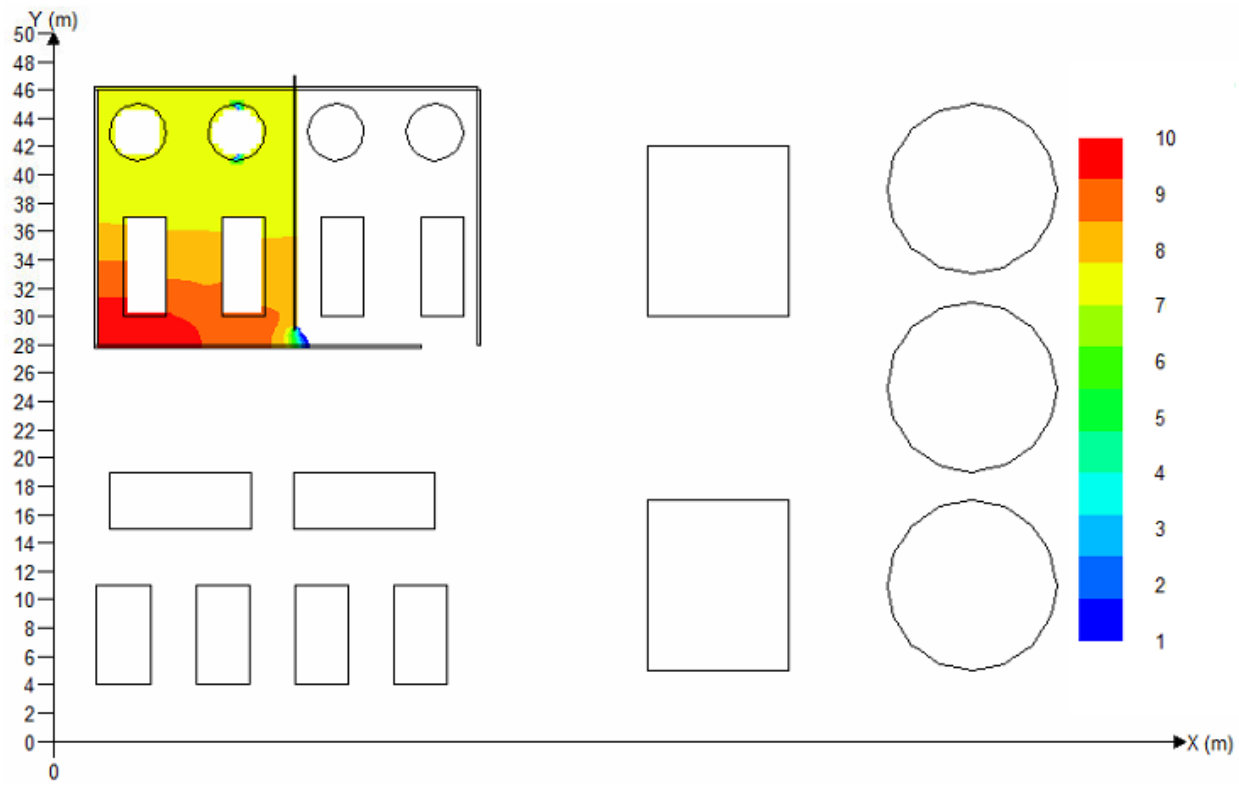

Fig. 12. Explosion risk profile at $180 \mathrm{~s}$

\subsection{Combustion product impact}

The toxic concentration $\left(\mathrm{mg} / \mathrm{m}^{3}\right)$ data obtained from the fire and explosion simulations were used for the toxicity assessment. The concentrations of contaminants are high near the fire and explosion locations and confined areas. The toxic concentration of $\mathrm{NO}_{2}$ is given in Fig. 13. In confined areas, the concentration of $\mathrm{NO}_{2}$ is more than $10^{5} \mathrm{mg} / \mathrm{m}^{3}$. Carbon monoxide is very toxic and a concentration of $1.28 \%$ leads to death within 2-3 minutes (Struttmann et al., 1998). The toxic concentration of $\mathrm{CO}$ is illustrated in Fig. 14. The higher concentrations of $\mathrm{NO}_{2}$ are present in larger areas of the layout than those of $\mathrm{CO}$. The obtained $\mathrm{NO}_{2}$ and $\mathrm{CO}$ values are relatively high because these concentrations were measured when there was ongoing fire. Risk values are high around the fire and VCE locations due to higher concentrations of contaminants. This is because a risk value directly depends on exposure duration and concentration. 


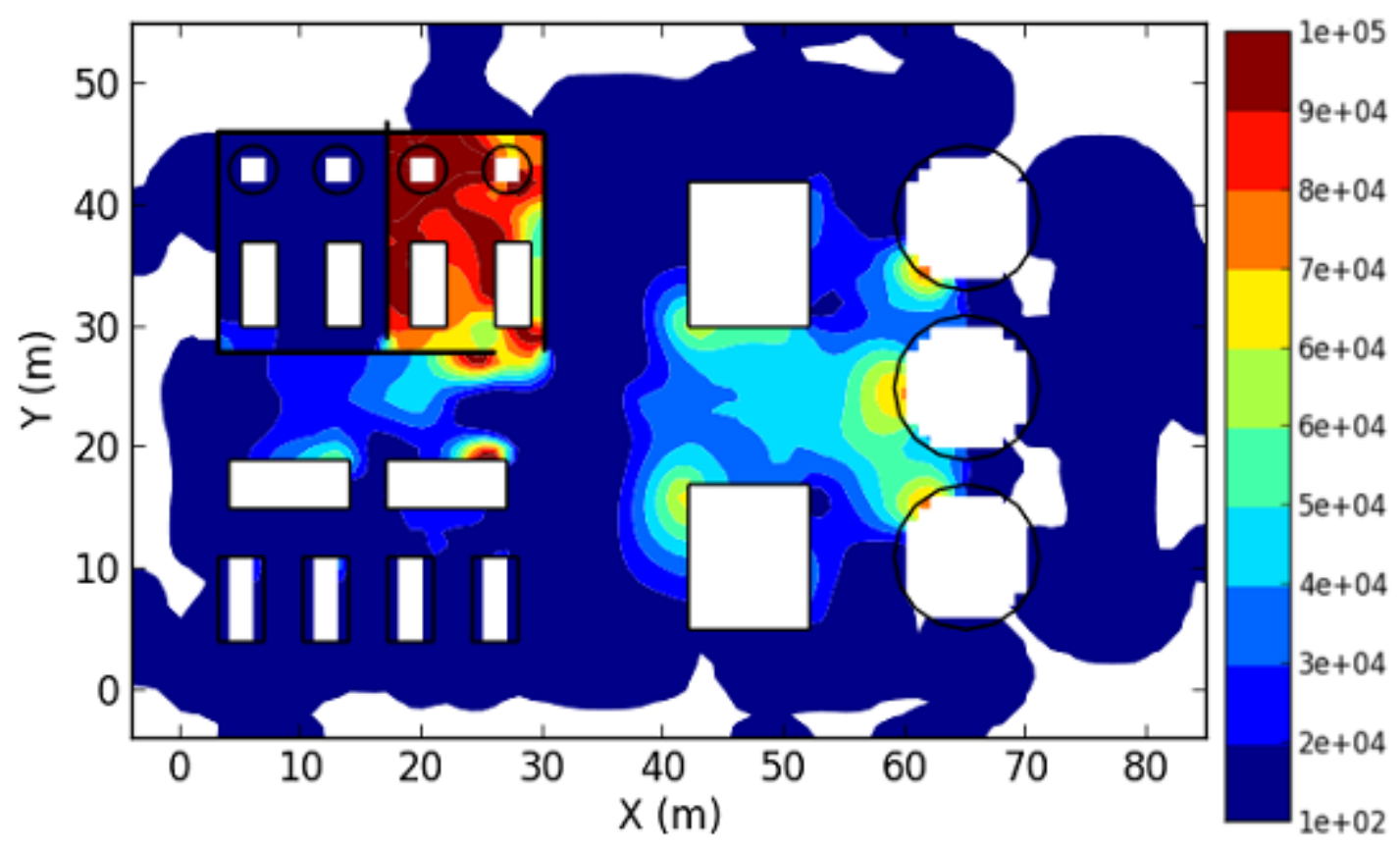

Fig. 13. Concentration of $\mathrm{NO}_{2}$ over the layout $\left(\mathrm{mg} / \mathrm{m}^{3}\right)$ at $180 \mathrm{~s}$

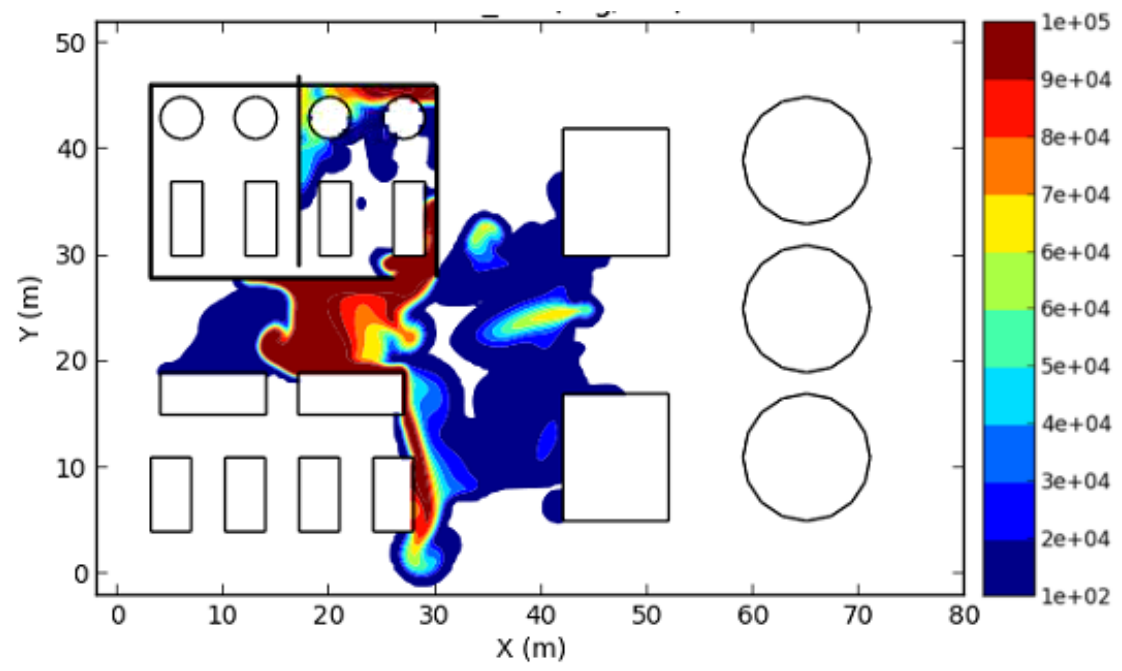

Fig. 14. Toxic concentration of $\mathrm{CO}\left(\mathrm{mg} / \mathrm{m}^{3}\right)$ at $180 \mathrm{~s}$

\subsection{Integrated impact during transition of fire to $\mathrm{VCE}$}

In most fire and/or explosion events, injury or fatality can be caused by combustion products in addition to radiation or overpressure hazards. Fig. 15 demonstrates the integrated risk contours in the layout because of thermal radiation and overpressure during the fire and VCE. For simplicity, the range of risk index is normalised between 1 and 10 in the integrated risk profile. High risk indices are available in the fire location and the VCE area due to the inherent nature of those events. 


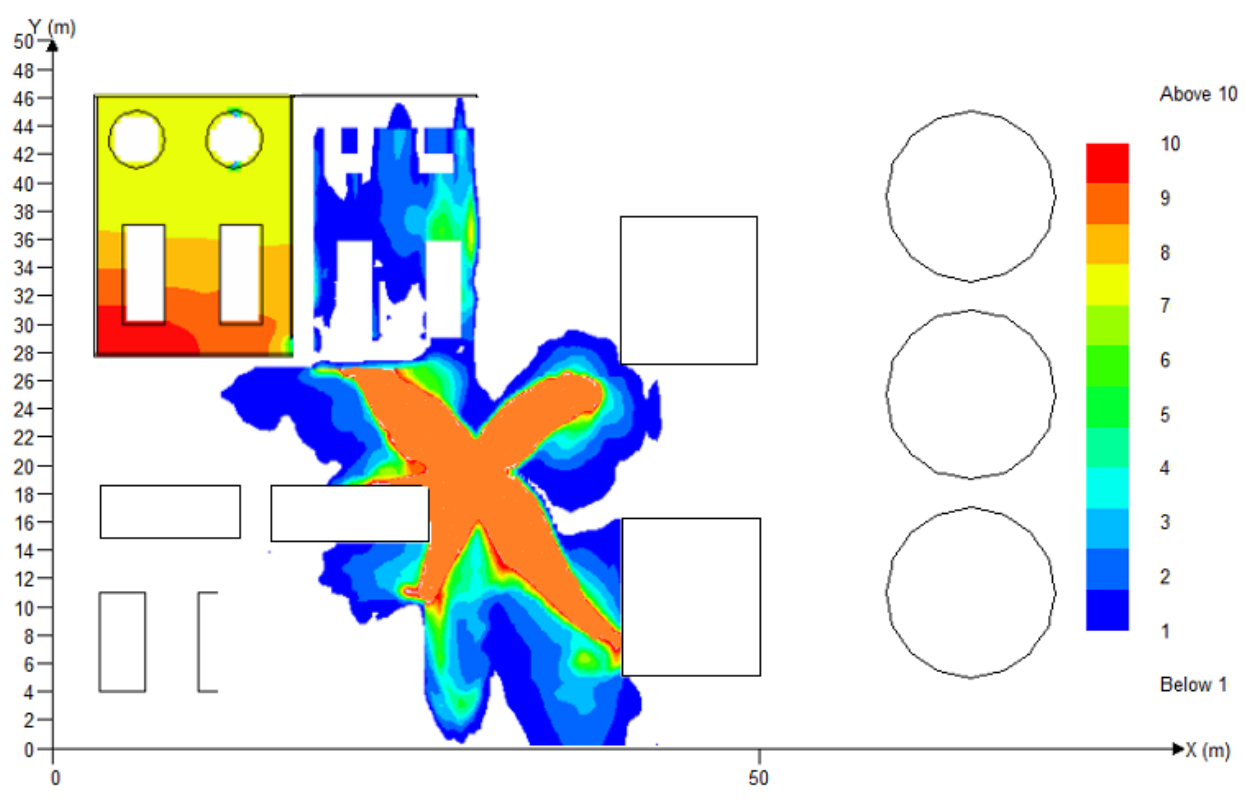

Fig. 15. Integrated risk profile of the fire and the VCE at $180 \mathrm{~s}$

In toxicity risk assessment, an integrated risk of both contaminants is considered as shown in Fig. 16. The total combustion product risk shows that significant portions of the facility exceed the acceptable level of risk which is 1 . The integrated risk profile of contaminants indicates that the high-risk area is larger than that of the integrated impact of fire and VCE as seen in Fig. 15 and Fig. 16. However, due to the short exposure duration, the severity of the combustion products is lower than that of thermal radiation and overpressure. This shows that the impact of transitional events such as fire and VCE along with combustion products is more severe than an individual phenomenon because more portions of the facility exceeded the acceptable level of risk.

The current approach incorporates an additional feature to the previous integrated consequence studies such as Khan and Amyotte (2004) and Dadashzadeh et al. (2013b). Khan and Amyotte (2004) incorporated fire, explosion and toxic release damage indices, but did not directly assess the consequence. The adopted technique in Khan and Amyotte (2004) cannot be useful for visualizing the area directly affected by fire, explosion and combustion products. The severity of consequence would have been different if the impact of the combustion product was considered by Dadashzadeh et al. (2013b). During a fire and/or explosion, the potential risk from combustion products can be too simple to ignore because toxicity has been a major cause of death and injury from fires (Hartzell, 1992).

This paper illustrated only a specific case study. However, any changes in operating conditions such as wind speed, wind direction, snow, rain or other parameters can be 
incorporated in this approach. Therefore, a range of scenarios can be envisaged and evaluated accordingly.

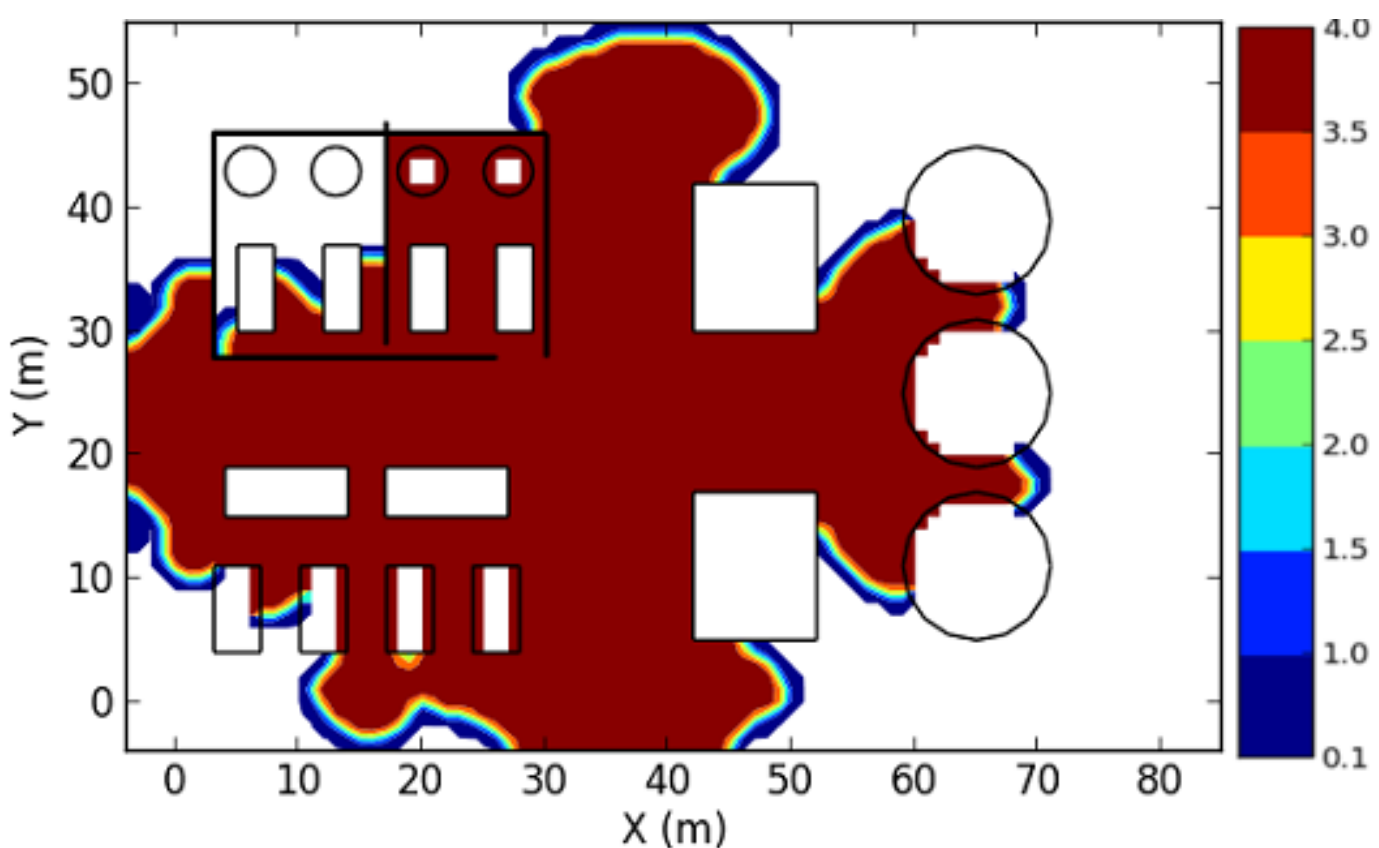

Fig. 16. Integrated risk of combustion products at $180 \mathrm{~s}$

\section{Conclusions}

In Liquified Natural Gas (LNG) processing facilities, there is a possibility of a fire transitioning into a Vapour Cloud Explosion (VCE) or vice-versa during an accidental release of hydrocarbons as demonstrated in various past fire and explosion accidents. Identification of potential location of transitional events is useful for understanding the occurrence of cascading accident scenarios. A framework has been proposed for modelling transitional events (fire, VCE and combustion product release) and their integrated consequences using Computational Fluid Dynamics (CFD). The proposed framework was applied to a case study considering an accidental LNG release, including vaporisation, a pool fire and a VCE. The impact of each individual event was assessed, and an integrated consequence was modelled using a risk-based approach. The severity of risk during each event in the layout was compared. By analysing the LNG spill, vaporisation, dispersion and subsequent fire in the layout, it is foreseeable that a pool fire can transit to a VCE because of the availability of required suitable conditions such as a flammable vapour concentration, ignition source and congestion/confinement. The risk of the overpressure was limited to confined spaces and was insignificant in other areas. The risk of thermal radiation was present in a larger area in comparison to the VCE. The risk of combustion products was present in a larger area than those of radiation and the overpressure, 
but its severity was lower due to the short exposure duration. It was found that the integrated risk of transitional events was higher than that of the individual risk.

A change in weather conditions and source terms may affect the outcome of an analysis related to gas leak and dispersion. Responses to gas leak and its dispersion are strongly dependent on these parameters and one set of parameters may not represent all cases. For illustration purpose, this study has presented only a specific case. Once operating conditions such as wind speed, wind direction, snow, rain or other parameter changes, the response need to be evaluated accordingly. The current study serves to highlight the importance of transitional events modelling and expands the scope of the integrated consequence modelling approach. Despite having complex correlations among various parameters involved in LNG spill and subsequent events, the integrated risk profiles can be effective for designing safety systems to mitigate potential effects and risks of thermal radiation, overpressure and combustion products during fire and/or explosion events. Consideration of effects among thermal radiation, overpressure and combustion products in the transitional event modelling, makes the study unique and realistic in safety analysis of an LNG processing facility.

\section{Acknowledgement}

The first author, Til Baalisampang would like to acknowledge the financial support received from the Australian Maritime College (AMC) of the University of Tasmania. The author thankfully acknowledges the technical support received from the Centre for Risk, Integrity and Safety Engineering (c-RISE), Faculty of Engineering \& Applied Science, Memorial University of Newfoundland, St. John's, NL, Canada.

\section{References}

1. Abdolhamidzadeh, B., Abbasi, T., Rashtchian, D., Abbasi, S.A., 2011. Domino effect in process-industry accidents - An inventory of past events and identification of some patterns. Journal of Loss Prevention in the Process Industries 24, 575-593.

2. Al-shanini, A., Ahmad, A., Khan, F., 2014. Accident modelling and analysis in process industries. Journal of Loss Prevention in the Process Industries 32, 319-334.

3. Alzbutas, R., 2015. Probabilistic dynamics for integrated analysis of accident sequences considering uncertain events. Science and Technology of Nuclear Installations 2015.

4. Assael, M.J., Kakosimos, K.E., 2010. Fires, explosions, and toxic gas dispersions: Effects calculation and risk analysis. CRC Press. 
5. Atkinson, G., Cowpe, E., Halliday, J., Painter, D., 2017. A review of very large vapour cloud explosions: Cloud formation and explosion severity. Journal of Loss Prevention in the Process Industries 48, 367-375.

6. Baalisampang, T., Abbassi, R., Garaniya, V., Khan, F., Dadashzadeh, M., 2017a. Fire impact assessment in FLNG processing facilities using Computational Fluid Dynamics (CFD). Fire Safety Journal 92, 42-52.

7. Baalisampang, T., Abbassi, R., Garaniya, V., Khan, F., Dadashzadeh, M., 2017b. Modelling the impacts of fire in a typical FLNG processing facility, Paper Presented at the International Conference on Safety and Fire Engineering-SAFE'17.

8. Baalisampang, T., Abbassi, R., Garaniya, V., Khan, F., Dadashzadeh, M., $2018 \mathrm{a}$. Review and analysis of fire and explosion accidents in maritime transportation. Ocean Engineering 158, 350-366.

9. Baalisampang, T., Abbassi, R., Khan, F., 2018b. Overview of Marine and Offshore Safety. Methods in Chemical Process Safety.

10. Baalisampang, T., Khan, F., Garaniya, V., Chai, S., Abbasi, R., 2016. An Inherently Safer Layout Design for the Liquefaction Process of an FLNG Plant. International Journal of Maritime Engineering 158, Part A2, 91-102.

11. Baksh, A.A., Abbassi, R., Garaniya, V., Khan, F., 2016a. An Application of BN to Envisage Potential Accidents in FLNG Facility, The Twelfth ISOPE Pacific/Asia Offshore Mechanics Symposium. International Society of Offshore and Polar Engineers, Gold Coast, Queensland, Australia, pp. 1-8.

12. Baksh, A.A., Abbassi, R., Garaniya, V., Khan, F., 2016b. A network based approach to envisage potential accidents in offshore process facilities. Process Safety Progress, 114.

13. Baksh, A.A., Khan, F., Gadag, V., Ferdous, R., 2015. Network based approach for predictive accident modelling. Safety science 80, 274-287.

14. Broadribb, M., 2006. Lessons from Texas City - A case history. Loss Prevention Bulletin Institution of Chemical Engineers 192, 3.

15. BSEE, 2013. Investigation of November 16, 2012, Explosion, Fire and Fatalities at West Delta Block 32 Platform E.

16. Center for Chemical Process Safety, 1996. Guidelines for evaluating process plant buildings for external explosions and fires. John Wiley \& Sons, Incorporated.

17. Clancey, V., 1972. Diagnostic features of explosion damage, 6th Int. Meeting of Forensic Sciences, Edinburgh, 1972. 
18. Crowl, D.A., Louvar, J.F., 2011. Chemical process safety: fundamentals with applications. Prentice Hall.

19. Dadashzadeh, M., Abbassi, R., Khan, F., Hawboldt, K., 2013a. Explosion modeling and analysis of BP Deepwater Horizon accident. Safety science 57, 150-160.

20. Dadashzadeh, M., Khan, F., Abbassi, R., Hawboldt, K., 2014. Combustion products toxicity risk assessment in an offshore installation. Process Safety and Environmental Protection 92, 616-624.

21. Dadashzadeh, M., Khan, F., Hawboldt, K., Amyotte, P., 2013b. An integrated approach for fire and explosion consequence modelling. Fire Safety Journal 61, 324-337.

22. Deepwater Horizon Study Group (DHSG), 2011. Final report on the Investigation of the Macondo Well Blowout.

23. DNV-GL, 2018. Digital Solutions SAFETI.

24. Fattakhova, E.Z., Barakhnina, V.B., 2015. Accident rate analysis on the offshore oil and gas production installations and plat-forms. International Journal of Applied and Fundamental Research.

25. Figueroa, V.G., Lopez, C., O’Rourke, K.K., 2011. LNG Cascading Damage Study Volume II: Flow Analysis for Spills from MOSS and Membrane LNG Cargo Tanks. Sandia National Laboratories, Albuquerque, NM.

26. Foss, M.M., Delano, F., Gulen, G., Makaryan, R., 2003. LNG safety and security. Center for Energy Economics (CEE).

27. Gavelli, F., Davis, S.G., Hansen, O.R., 2011. Evaluating the potential for overpressures from the ignition of an LNG vapor cloud during offloading. Journal of Loss Prevention in the process industries 24, 908-915.

28. GexCon, 2018a. EFFECTS: Advanced, easy-to-use Consequence Analysis.

29. GexCon, 2018b. Riskcurves: Comprehensive Quantitative Risk Analysis.

30. GexCon AS, 2013. FLACS v10. 0 User's Manual. January.

31. HAMSAGARS, HAMS-GPS QRA HAZOP EHS Software. HAMSAGARS, New Delhi.

32. Hansen, O., Renoult, J., Sherman, M., Tieszen, S., 2005. Validation of FLACShydrogen CFD consequence prediction model against large scale H2 explosion experiments in the FLAME facility, Proceedings of 1st International Conference on Hydrogen Safety, Pisa, Italy.

33. Hartzell, G.E., 1992. Advances in combustion toxicology. CRC Press.

34. Hull, T.R., Stec, A.A., 2010. Introduction to fire toxicity, Chapter 1. 
35. Ikealumba, W.C., Wu, H., 2014. Some recent advances in liquefied natural gas (LNG) production, spill, dispersion, and safety. Energy \& Fuels 28, 3556-3586.

36. Jagger, S., O’Sullivan, S., 2004. Human vulnerability to thermal radiation offshore. Health and Safety Laboratory, Harpur Hill, Buxton, Derbyshire.

37. Khan, F.I., Abbasi, S., 1999. Major accidents in process industries and an analysis of causes and consequences. Journal of Loss Prevention in the process Industries 12, 361378.

38. Khan, F.I., Amyotte, P.R., 2004. Integrated inherent safety index (I2SI): a tool for inherent safety evaluation. Process safety progress 23, 136-148.

39. Kim, W.K., Salvesen, H.-C., 2002. A study for prevention of Unconfined Vapor Cloud Explosion from spilled LNG confined in dike, CCPS Conference Proceedings, Jacksonville Florida.

40. Koo, J., Kim, H., So, W., Kim, K., Yoon, E., 2009. Safety assessment of LNG terminal focused on the consequence analysis of LNG spills, Proceedings of the 1st annual gas processing symposium.

41. Kundu, S., Zanganeh, J., Moghtaderi, B., 2016. A review on understanding explosions from methane-air mixture. Journal of Loss Prevention in the Process Industries 40, 507523.

42. Lea, C., Ledin, H., 2002. A review of the state-of-the-art in gas explosion modelling. Health and Safety Laboratory.

43. Lewis, S., 2005. An overview of leading software tools for QRA. American Society of Safety Engineers-Middle East, 18-22.

44. Manca, D., Brambilla, S., 2012. Dynamic simulation of the BP Texas City refinery accident. Journal of Loss Prevention in the Process Industries 25, 950-957.

45. Mannan, S., 2012. Lees' Loss prevention in the process industries: Hazard identification, assessment and control. Butterworth-Heinemann.

46. National Research Council, 1998. Assessment of Exposure-Response Functions for Rocket-Emission Toxicants. National Academies Press.

47. Niazi, U.M., Nasif, M.S., Muhammad, M.B., Imran, M., 2018. Integrated Consequence Modelling for Fire Radiation and Combustion Product Toxicity in offshore Petroleum Platform using Risk Based Approach, MATEC Web of Conferences. EDP Sciences, p. 06013.

48. Offshore Post-Everything offshore energy, 2015. Abkatun Offshore Explosion Findings Released. 
49. OPG, 2010a. Consequence modelling, OPG Risk Assessment Data Directory.

50. OPG, 2010b. Major accidents OPG Risk Assessment Data Directory.

51. Ouddai, R., Chabane, H., Boughaba, A., Frah, M., 2012. The Skikda LNG accident: losses, lessons learned and safety climate assessment. International Journal of Global Energy Issues 35, 518-533.

52. Pate -Cornell, M.E.L., 1993. Learning from the Piper Alpha Accident: A postmortem Analysis of Technical and Organizational Factors. Risk Analysis 13, 215-215.

53. Petrie, J.R., Großbritannien, D.o.E., 1988. Piper Alpha Technical Investigation: Interim Report. Department of Energy.

54. Petti, J.P., Kalan, R.J., 2011. LNG cascading damage study. Volume I, fracture testing report. Sandia National Laboratories.

55. Petti, J.P., Lopez, C., Kalan, R., Dempsey, J.F., Villa, D., Hightower, M.M., Wellman, G., 2013. LNG vessel cascading damage structural and thermal analyses. Sandia National Laboratories (SNL-NM), Albuquerque, NM (United States); Sandia National Laboratories.

56. Petti, J.P., Wellman, G.W., Villa, D., Lopez, C., Figueroa, V.G., Heinstein, M., 2011. LNG Cascading Damage Study Volume III: Vessel Structural and Thermal Analysis Report. Sandia National Laboratories, Albuquerque, NM.

57. Pitblado, R., Baik, J., Hughes, G., Ferro, C., Shaw, S., 2005. Consequences of liquefied natural gas marine incidents. Process safety progress 24, 108-114.

58. Planas-Cuchi, E., Montiel, H., Casal, J., 1997. A survey of the origin, type and consequences of fire accidents in process plants and in the transportation of hazardous materials. Process Safety and Environmental Protection 75, 3-8.

59. Purser, D.A., Maynard, R.L., Wakefield, J.C., 2015. Toxicology, survival and health hazards of combustion products. Royal Society of Chemistry.

60. Soman, A., Sundararaj, G., 2012. Consequence Assessment of Vapour Cloud Explosion Involving Hydrogen Release. International journal of emerging technology and advanced engineering 2, 291-296.

61. Struttmann, T., Scheerer, A., Prince, T.S., Goldstein, L.A., 1998. Unintentional carbon monoxide poisoning from an unlikely source. The Journal of the American Board of Family Practice 11, 481-484.

62. Tam, V., Lee, R., 1998. Gas explosion modelling of FPSO. Journal of loss prevention in the process industries $11,67-73$. 
63. Tatom, J., Swisdak, M., IME, L.S., 2011. IMESAFR Version 2.0: A Next Generation Tool for Managing Risk Associated with Commercial Explosives Operations. SAFEX International.

64. US Government Accountability Office (GAO), 2007. Report to Congressional Requesters, public safety consequences of a terrorist attack on a tanker carrying liquefied natural gas need clarification. US Government Accountability Office (GAO) Washington, DC 20548.

65. Woodward, J.L., 2010. Estimating the flammable mass of a vapor cloud. John Wiley \& Sons.

66. Yeo, C., Bhandari, J., Abbassi, R., Garaniya, V., Chai, S., Shomali, B., 2016. Dynamic risk analysis of offloading process in floating liquefied natural gas (FLNG) platform using Bayesian Network. Journal of Loss Prevention in the Process Industries 41, 259269.

67. Zheng, B., Chen, G.h., 2011. Storage tank fire accidents. Process Safety Progress 30, 291-293. 